\title{
Análise da dinâmica de uma rede para a dengue
}

\author{
Laura Victoria Forero Vega
}

\author{
DisSERTAÇÃO APRESENTADA \\ $\mathrm{AO}$ \\ Instituto De Matemática e EstatísticA \\ DA \\ Universidade DE SÃo PaUlo \\ PARA \\ OBTENÇÃO DO TITULO \\ $\mathrm{DE}$ \\ Mestre em CiÊnCIAS \\ Programa: Matemática Aplicada \\ Orientador: Prof. Dr. Sérgio Muniz Oliva Filho
}

Durante o desenvolvimento deste trabalho o autor recebeu auxilio financeiro da CAPES 


\section{Análise da dinâmica \\ de uma rede para a dengue}

Esta é a versão original da dissertação elaborada pelo candidato Laura Victoria Forero Vega, tal como submetida à Comissão Julgadora. 


\section{Analise de una rede de mobilidade para a dengue}

Esta versão da dissertação contem as correções e alterações sugeridas pela Comissão Julgadora durante a defesa da versão original do trabalho, realizada em 03/10/2017. Uma copia da versão original esta disponível no Instituto de Matemática e Estatística da Universidade de São Paulo.

Comissão Julgadora:

- Prof. Dr. Sérgio Muniz Oliva Filho (orientador) - IME-USP

- Prof. Dr. Eduardo Massad - FM-USP

- Prof. Dr. Fernando L. P. Santos - UNESP 


\section{Agradecimentos}

A meus pais Aura e Adán e meus irmãos Andrés e Felipe, por sua compreensão e amor todo o tempo, por seu apoio incondicional para meus projetos.

Agradeço enormemente a meu orientador Sérgio, por desde o principio oferecer o melhor dele, por sua amizade e por sempre ter me ajudado.

Para mim foi um prazer ter sido parte da melhor universidade de América Latina, Universidade de São Paulo agradeço a oportunidade. A Capes pela ajuda financeira.

Ao seminário de epidemiologia, aos professores por seus aportes, aos orientandos do grupo pela ajuda acadêmica e mais que isso, pela amizade.

Desde a Colômbia tem muitas pessoas que sempre enviaram boas energias para mim: tios, primos, amigos, colegas, vizinhos e professores; particularmente a minhas tias Yolanda e Dioselina, meu orientador de graduação Carlos Orlando, a minha melhor amiga Vanessa e a meu colega Gabriel. Muito obrigada!!

Em dois anos conheci pessoas que fizeram parte desta experiencia, dando carinho e companhia. Deixam para mim lembranças de risadas, de aprendizagem e de boas amizades, agradeço cada instante. 


\section{Resumo}

Forero, V. L. V. Análise da Dinâmica de uma Rede para o Dengue. 2017. 120 f. Dissertação (Mestrado) - Instituto de Matemática e Estatística, Universidade de São Paulo, São Paulo, 2017.

Na modelagem epidemiológica é importante descrever situações da vida real, neste caso baseados no artigo (Brockmann e Helbing [2013]) apresentamos um modelo da dinâmica da propagação de uma doença infecciosa numa população que está divida em regiões e entre alguma delas existe mobilidade, representados por uma rede. Com o fim de saber se dada uma origem em quanto tempo e quantos casos são esperados nas outras regiões, expomos a definição da distância efetiva e consequentemente os caminhos mais prováveis dependente da mobilidade que respondem as questões.

A dengue é uma doença infecciosa que vem sendo uma preocupação no mundo, particularmente no Brasil é um problema de saudê publica. No ano 2012 o estado de Rio de Janeiro reportou 13 cidades com maior incidência nas quais 7 delas estão correlacionadas, porém não é estabelecido como foi a mobilidade para ter estes resultados. Nós propomos aplicamos o modelo mencionado, obtendo as probabilidades das viagens entre estas cidades.

Palavras-chave: Modelagem epidemiológica, redes, distância efetiva, caminhos mais prováveis, dengue no Brasil. 


\section{Abstract}

Forero, V. L. V. Analysis of the Dynamics of a Network for Dengue. 2017. 120 f. Dissertação (Mestrado) - Instituto de Matemática e Estatística, Universidade de São Paulo, São Paulo, 2017.

In epidemiological modeling it is important to describe real-life situations, in this case based on the article (Brockmann e Helbing [2013]) we present a model of the dynamics of the spread of an infectious disease in a population that is divided into regions and between some of them there is mobility, represented by a network In order to know if given an origin in how long and how many cases are expected in the other regions, we present the definition of the effective distance and consequently the most likely paths depending on the mobility that answer the questions.

Dengue is an infectious disease that has been a concern in the world, particularly in Brazil is a problem of public health. In the year 2012 the state of Rio de Janeiro reported 13 cities with higher incidence in which 7 of them are correlated, but it is not established how mobility was to have these results. We propose apply the mentioned model, obtaining the probabilities of travel between these cities.

Keywords: Epidemic modeling, networks, effective distance, more probable paths, dengue in Brazil. 


\section{Sumário}

$\begin{array}{ll}\text { Lista de Símbolos } & \text { ix }\end{array}$

Lista de Figuras $\quad$ xi

Lista de Tabelas $\quad$ xiii

$\begin{array}{ll}\text { Introdução } & 1\end{array}$

1 Modelagem epidemiológica $\quad 3$

1.1 Modelo SIR . . . . . . . . . . . . . . . . . . . . . . . . . . . 3

1.2 Redes . . . . . . . . . . . . . . . . . . . . . . 8

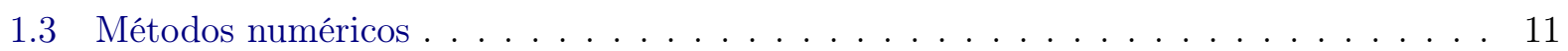

2 Distância efetiva e caminhos mais prováveis $\quad 15$

2.1 Motivação . . . . . . . . . . . . . . . . . . . . . . . . . . . 15

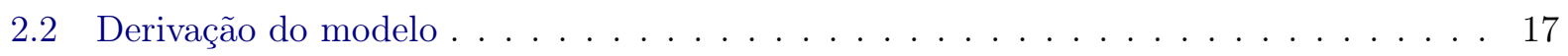

2.3 Resultados . . . . . . . . . . . . . . . . . . . . . . . . . 23

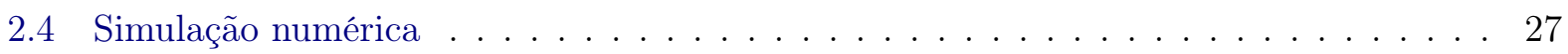

$\begin{array}{lll}3 & \text { Aplicação } & 37\end{array}$

3.1 Dengue . . . . . . . . . . . . . . . . . . . . . . . . 37

3.2 Balanço da dengue no Brasil . . . . . . . . . . . . . . . . . 38

3.3 Um problema . . . . . . . . . . . . . . . . . . . . . . . . 39

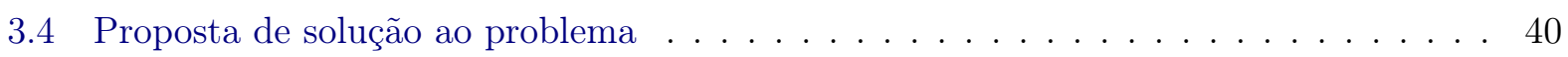

3.5 Análises da proposta . . . . . . . . . . . . . . . . . . . . . 45

$\begin{array}{ll}\text { Conclusões } & 49\end{array}$

$\begin{array}{ll}\text { Referências Bibliográficas } & 51\end{array}$ 


\section{Lista de Símbolos}

$R_{0} \quad$ numero de reprodução básico

$N_{n}$ tamanho da população $n$

$F_{n m}$ quantidade de indivíduos mobilizando-se da população $n$ até a população $m$ por dia

$w_{n m}$ taxa de mobilidade da população $n$ até a população $m$ por dia

$\Phi \quad$ quantidade total de indivíduos mobilizando-se em uma rede por dia

$\Omega \quad$ tamanho total da população em uma rede

$c_{n}$ tamanho relativo da população $n$

$f_{n m} \quad$ fração de fluxo da população $n$ para a $m$ por dia.

$\gamma \quad$ taxa de mobilidade global por dia.

$\omega_{n} \quad$ taxa de saída da população $n$ por dia.

$f_{n} \quad$ fracão de fluxo total da população $n$ por dia 


\section{Lista de Figuras}

1.1 Exemplo de uma rede de 4 nós . . . . . . . . . . . . . . . . . . . . . . . 9

2.1 Propagação da doença SARS em 2003 por países, relacionando distância geográfica $D_{g}$ e o tempo de chegada $T_{a}$ com respeito a seu país de origem, China. Imagem tomada (Brockmann e Helbing [2013]) . . . . . . . . . . . . . . . . . . . 16

2.2 Propagação da doença H1N1 em 2009 por países relacionando distância geográfica $D_{g}$ e tempo de chegada $T_{a}$ com respeito a seu país de origem, México. Imagem de (Brockmann e Helbing [2013]) . . . . . . . . . . . . . . . . . . . . . 16

2.3 Exemplo da mobilidade de uma rede de $M \geq 9$ nós . . . . . . . . . . . . . . . 22

2.4 Representação dos possíveis caminhos mais prováveis da figura 2.3 . . . . . . . . . . . 23

2.5 Rede global de viagens aéreas com 4069 nós e 25453 conexões não direcionados. Imagem tomada de (Brockmann e Helbing [2013]) . . . . . . . . . . . . . . . . . . . 24

2.6 Propagação da doença H1N1 de 2009 por países relacionando distância efetiva $D$ e tempo de chegada $T_{a}$ com respeito a seu país de origem México. Imagem de (Brockmann e Helbing [2013]) . . . . . . . . . . . . . . . . . . . . . . . 24

2.7 Propagação da doença $S A R S$ de 2003 por países relacionando distância efetiva $D$ e tempo de chegada $T_{a}$ com respeito a seu pais de origem China. Imagem de (Brockmann e Helbing [2013]) . . . . . . . . . . . . . . . . . . . . . 25

2.8 Propagação de uma doença simulada pela rede global relacionando distância geográfica e tempo de chegada com respeito a seu aeroporto de origem Hong Kong. Imagem de (Brockmann e Helbing [2013]) . . . . . . . . . . . . . . . . . . . . . . . 25

2.9 Propagação de uma doença simulada pela rede relacionando distância efetiva e tempo de chegada com respeito a seu aeroporto de origem Hong Kong. Imagem de (Brockmann e Helbing

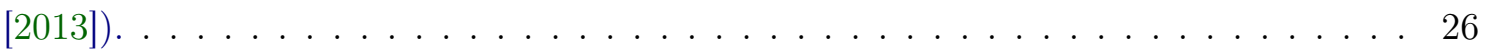

2.10 Grafo de caminhos mais prováveis de uma propagação de uma doença simulada pela rede onde a origem é o aeroporto de origem Hong Kong. Imagem de (Brockmann e Helbing

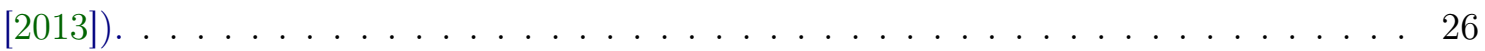

2.11 Snapshots por dias da propagação de uma rede com origem em Hong Kong da rede e do grafo dos caminhos mais prováveis onde. Imagem de (Brockmann e Helbing [2013]). 27

2.12 Rede de simulação . . . . . . . . . . . . . . . . . . . . . . . . . . . 28

2.13 Grafo de caminhos mais prováveis da simulação 3. . . . . . . . . . . . . . . . . . . . 29

2.14 Relação de distância efetiva e o tempo de chegada da doença do exemplo 1. . . . . . . 30

2.15 Dinâmica da fracão de infectados de cada nó do exemplo 1. . . . . . . . . . . . . . . 30

2.16 Dinâmica da propagação do exemplo $1 . \ldots \ldots \ldots$. . . . . . . . . . . 31 
2.17 Grafo de caminhos mais prováveis da simulação $1 \ldots$. . . . . . . . . . . . . . . . 32

2.18 Relação de distancia efetiva e tempo de chegada em dias do exemplo 2. . . . . . . . . 33

2.19 Dinâmica da fracão de infectados de cada nó do exemplo 2 . . . . . . . . . . . . . . . 33

2.20 Relação de distancia efetiva e tempo de chegada em dias do exemplo $3 . \quad$. . . . . . . . 34

2.21 Dinâmica da fracão de infectados de cada nó do exemplo 3. . . . . . . . . . . . . . 34

3.1 (a) Número de casos confirmados por laboratório de dengue no Brasil de 1994 a 2014.

(b) Mortes por causa da dengue no Brasil de 1994 a 2014. Imagem de (Fares et al.

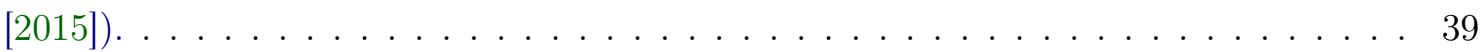

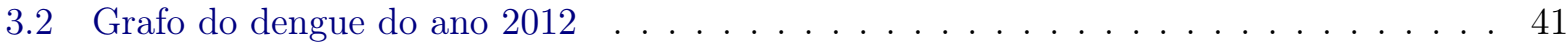

3.3 Solução $j(t)$ de um sistema SIR local normalizado com $N=6320446, \alpha=0.6543532$, $\beta=0.591573, S(0)=0.966527, I(0)=6.590943 e-05$ e $t \in[0,365]$ de cor azul, correspondente a cidade de Rio de Janeiro. Junto com os dados reais normalizados de infectados do ano 2012 da mesma cidade de cor vermelha. . . . . . . . . . . . . . .

3.4 Solução $j_{1}(t)$ do sistema do estado Rio de Janeiro de 2012 com $t \in[0,365]$ de cor azul, correspondente a cidade de Rio de Janeiro, junto com os dados reais normalizados dos infectados

3.5 Solução $j_{2}(t)$ do sistema do estado Rio de Janeiro de 2012 com $t \in[0,365]$ de cor azul, correspondente a cidade de Itaboraí, junto com os dados reais normalizados dos infectados. . . . . . . . . . . . . . . . . . . . . .

3.6 Solução $j_{3}(t)$ do sistema do estado Rio de Janeiro de 2012 com $t \in[0,365]$ de cor azul, correspondente a cidade de Nilópolis, junto com os dados reais normalizados de infectados.

3.7 Solução $j_{4}(t)$ do sistema do estado Rio de Janeiro de 2012 com $t \in[0,365]$ de cor azul, correspondente a cidade de Niterói, junto com os dados reais normalizados de infectados.

3.8 Solução $j_{5}(t)$ do sistema do estado Rio de Janeiro de 2012 com $t \in[0,365]$ de cor azul, correspondente a cidade de São Gonçalo, junto com os dados reais normalizados dos infectados.

3.9 Solução $j_{6}(t)$ do sistema do estado Rio de Janeiro de 2012 com $t \in[0,365]$ de cor azul, correspondente a cidade de Valência, junto com os dados reais normalizados de

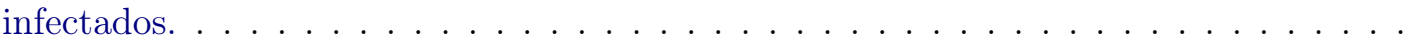

3.10 Solução $j_{3}(t)$ do sistema do estado Rio de Janeiro de 2012 com $t \in[0,365]$ de cor azul, correspondente a cidade de Angra dos Reis, junto com os dados reais normalizados de infectados.

3.11 Dinâmica dos infectados de todos os nós do sistema do estado Rio de Janeiro de 2012 com $t \in[0,365]$ 


\section{Lista de Tabelas}

3.1 Atividade do Dengue no Brasil entre 1845 até 2014 . . . . . . . . . . . . . . . . . . 38

3.2 Correlação do ano 2012 do estado de Rio de Janeiro . . . . . . . . . . . . . . . . . . . 40

3.3 Estimativa das condições inicias do sistema de Rio de Janeiro de 2012 . . . . . . . . . 42

3.4 Erro de cada nó no sistema de Rio de Janeiro de $2012 \ldots \ldots$. . . . . . . . . . . . . . . 43

3.5 Estimativa dos parâmetros $\alpha, \beta$ e condições iniciais se cada nó fosse uma dinâmica de um sistema SIR local normalizado, além do erro obtido para $n=2,3, \ldots, 7 \ldots \ldots$ 


\section{Introdução}

Existem diferentes maneiras pelas quais situações da vida real podem ser descritas, é possível usar palavras, desenhos ou esboços, modelos físicos, programas de computador ou modelos matemáticos; este último, usa a base teórica de áreas como equações diferenciais, geometria, sistemas dinâmicos, entre outras; onde cada formulação tem um significado dependente da representação real e com isso, matematicamente permite-se demostrar suas propriedades ou características.

As dinâmicas que mudam através de tempo, com frequência, são desenvolvidas pelas equações diferenciais, tanto ordinárias como parciais, que começaram a ser estudadas pelo matemático Vito Volterra, ele desenvolveu em 1925 um modelo de equações diferenciais ordinárias onde analisou o crescimento da população de tubarões e o decrescimento da população dos demais peixes em um mar da Itália; porém, o biofísico Alfred Lotka, no mesmo ano, estudou a interação predador-caça, apresentando a mesma modelagem. Como ambos publicaram a mesma equação, o modelo foi chamado de Lotka-Volterra (Hofbauer et al. [1988]) e desde então em diversas áreas foi expandido este conceito que pode ser visto com mais detalhes em (Takeuchi [1996]).

A propagação de uma doença infecciosa em uma situação que já esteve presente através da história, causando além de mortes também mudanças sócio-econômicas a nível global, resulta uma área de estudo que tem como objetivo a detecção, a prevenção, a terapia e o controle de situações futuras. A modelação matemática destas dinâmicas começou a ser desenvolvida em 1927 por Anderson Kermack e William McKendrick que utilizaram um sistema de equações diferenciais ordinárias para descrever a dinâmica de uma doença em uma população tomando a ideia do modelo de LotkaVolterra (Kermack e McKendrick [1927]).

Inicialmente a modelação define a categoria dos indivíduos no processo, podendo ser suscetíveis, latentes, infectados ou recuperados; logo descrever como passa de uma categoria a outra; e posteriormente expor sua descrição matemática através do tempo das categorias dos indivíduos. Após, a ideia é adicionar ao modelo mais situações da vida real como: nascimentos, mortes, migração, vacinação, vetores, mutações, entre outras (Keeling e Rohani [2008]), assim diferentes autores vem estudando este tipo de dinâmicas, em livros como (Bailey et al. [1975], Anderson et al. [1992]) podemos encontrar um resumo histórico mais detalhado.

Neste trabalho temos como primeiro objetivo expor um modelo que descreve a dinâmica de uma doença infecciosa com indivíduos suscetíveis, infectados e recuperados distribuídos em populações e que tem mobilidade entre as regiões cujos análises permitem determinar a origem, os tempos de chegada e quantos há casos em cada população todo isto baseado no artigo (Brockmann e Helbing [2013]). O segundo objetivo é aplicar este modelo à dinâmica da doença infecciosa da dengue do ano 2012 no estado de Rio de Janeiro, o que nos permite obter informação sobre a mobilidade humana entre algumas cidades do estado.

No capítulo 1, desenvolvemos as ferramentas matemáticas para o entendimento da modelagem epidemiológica, começamos como a introdução ao sistema SIR local, baseado em (Keeling e Rohani [2008]), mostrando várias das suas propriedades qualitativas e quantitativas, em seguida apresentamos o conceito de redes e expandimos o sistema SIR neste contexto. Além disso, expomos alguns 
métodos numéricos para a resolução computacional do modelo: tais como o métodos de Runge Kutta, o método de Monte Carlo.

No capítulo 2, baseados no artigo (Brockmann e Helbing [2013]), aprofundamos a motivação dos autores e apresentamos alguns exemplos de epidemias no mundo e seu impacto social e econômico, e com isso, expomos os objetivos da pesquisa dos autores com o fim de prever um possível próximo evento. Em seguida, desenvolvemos detalhadamente o modelo proposto, incluindo a descrição dos parâmetros, suas propriedades e uma definição de distância efetiva, explicando os caminhos mais prováveis. A partir disso, apresentamos os resultados obtidos da aplicação aos casos das doenças SARS de 2003 e H1N1 de 2009, mostrando seu resultado ótimo; além de mostrar um exemplo hipotético de uma possível epidemia que começou em Hong Kong. Em seguida simulamos três exemplos feitos por nós, para ilustrar as conclusões do artigo.

No capítulo 3, inicialmente, apresentamos a doença da dengue, dando uma noção sobre sua transmissão, tipos de dengue, sintomas e característica do mosquito. Além disso, expomos um balanço geral de seu desenvolvimento no Brasil. Em seguida, exibimos a situação de um problema a resolver e apresentamos nosso objetivo e questão em aberto. A partir disso, mostramos com detalhe nossa ideia de solução e todo seu desenvolvimento chegando aos resultados teóricos, numéricos e fazemos um balanço em geral da nossa proposta.

Finalmente, realizamos as considerações finais sobre todo o trabalho, concluímos a aplicação do modelo e propomos um estudo para trabalhos posteriores. 


\section{Capítulo 1}

\section{Modelagem epidemiológica}

Um modelo matemático é uma representação simplificada da realidade, ou uma interpretação de um fragmento de um sistema, segundo uma estrutura de conceitos mentais. Uma epidemia é a concentração de determinados casos de uma doença em um mesmo local e época, claramente em excesso em relação ao que seria teoricamente esperado.

Neste capitulo apresentamos a teoria sobre os modelos SIR locais e posteriormente estendido a uma rede; e introduzimos alguns métodos numéricos utilizados para simular computacionalmente.

\subsection{Modelo SIR}

Uma doença é definida como a condição do corpo, ou uma parte do corpo, na qual suas funções estão perturbadas ou transtornadas; um afastamento do estado de saúde normal, especialmente causado por mudanças estruturais. Existem vários tipos de classificação sobre elas, mas nesta ocasião estamos interessados nas infecciosas; ou seja quando a doença é transmitida entre indivíduos, cuja causa está determinada por um patógeno que chega ao indivíduo por meio da transmissão (ver mais em Bennett et al. [2014]).

Estas doenças podem ser agudas ou crônicas, a primeira referi-se a uma resposta rápida para ficar imune (livre da doença) após um curto período de tempo (dias ou semanas), enquanto que crônica é depois de um longo tempo (meses, anos).

Um tipo de modelo matemático que descreve a dinâmica de uma doença infecciosa aguda é o modelo SIR (Keeling e Rohani [2008]), que se caracteriza por uma divisão da população: Suscetíveis (se não foram expostos ao patógeno), Infectados (se atualmente possuem o patógeno) ou Recuperados (se tiverem eliminado com êxito a infecção); assim a transição possível é de suscetíveis a infectados e de infectados a recuperados.

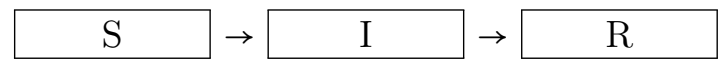

Para passar de suscetível a infectado dever ter existido a transmissão do patógeno, isto envolve três fatores importantes: a prevalência dos infectados, a estrutura do contacto da população e a probabilidade de transmissão dado o contato.

De fato, supomos que um indivíduo suscetível em um tempo $t_{0}$, em uma certa população de tamanho $N\left(t_{0}\right)$ que tem uma taxa $\kappa$ de contatos por unidade de tempo com outros indivíduos, e nesse instante existem $I\left(t_{0}\right)$ infectados ou seja, $\frac{I\left(t_{0}\right)}{N\left(t_{0}\right)}$ é a fracão de infectados. Durante um intervalo de tempo $\left[t_{0}, \delta t+t_{0}\right]$ com $\delta>0$, esse suscetível tem $\left(\kappa \frac{I\left(t_{0}\right)}{N\left(t_{0}\right)}\right) \delta t$ contatos com infectados. 
A probabilidade de ser transmitido o patógeno é denotada por $c$, ou seja que, $1-c$ é a probabilidade de não ser transmitida, logo a probabilidade, denotada por $1-\delta q$, do indivíduo suscetível escapar da infeção durante o intervalo $\left[t_{0}, \delta t+t_{0}\right]$ é dada por

$$
1-\delta q=(1-c)^{\left(\kappa \frac{I\left(t_{0}\right)}{N\left(t_{0}\right)}\right) \delta t}
$$

assim a probabilidade de ficar infectado nesse intervalo é $\delta q$. Definindo, $\alpha=-\kappa \log (1-c)$, temos que

$$
\delta q=1-\exp \left(-\frac{\alpha I\left(t_{0}\right)}{N\left(t_{0}\right)} \delta t\right)
$$

expandindo $\exp \left(-\frac{\alpha I\left(t_{0}\right)}{N\left(t_{0}\right)} \delta t\right)$ em série de Taylor em torno do ponto $\delta t$ temos

$$
\begin{aligned}
\delta q & =1-\left(1-\frac{\alpha I\left(t_{0}\right)}{N_{0}} \delta t+\frac{1}{2 !}\left(\frac{\alpha I\left(t_{0}\right)}{N\left(t_{0}\right)}\right)^{2} \delta t^{2}-\frac{1}{3 !}\left(\frac{\alpha I\left(t_{0}\right)}{N\left(t_{0}\right)}\right)^{3} \delta t^{3}+\ldots\right) \\
& =\frac{\alpha I\left(t_{0}\right)}{N\left(t_{0}\right)} \delta t-\frac{1}{2 !}\left(\frac{\alpha I\left(t_{0}\right)}{N\left(t_{0}\right)}\right)^{2} \delta t^{2}+\frac{1}{3 !}\left(\frac{\alpha I\left(t_{0}\right)}{N\left(t_{0}\right)}\right)^{3} \delta t^{3}+\ldots,
\end{aligned}
$$

dividindo-se por $\delta t$ a ambos lado da equação, obtemos

$$
\frac{\delta q}{\delta t}=\frac{\alpha I\left(t_{0}\right)}{N\left(t_{0}\right)}-\frac{1}{2 !}\left(\frac{\alpha I\left(t_{0}\right)}{N\left(t_{0}\right)}\right)^{2} \delta t+\frac{1}{3 !}\left(\frac{\alpha I\left(t_{0}\right)}{N\left(t_{0}\right)}\right)^{3} \delta t^{2}+\ldots
$$

e quando $\delta t \rightarrow 0$, obtemos finalmente

$$
\frac{d q}{d t}=\alpha \frac{I\left(t_{0}\right)}{N\left(t_{0}\right)}
$$

esta última expressão representa a taxa de transmissão por indivíduo suscetível no instante $t_{0}$. Agora, expandindo esse resultado para toda a população suscetível $S(t)$, em qualquer tempo $t$, temos que a taxa de transmissão vem dada pela equação

$$
\frac{d S(t)}{d t}=-\alpha \frac{I(t) S(t)}{N(t)} .
$$

Quando o indivíduo é infectado, obtemos o valor médio $\frac{1}{\beta}$ da quantidade de tempo que fica nesta etapa, simplesmente com os dados clínicos, logo é considerada a taxa de recuperação como $\beta$ (Keeling e Rohani [2008]). Portanto temos um sistema de equações diferencias ordinárias descrevendo a dinâmica

$$
\begin{aligned}
\frac{d S(t)}{d t} & =-\frac{\alpha S(t) I(t)}{N(t)} \\
\frac{d I(t)}{d t} & =\frac{\alpha S(t) I(t)}{N(t)}-\beta I(t) \\
\frac{d R(t)}{d t} & =\beta I(t)
\end{aligned}
$$


Temos que a população total é constante. Logo,

$$
\begin{aligned}
\frac{d N(t)}{d t} & =\frac{d S(t)}{d t}+\frac{d I(t)}{d t}+\frac{d R(t)}{d t} \\
& =-\frac{\alpha S(t) I(t)}{N(t)}+\frac{\alpha S(t) I(t)}{N(t)}-\beta I(t)+\beta I(t) \\
& =0
\end{aligned}
$$

Logo consideramos $N=N(t)$ para todo $t \geq 0$. Com isso o sistema SIR local é definido como

$$
\begin{aligned}
\frac{d S(t)}{d t} & =-\frac{\alpha S(t) I(t)}{N} \\
\frac{d I(t)}{d t} & =\frac{\alpha S(t) I(t)}{N}-\beta I(t) \\
\frac{d R(t)}{d t} & =\beta I(t)
\end{aligned}
$$

e adicionamos as condições iniciais $S(0), I(0), R(0)$.

A quantidade $\lambda=\frac{\alpha S(t) I(t)}{N}$ é conhecida como a força da infeção e em palavras qualitativas é definida como a densidade de incidência, ou seja, corresponde ao número de casos novos por unidades de tempo divido pela população total. (Keeling e Rohani [2008])

Ao realizar a normalização ao sistema SIR local $j(t)=\frac{I(t)}{N}, s(t)=\frac{S(t)}{N}$ e $r(t)=\frac{R(t)}{N}$, obtemos o seguinte sistema que chamamos de sistema SIR local normalizado

$$
\begin{aligned}
& \frac{d s(t)}{d t}=-\alpha s(t) j(t) \\
& \frac{d j(t)}{d t}=\alpha s(t) j(t)-\beta j(t) \\
& \frac{d r(t)}{d t}=\beta j(t)
\end{aligned}
$$

Claramente, para que a dinâmica seja efetiva, no instante inicial devem existir indivíduos suscetíveis e pelo menos um infectado. Seguem algumas propriedades do sistema que caracterizam a dinâmica da doença.

O sistema SIR local com condições iniciais $(S(0), I(0), R(0))$, têm singularidades $(x, 0, y)$ com $x, y \in \mathbb{R}$. De fato, pela equação (1.3), temos que $\beta I(t)=0$, ou seja $I(t)=0$, e com isso para (1.1) e (1.2) também anula-se.

Lema 1.1 O sistema SIR local com condições inicial $S(0), I(0), R(0) \geq 0$ satisfaz que $S(t), I(t), R(t) \geq 0$ para todo $t \geq 0$.

Demostração: Se em algum tempo $t^{*}>0, I\left(t^{*}\right)=0$ então $\left(S\left(t^{*}\right), I\left(t^{*}\right), R\left(t^{*}\right)\right)$ é um equilíbrio, ou seja, o sistema permanece nesse ponto. Logo vamos supor que $I\left(t^{*}\right) \neq 0$, se $S\left(t^{*}\right)=0$ e $R\left(t^{*}\right)>0$ então $\frac{d S\left(t^{*}\right)}{d t}=0$, o que significa que $S(t)=0$ para todo $t \geq t^{*}$, assim $S(t), I(t), R(t) \geq 0$ para todo $t \geq 0$. Similarmente se $R\left(t^{*}\right)=0$ e $S\left(t^{*}\right)>0$ então $\frac{d R\left(t^{*}\right)}{d t} \geq 0$, o que significa que permanece não negativa, e logo $S(t), I(t), R(t) \geq 0$ para todo $t \geq 0$.

Consequentemente, podemos afirmar que $R(t)$ é uma função crescente e $S(t)$ uma função decrescente. Portanto $0 \leq S(t) \leq S(0)<N$ e $R(0) \leq R(t) \leq N$ e se segue que $\lim _{t \rightarrow \infty} S(t), \lim _{t \rightarrow \infty} R(t)$ existem e por a população ser constante, $I(t)=N-S(t)-R(t)$ e assim $\lim _{t \rightarrow \infty} I(t)$ existe também. Todo isto funciona igual para o sistema SIR local normalizado. 
Lema 1.2 Para o sistema SIR local com condições iniciais $S(0), I(0), R(0) \geq 0$, a doença sempre desaparece, ou seja,

$$
\lim _{t \rightarrow \infty} I(t)=0
$$

Demostração: Dado que $R(t) \leq N, \lim _{t \rightarrow \infty} R(t)$ existe e é uma função crescente, então $\lim _{t \rightarrow \infty} \frac{d R(t)}{d t}=0$, ou seja que $\lim _{t \rightarrow \infty} \beta I(t)=0$ e portanto $\lim _{t \rightarrow \infty} I(t)=0$.

Uma medida de transmissão da doença é o número de reprodução básico $R_{0}$, definido como o número médio de pessoas infecciosas resultantes de uma pessoa infecciosa típica após a sua introdução numa população totalmente susceptível (Keeling e Rohani [2008]).

Para o sistema SIR local, se supomos que toda a população é suscetível $S(0)=N$, então $\alpha$ é o número de indivíduos efetivamente infectados por uma determinada pessoa por unidade de tempo e, portanto, $\frac{\alpha}{\beta}$ é o número de indivíduos eficazmente infectados por uma pessoa infecciosa durante a totalidade do período infeccioso, em conclusão, para esta dinâmica $R_{0}=\frac{\alpha}{\beta}$.

Teorema 1.3 Para o sistema SIR local com condições iniciais $I(0)=1, S(0)=N, R(0)=0$,

1. Se $R_{0}<1$, então $I(t)$ decresce monotonamente a zero quando, $t \rightarrow \infty$.

2. Se $R_{0}=1$, então decresce ao zero quando $t \rightarrow \infty$.

3. Se $R_{0}>1$, então $I(t)$ começa crescendo, atinge um máximo e decresce ao zero quando $t \rightarrow \infty$.

Demostração:

1. Dado que $R_{0}<1$ então $\alpha-\beta<0$, com isso na equação (1.2) temos que

$$
\begin{aligned}
\frac{d I(t)}{d t} & =\left(\frac{\alpha S(t)}{N}-\beta\right) I(t) \\
& \leq\left(\frac{\alpha S(0)}{N}-\beta\right) I(t) \\
& =(\alpha-\beta) I(t) \\
& <0
\end{aligned}
$$

e junto como o Lema (1.1), obtemos que uma função monótona decrescente.

2. Similar a item anterior, temos que $\frac{d I(t)}{d t} \leq I(t)$ pelo Lema (1.2) decresce quando $t \rightarrow \infty$.

3. Dado que $R_{0}>1$ então $\alpha-\beta>0$ e quando $t=0$ temos na equação (1.2) que,

$$
\begin{aligned}
{\left[\frac{d I(t)}{d t}\right]_{t=0} } & =\left[\left(\frac{\alpha S(t)}{N}-\beta\right) I(t)\right]_{t=0} \\
& =\left(\frac{\alpha S(0)}{N}-\beta\right) I(0) \\
& =(\alpha-\beta) I(0) \\
& >0
\end{aligned}
$$


ou seja, que $I(t)$ começa crescendo. Além disso, $I(t) \neq 0$ só tem um ponto critico, de fato igualando a equação 1.2 a zero, temos que

$$
\begin{aligned}
\left(\frac{\alpha S(t)}{N}-\beta\right) I(t) & =0 \\
\frac{\alpha S(t)-\beta N}{N} & =0 \\
\alpha S(t)-\beta N & =0 \\
S(t) & =\frac{\beta N}{\alpha},
\end{aligned}
$$

então este ponto critico é atingido e pelo Lema (1.2), $I(t)$ decresce depois de atingir o maximo.

Além disso, na mecânica, uma constante de movimento é uma quantidade que é conservada em todo o movimento, impondo, de fato, uma restrição ao movimento. No entanto, é uma restrição matemática, a consequência natural das equações de movimento, ao invés de uma restrição física. Neste caso o sistema SIR tem uma constante de movimento para os suscetíveis e os infectados, de fato

Lema 1.4 Para o sistema SIR local com condições iniciais $I(0), S(0), R(0) \geq 0$ temos que

$$
-I(t)-S(t)+\frac{\beta N}{\alpha} \log (S(t))=-I(0)-S(0)+\frac{\beta N}{\alpha} \log (S(0)) .
$$

Demostração: Dividindo a equação (1.1) em (1.2), temos que

$$
\begin{aligned}
\frac{d S}{d I} & =\frac{-\alpha S(t) I(t)}{\alpha S(t) I(t)-\beta N I(t)} \\
\frac{\alpha S(t) I(t)-\beta N I(t)}{-\alpha S(t) I(t)} d S & =d I \\
\left(-1+\frac{N \beta}{\alpha S}\right) d S & =d I
\end{aligned}
$$

sendo uma equação diferencial de variáveis separáveis, e integrando, obtemos

$$
-S(t)+\frac{\beta N}{\alpha} \log S(t)=I(t)+c \operatorname{com} c \in \mathbb{R}
$$

ou seja, $c=-I(t)-S(t)+\frac{\beta N}{\alpha} \log S(t)$. Com as condições iniciais, obtemos que $c=-I(0)-S(0)+\frac{\beta N}{\alpha} \log S(0)$ e em consequência o resultado.

Como sabemos, a função $I(t)$ atinge o máximo $I_{\max }$ quando $S(t)=\frac{\beta N}{\alpha}$, e como consequência do lema anterior

$$
\begin{aligned}
I_{\max } & =-\frac{\beta N}{\alpha}+\frac{\beta N}{\alpha} \log (S(t))+I(0)+S(0)-\frac{\beta N}{\alpha} \log (S(0)) \\
& =-\frac{\beta N}{\alpha}+\frac{\beta N}{\alpha} \log \left(\frac{\beta N}{\alpha}\right)+I(0)+S(0)-\frac{\beta N}{\alpha} \log (S(0)) \\
& =I(0)+S(0)-\frac{\beta N}{\alpha}+\frac{\beta N}{\alpha}\left(\log \left(\frac{\beta N}{\alpha}\right)-\log (S(0))\right) \\
& =I(0)+S(0)+\frac{\beta N}{\alpha}\left(\log \left(\frac{\beta N}{\alpha S(0)}\right)-1\right)
\end{aligned}
$$

Além disso, dado que a doença sempre desaparece e que $S(t)$ é uma função decrescente, poderíamos pensar que os suscetíveis também tendem a 0 , mas não é assim. De fato, 
Lema 1.5 O sistema SIR local com condições inicias não negativas, satisfaz que

$$
\lim _{t \rightarrow \infty} S(t) \geq S(0) \exp \left(\frac{\alpha}{\beta N}(R(0)-N)\right)>0 .
$$

Demostração: Fazendo a divisão da equação (1.1) na equação (1.2) temos que

$$
\begin{aligned}
\frac{d S}{d R} & =\frac{\alpha I(t) S(t)}{\beta N I(t)} \\
\frac{d S}{d R} & =\frac{-\alpha S(t)}{\beta N} \\
\frac{1}{S} d S & =\frac{-\alpha}{\beta N} d R
\end{aligned}
$$

sendo esta ultima, uma equação diferencial de variáveis separáveis, e logo integrando a ambos lados, obtenemos que

$$
\begin{aligned}
\log S(t) & =-\frac{\alpha}{\beta N} R(t)+c \quad \text { com } c \in \mathbb{R} \\
S(t) & =c \exp \left(-\frac{\alpha}{\beta N} R(t)\right),
\end{aligned}
$$

com as condições iniciais, temos que $c=I(0) \exp \left(\frac{\alpha}{\beta N} R(0)\right)$, e logo $S(t)=I(0) \exp \left(\frac{\alpha}{\beta N}(R(0)-R(t))\right)$ e como $R(t)$ é uma função decrescente, obtemos o resultado.

Em particular se $R(0)=0$, temos que $S(t) \geq S(0) \exp \left(-\frac{\alpha}{\beta}\right)$, ou seja que

$\lim _{t \rightarrow \infty} S(t)>S(0) \exp \left(-\frac{\alpha}{\beta}\right)$.

O modelo da forma como está descrito é suficientemente para analisar a dinâmica epidemiológica sob o ponto de vista matemática. Mas não considera outros aspectos da doença, por exemplo a existência de vetores (outro tipo de indivíduos que também são transmissores do patógeno), nem situações que podem ser muito importantes na dinâmica, como por exemplo os nascimentos, mortes ou migrações. Porém já existem modelos que descrevem estas e outras situações que podem acontecer, ver mais em (Keeling e Rohani [2008], Anderson et al. [1992]).

\subsection{Redes}

Na secção anterior a dinâmica da doença foi considerada para uma população, porém, se a ideia é descrever uma dinâmica mais real, os modelos de redes mostram uma boa representação da dinâmica de mobilidade entre populações (Brockmann et al. [2009],Brockmann et al. [2006]).

Consideramos uma população que está subdividida em $M$ regiões ou populações menores, enumeradas por $n=1,2, \ldots, M$, tendo entre algumas delas mobilidade de indivíduos, o modelo de rede permite uma representação desta dinâmica por meio de um grafo que tem nós ou vértices simbolizados por pontos; e arestas ou ligações simbolizadas por flechas direcionadas.

Os nós correspondem a cada população $n$ e a posição de cada um respeita a escala da distância geográfica real; e uma flecha que sai da população $n$ até a $m$ corresponde a existência de mobilidade de indivíduos da população $n$ para a $m$, neste caso dizemos que $n$ tem conexão direta (ou simplesmente conexão) com $m$. Um caminho é o conjunto de nós ordenados $\Gamma=\left\{n_{0}, n_{1}, \ldots, n_{k}\right\}$ que representá uma rota entre nós para a mobilidade da população $n_{0}$ para a $n_{k}$, claramente entre dois nós seguidos deve existir a conexão e $-\Gamma$ corresponde ao caminho no sentido contrario (se existir) de $\Gamma$. Além disso, se diz que o grafo é conectado se sempre existe um caminho entre duas populações 
quaisquer.

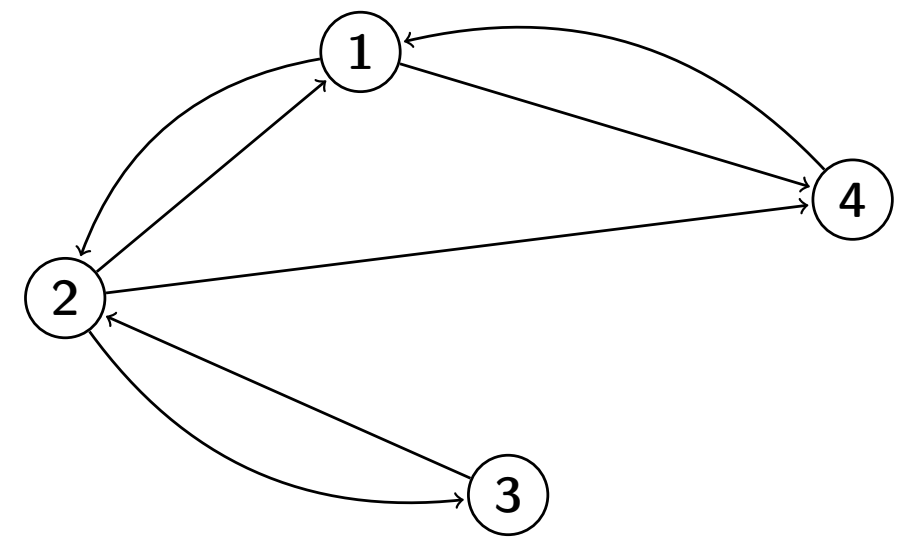

Figura 1.1: Exemplo de uma rede de 4 nós

Na Figura 1.1, podemos afirmar que a população 1 tem conexão direta com as populações 2 e 4, enquanto que não tem com a população 3 . Existem dois caminhos possíveis para ir de 3 a 1 , $\Gamma_{1}=\{3,2,1\}$ e $\Gamma_{2}=\{3,2,4,1\}$.

Dada a conexão da população $n$ para $m, w_{n m} \in[0,1]$ corresponde a taxa de mobilidade de $n$ a $m$ por unidade de tempo, este valor é estimado por meio dos dados de mobilidade: se $F_{n m}$ é o número de indivíduos se locomovendo da população $n$ para $m$ por unidade de tempo então, $w_{n m}=\frac{F_{n m}}{N_{n}}$, onde $N_{n}$ é o tamanho da população $n$. Cabe ressaltar que $F_{n m}$ é um valor médio, a população é constante e $F_{n n}=0$.

Em particular, se temos dois nós que estão conectados em ambas direções e que viajam a mesma quantidade de indivíduos então

$$
F_{m n}=w_{m n} N_{m}=w_{n m} N_{n}=F_{n m} .
$$

Passando ao contexto das doenças infecciosas, a conexão de duas populações significa a possibilidade da transmissão por meio da mobilidade, neste caso é assumido que as viagens entre as regiões são rápidas o bastante para que não haja transmissão da doença durante o percurso, assim as infecções só acontecem na região de destino ou de origem. A dinâmica de mobilidade vem dada pelo sistema que chamamos Sistema SIR em uma rede

$$
\begin{aligned}
& \frac{d S_{n}(t)}{d t}=-\frac{\alpha S_{n}(t) I_{n}(t)}{N_{n}}+\sum_{m \neq n}\left(w_{m n} S_{m}(t)-w_{n m} S_{n}(t)\right) \\
& \frac{d I_{n}(t)}{d t}=\frac{\alpha S_{n}(t) I_{n}(t)}{N_{n}}-\beta I_{n}+\sum_{m \neq n}\left(w_{m n} I_{m}(t)-w_{n m} I_{n}(t)\right) \\
& \frac{d R_{n}(t)}{d t}=\beta I_{n}(t)+\sum_{m \neq n}\left(w_{m n} R_{m}(t)-w_{n m} R_{n}(t)\right)
\end{aligned}
$$

junto com as condições iniciais $\left(S_{n}(0), I_{n}(0), R_{n}(0)\right)$.

Simplesmente, supomos que temos o sistema SIR local acrescido da taxa de indivíduos chegando menos a taxa de indivíduos saindo conforme seu estado na doença. Também consideramos que todas as populações têm a mesma taxa de contato $\alpha$ e a mesma taxa de recuperação $\beta$. Esta dinâmica considera que os indivíduos mobilizando-se mantê-se um tempo em seu destino, ou seja não são viagens por unidade de tempo. 
De novo, para que a dinâmica tenha sentido, no instante inicial devem existir indivíduos suscetíveis e pelo menos um infectado. Para entender com mais detalhe o sistema, seguem algumas propriedades do sistema que caracterizam a dinâmica da doença.

Lema 1.6 O sistema SIR em uma rede com condições iniciais $S_{n}(0), I_{n}(0), R_{n}(0)$, tem que $N_{n}(t)=N_{n}+\left(\sum_{m \neq n}\left(F_{m n}-F_{n m}\right)\right) t$. para todo $n=1,2, \ldots, M$.

Demostração: Somando as equações (1.5), (1.6) e (1.7), obtemos

$$
\begin{aligned}
\frac{d N_{n}(t)}{d t} & =\frac{d S_{n}(t)}{d t}+\frac{d I_{n}(t)}{d t}+\frac{d R_{n}(t)}{d t} \\
& =\sum_{m \neq n}\left(w_{m n}\left(S_{m}(t)+I_{m}(t)+R_{m}(t)\right)-w_{n m}\left(S_{n}(t)+I_{n}(t)+R_{n}(t)\right)\right. \\
& =\sum_{m \neq n}\left(w_{m n} N_{m}(t)-w_{n m} N_{n}(t)\right) \\
& =\sum_{m \neq n}\left(F_{n m}-F_{m n}\right)
\end{aligned}
$$

$\log 0$

$$
N_{n}(t)=\left(\sum_{m \neq n}\left(F_{n m}-F_{m n}\right)\right) t+c
$$

e dado que no instante inicial cada população é igual a $N_{n}$, então temos o resultado.

Em particular, se supomos a equação (1.4), a população permanece constante todo o tempo.

Lema 1.7 Se o sistema SIR em uma rede tem condições iniciais $S_{n}(0), I_{n}(0), R_{n}(0) \geq 0$ para todo $n=1,2, \ldots, M$, então $S_{n}(t), I_{n}(t), R_{n}(t) \geq 0$ para todo $t \geq 0$ e $n=1,2, \ldots, M$.

Demostração: Se em algum tempo $t^{*}>0$, existe $n=1,2, \ldots, M$ tal que $S_{n}\left(t^{*}\right)=0$, e o resto é ainda positivo, então $\frac{d S_{n}\left(t^{*}\right)}{d t}=\sum_{m \neq n} w_{m n} S_{m}\left(t^{*}\right)$, e por definição $w_{m n} \geq 0$ para todo $n, m$, então $\frac{d S_{n}\left(t^{*}\right)}{d t}>0$ ou que significa que $S(t)$ cresce logo de $t^{*}$ e, portanto,

$S_{n}(t), I_{n}(t), R_{n}(t) \geq 0$ para todo $t \geq 0$ e $n=1,2, \ldots, M$. Similarmente, se supomos em algum tempo $t^{*}>0$ que existe $n=1,2, \ldots, M$ tal que $I_{n}\left(t^{*}\right)=0$, e o resto é ainda positivo temos que $S_{n}(t), I_{n}(t), R_{n}(t) \geq 0$ para todo $t \geq 0$ e $n=1,2, \ldots, M$.

Se em algum tempo $t^{*}>0$, existe $n=1,2, \ldots, M$ tal que $R_{n}\left(t^{*}\right)=0$, e o resto é ainda positivo, então $\frac{d R_{n}\left(t^{*}\right)}{d t}=\beta I_{n}+\sum_{m \neq n} w_{m n} S_{m}\left(t^{*}\right)$, e por definição $w_{m n} \geq 0$ para todo $n, m$, então $\frac{d R_{n}\left(t^{*}\right)}{d t}>0 \operatorname{logo}$ $S_{n}(t), I_{n}(t), R_{n}(t) \geq 0$ para todo $t \geq 0$ e $n=1,2, \ldots, M$.

Se consideramos a população maior $N=\sum_{n} N_{n}$ (a união de todas as populações $n=1,2, \ldots, M$ ) então o sistema total da dinâmica está determinado por

$$
\begin{aligned}
& \frac{d S_{N}(t)}{d t}=-\alpha \sum_{n} \frac{S_{n}(t) I_{n}(t)}{N_{n}} \\
& \frac{d I_{N}(t)}{d t}=\alpha \sum_{n} \frac{S_{n}(t) I_{n}(t)}{N_{n}}-\beta I_{N} \\
& \frac{d R_{N}(t)}{d t}=\beta I_{N}(t)
\end{aligned}
$$


onde $S_{N}=\sum_{n} S_{n}, I_{N}=\sum_{n} I_{n}$ e $R_{N}=\sum_{n} R_{n}$.

Este sistema global resulta parecido ao sistema SIR local. Dessa forma, satisfaz algumas das propriedades apresentadas na secção anterior, como a população total permanecer constante, $I_{N}, S_{N}$ e $R_{N}$ são funções não negativas e $S_{N}$ e $R_{N}$ resultam decrescente e crescente respetivamente. Consequentemente, $\lim _{n \rightarrow \infty} S_{N}, \lim _{n \rightarrow \infty} I_{N}$ e $\lim _{n \rightarrow \infty} R_{N}$ existem.

Lema 1.8 Se o sistema SIR em uma rede têm condições iniciais $S_{n}(0), I_{n}(0), R_{n}(0) \geq 0$ com $n=1,2, \ldots, M$, então a doença sempre desaparece, ou seja,

$$
\lim _{t \rightarrow \infty} I_{N}(t)=0 .
$$

Demostração: Dado que $R_{N}(t) \leq N, \lim _{t \rightarrow \infty} R_{N}(t)$ existe e $R_{N}(t)$ ser uma função decrescente, então $\lim _{t \rightarrow \infty} \frac{d R_{N}(t)}{d t}=0$, ou seja que $\lim _{t \rightarrow \infty} \beta I_{N}(t)=0$ e portanto $\lim _{t \rightarrow \infty} I_{N}(t)=0$.

Por conseguinte $\lim _{n \rightarrow \infty} I_{n}=0$ para todo $n=1,2, \ldots, M$. Além disso temos que $(x, 0, y)$ com $x, y \in \mathbb{R}$ são todas as singularidades do sistema global similar ao sistema SIR local. Agora,

$\left(x_{1}, 0, y_{1}, x_{2}, 0, y_{2}, \ldots, x_{M}, 0, y_{M}\right)$ com $x_{i}, y_{i} \in \mathbb{R}$ resultam singularidades do sistema SIR em uma rede satisfazendo a equação 1.4, porém não podemos garantir que sejam as únicas singularidades, poderia ter mais dependentes das taxas de mobilidade entre as populações.

Se o sistema SIR em uma rede tem condições iniciais $S_{n}(0), I_{n}(0), R_{n}(0) \geq 0$ para todo $n=1,2, \ldots, M$ não podemos garantir que $S_{n}(t)$ é uma função decrescente e $R_{n}(t)$ é uma função crescente para todo $n=1,2, \ldots, M$, como no caso local, nem sequer considerando a equação 1.4 é possível. Como exemplo simples, supomos duas populações 1 e $2 \mathrm{com} n_{1}=1000, n_{2}=2000$ e $F_{12}=F_{21}=30$, além disso supomos as condições $S_{1}=n_{1}, I_{1}=0, S_{2}=n_{2}-1, I_{2}=1$ e $R_{1}=R_{2}=0$, ou seja, resulta um infectado na população 2 e naturalmente o resto de população fica suscetível. Então $\frac{d S_{2}(0)}{d t}=-0.9995 \alpha+0.015$, o que significa que existem valores positivos de $\alpha$ para os quais $\frac{d S_{2}(0)}{d t}$ pode ser positiva.

No sistema total resulta o número de reprodução básico é $R_{0}=\frac{\alpha}{\beta}$, de fato, supondo $S_{N}(0)=N-1$ e $I_{N}(0)=1$ então temos $\alpha$ infectados e o tempo de recuperação é igual a $\beta$. Porém este valor pode ser obtido para cada população, claramente vai depender das taxas de saída e entrada, seu cálculo resulta um estudo mais completo, recomendamos (Alvim et al. [2013]).

\subsection{Métodos numéricos}

Nas seções anteriores apresentamos uma introdução da modelagem epidêmica, onde descrevemos o numero de infectados, suscetíveis e recuperados por um sistema de equações diferencias ordinárias. Porém tal sistema não pode ser resolvido de forma explicita, em consequência usamos métodos numéricos para poder aproximas as soluções. Além disso, em algumas situações saber os parâmetros do sistema pode ser difícil e, portanto, é necessário estimar-los.

\section{Runge Kutta}

Para uma equação diferencial ordinária

$$
\frac{d u(t)}{d t}=f(t, u)
$$

com condição inicial $u(a)=\theta$ é possível aproximar a solução $u(t)$ para todo $t \in[a, b]$. O processo consiste em dividir o intervalo $[a, b]$ em $h$ subintervalos, e assim enumeramos $t_{i}=a+i h$ com 
$i=1,2, \ldots, m$ onde $t_{m}=b$, então a solução $u\left(t_{i+1}\right)$ tem aproximação por série de Taylor (supondo que $u$ admite $n$ derivadas) por

$$
u\left(t_{i+1}\right)=u\left(t_{i}\right)+h \frac{d u\left(t_{i}\right)}{d t}+\frac{h^{2}}{2} \frac{d^{2} u\left(t_{i}\right)}{d t^{2}}+\ldots+\frac{h^{n}}{n !} \frac{d^{n} u\left(t_{i}\right)}{d t^{n}}+O\left(h^{n+1}\right)
$$

pela equação (1.8) temos que

$$
\begin{aligned}
u\left(t_{i+1}\right) & =u\left(t_{i}\right)+h f\left(t_{i}, u\left(t_{i}\right)\right)+\frac{h^{2}}{2} f^{\prime}\left(t_{i}, u\left(t_{i}\right)\right)+\ldots+\frac{h^{n}}{n !} f^{(n)}\left(t_{i}, u\left(t_{i}\right)\right)+O\left(h^{n+1}\right) \\
& =u\left(t_{i}\right)+h T^{n}\left(t_{i}, u\left(t_{i}\right)\right)
\end{aligned}
$$

$\operatorname{com} T^{n}\left(t_{i}, u\left(t_{i}\right)\right)=f\left(t_{i}, u\left(t_{i}\right)\right)+\frac{h}{2} f^{\prime}\left(t_{i}, u\left(t_{i}\right)\right)+\ldots+\frac{h^{n-1}}{n !} f^{(n-1)}\left(t_{i}, u\left(t_{i}\right)\right)$. Este processo é denominado método de Taylor de ordem $n$ que resulta com um erro da ordem $h^{n+1}$. Cabe ressaltar que temos que calcular as derivadas da função $f$.

O método de Runge-Kutta (Burden e Faires [1989]) evita as determinações de cada derivada ao deixar os termos em função de $f$ que já está definida. Por meio da aproximação polinomial de Taylor em duas variáveis da $f$ é possível concluir que para $a_{1}=1, \alpha_{1}=\frac{h}{2}$ e $\beta_{1}=\frac{h}{2} f(t, u)$, então $a_{1} f\left(t+\alpha_{1}, u+\beta_{1}\right)$ aproxima-se a $T^{2}(t, u)$, de modo que

$$
u\left(t_{i+1}\right)=u\left(t_{i}\right)+h f\left(t_{i}+\frac{h}{2}, u\left(t_{i}\right)+\frac{h}{2} f\left(t_{i}, u\left(t_{i}\right)\right)\right)+O\left(h^{2}\right) .
$$

Este é o método de Runge-Kutta de ordem 1. Similarmente, o método em ordem 4 determina os valores que aproximam a $T^{4}(t, u)$ e obtemos que

$$
u\left(t_{i+1}\right)=u\left(t_{i}\right)+\frac{1}{6}\left(k_{1}+2 k_{2}+2 k_{3}+k_{4}\right)+O\left(h^{4}\right)
$$

onde

$$
\begin{aligned}
& k_{1}=h f\left(t_{i}, u\left(t_{i}\right)\right) \\
& k_{2}=h f\left(t_{i}+\frac{h}{2}, t_{i}+\frac{1}{2} k_{1}\right) \\
& k_{3}=h f\left(t_{i}+\frac{h}{2}, t_{i}+\frac{1}{2} k_{2}\right) \\
& k_{4}=h f\left(t_{i+1}, u\left(t_{i}\right)+k_{3}\right) .
\end{aligned}
$$

Dado um sistema de equações diferenciais ordinárias

$$
\begin{aligned}
\frac{d u_{1}}{d t} & =f_{1}\left(t, u_{1}, u_{2}, \ldots, u_{3}\right) \\
\frac{d u_{2}}{d t} & =f_{2}\left(t, u_{1}, u_{2}, \ldots, u_{3}\right) \\
& \vdots \\
\frac{d u_{m}}{d t} & =f_{m}\left(t, u_{1}, u_{2}, \ldots, u_{3}\right)
\end{aligned}
$$

com $t \in[a, b]$ e condições iniciais $\left(u_{1}(a), u_{2}(a), \ldots, u_{m}(a)\right)=\left(\theta_{1}, \theta_{2}, \ldots, \theta_{m}\right)$. Pode-se expandir as ideias do método de Runge-Kutta de ordem 4 . Denotamos a $t_{j}=a+i h$ o ponto inicial do subintervalo 
e por simplicidade, $u_{i, j}=u_{i}\left(t_{j}\right)$ então

$$
u_{i, j+1}=u_{i, j}+\frac{1}{6}\left(k_{1, i}+2 k_{2, i}+2 k_{3, i}+k_{4, i}\right)+O\left(h^{4}\right)
$$

onde

$$
\begin{aligned}
k_{1, i} & =h f_{i}\left(t_{j}, u_{1, j}, u_{2, j}, \ldots, u_{m, j}\right) \\
k_{2, i} & =h f_{i}\left(t_{j}+\frac{h}{2}, u_{1, j}+\frac{1}{2} k_{1,1}, u_{2, j}+\frac{1}{2} k_{1,2}, \ldots, u_{m, j}+\frac{1}{2} k_{1, m}\right) \\
k_{3, i} & =h f_{i}\left(t_{j}+\frac{h}{2}, u_{1, j}+\frac{1}{2} k_{2,1}, u_{2, j}+\frac{1}{2} k_{2,2}, \ldots, u_{m, j}+\frac{1}{2} k_{2, m}\right) \\
k_{4, i} & =h f_{i}\left(t_{j}+h, u_{1, j}+k_{3,1}+w_{2, j}+k_{3,2}, \ldots, w_{m, j}+k_{3, m}\right)
\end{aligned}
$$

para cada $i=1,2, \ldots, m$

\section{Método de Monte Carlo}

Como foi mencionado, em algumas ocasiões é necessário estimar os parâmetros da dinâmica com base nos dados de infectados. O método de Monte Carlo (ou experiência de Monte Carlo) é uma ferramenta que pode estimar esses parâmetros. Este método é uma ampla classe de algoritmos computacionais que dependem de amostragem aleatória repetida para obter resultados numéricos.Sua ideia essencial é usar o teorema de dos grandes números para resolver problemas que podem ser deterministas. (Metropolis e Ulam [1949])

O método de Monte Carlo pode variar, mas tende conforme o algoritmo abaixo

- Definir um domínio de possíveis entradas

- Gerar entradas aleatoriamente de uma distribuição de probabilidade sobre o domínio

- Executar o modelo com essas entradas

- Comparar o resultado com um erro

- Iterar processo muitas vezes

- Escolher a entrada do erro menor

A principal ideia é que os resultados são calculados com base numa amostra aleatória repetida e numa análise estatística. As simulações de Monte Carlo são de fato experimentações aleatórias, no caso dos resultados dessas experiências não serem bem conhecidos. Além disso, são tipicamente caracterizadas por um grande número de parâmetros desconhecidos, muitos dos quais são difíceis de obter experimentalmente.

As entradas aleatórias devem passar por uma série de testes estatísticos, testando que os números estão uniformemente distribuídos ou seguem outra distribuição desejada quando um grande número suficiente de elementos da sequência são considerados é um dos mais simples e os mais comuns.

Algumas características para um método de Monte Carlo de alta qualidade é que o gerador de números têm um longo "período"antes que a sequência se repita e produz valores que passam testes de aleatoriedade. Há amostras suficientes para garantir resultados precisos e o algoritmo usado é válido para o que está sendo modelado simula o fenômeno em questão. 
Para calcular o erro, usaremos o método de mínimos quadrados, que corresponde a encontrar, de certo modelo, os parâmetros que minimizam a soma das distâncias ponto a ponto quadradas entre a previsão do modelo e os dados. Se temos $M$ pontos de dados $y_{i}$ com $n=1, \ldots, M$ e previsões do modelo para esses pontos de dados $\bar{y}_{i}$ a estatística de mínimos quadrados, notada por $m q$, é calculada assim:

$$
m q=\sum_{n=1}^{M}\left(y_{i}-\bar{y}_{i}\right)^{2}
$$

De um ponto de vista estatístico, um requisito implícito para que funcione o ajuste de mínimos quadrados é que os $y_{i}$ com $i=1,2, \ldots, M$ sejam distribuídos de forma aleatória, o teorema de GaussMárkov prova que os estimadores de mínimos quadráticos carecem de sesgo e que a mostra de dados não tem que ajustar-se, por exemplo, a uma distribuição normal. 


\section{Capítulo 2}

\section{Distância efetiva e caminhos mais prováveis}

O artigo The Hidden Geometry of Complex, Network-Driven Contagion Phenomena de Dirk Brockmann e Dirk Helbing (Brockmann e Helbing [2013]), apresenta uma nova definição de distância entre populações dependente da mobilidade com o fim de determinar os caminhos mais prováveis na propagação de uma doença infecciosa e, com isso, antecipar os tempos de chegadas. Neste capítulo expomos uma motivação do estudo, o desenvolvimento do modelo e os resultados obtidos pelos autores, além de algumas simulações própias.

\subsection{Motivação}

A propagação de doenças infecciosas pode afetar a vida de milhões de pessoas, alguns exemplos através da historia no mundo são:

- A varíola é uma doença provocada por vírus "Orthopoxvírus variolae", ela pode transmitida pelo ar por meio de gotículas que escapam quando uma pessoa infectada tosse, espirra ou fala; ou via itens contaminados: contato com roupas e lençóis. Só de 1896 a 1980 casou 300 milhões de mortos no mundo. (Rosengard et al. [2002])

- A Peste Negra, causada pelo contato com roedores infectados, as pulgas dos roedores recolhem a bactéria da sangue dos animais infectados, e quando estes morrem, procuram novos hóspedes como os humanos. No siglo XIV acabou com a metade da população europeia. (Ziegler [2013])

- A Cólera, uma doença transmitida entre os humanos, geralmente através da água, alimentos e talheres contaminados por uma bactéria. No siglo XIX deixou cerca de 20 mil vítimas na França. (Colwell et al. [1996])

- O HIV (vírus da imunodeficiência humana), transmitida por contato sexual, exposição a fluidos ou tecidos corporais infectados e de mãe para filho durante a gravidez, o parto ou a amamentação. Há registros desde 1980 de casos e estima-se que tem falecido pelo menos 25 milhões de pessoas no mundo.(Montagnier [2002])

Atualmente, o progresso da urbanização no mundo, junto com tem crescente conetividade entre cidades ou países, há incrementado o risco de propagação de algum patógeno. Porém a complexidade da mobilidade humana torna difícil desenvolver estratégias de contenção e mitigação.

Mais recentemente, em 2003 o síndrome respiratória aguda grave SRAG (em inglês SARS), cuja causa não foi ainda determinada. Trata-se de uma pneumonia atípica, apareceu por primeira vez em novembro de 2002 na província de Cantón, China. Propagou-se a Hong Kong e Vietnã a finais de fevereiro de 2003, e logo a outros países (ver a Figura 2.1); a doença teve uma taxa média de 
mortalidade global cerca de 13\%. (Cameron et al. [2008])

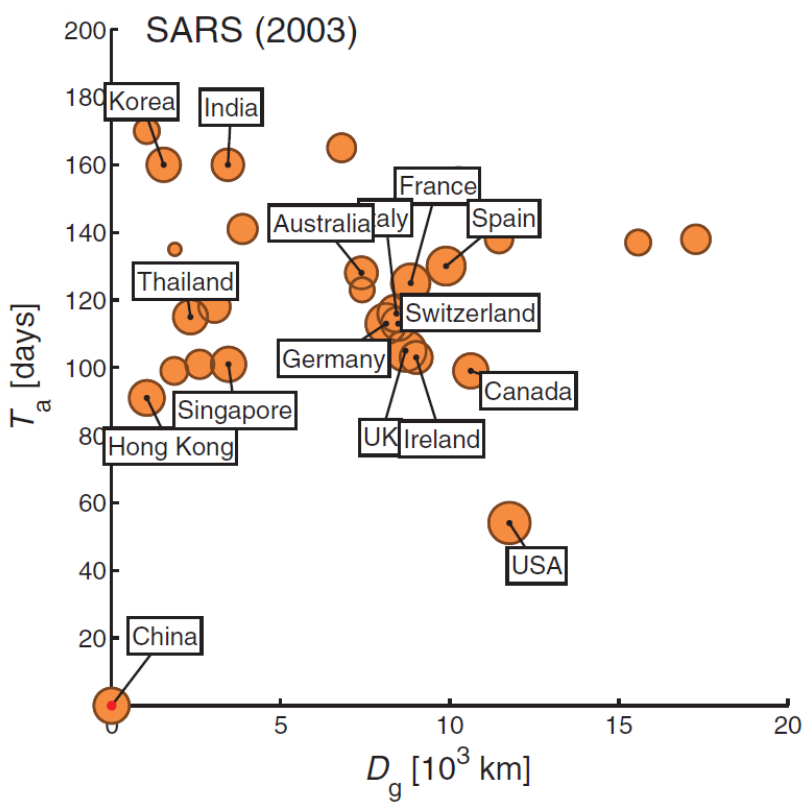

Figura 2.1: Propagação da doença SARS em 2003 por países, relacionando distância geográfica $D_{g}$ e o tempo de chegada $T_{a}$ com respeito a seu país de origem, China. Imagem tomada (Brockmann e Helbing [2013]).

Além disso, em 2009 surgiu a gripe H1N1, que resultou em um surto global de uma variante de gripe suína cujos primeiros casos ocorreram no México em meados do mês de março. Espalhou-se pelo mundo (ver a Figura 2.2), tendo começado pela América do Norte, atingindo pouco tempo depois a Europa e a Oceania, os dados afirmam que causou pelos menos 18500 mortes só no 2009. (Fineberg [2014])

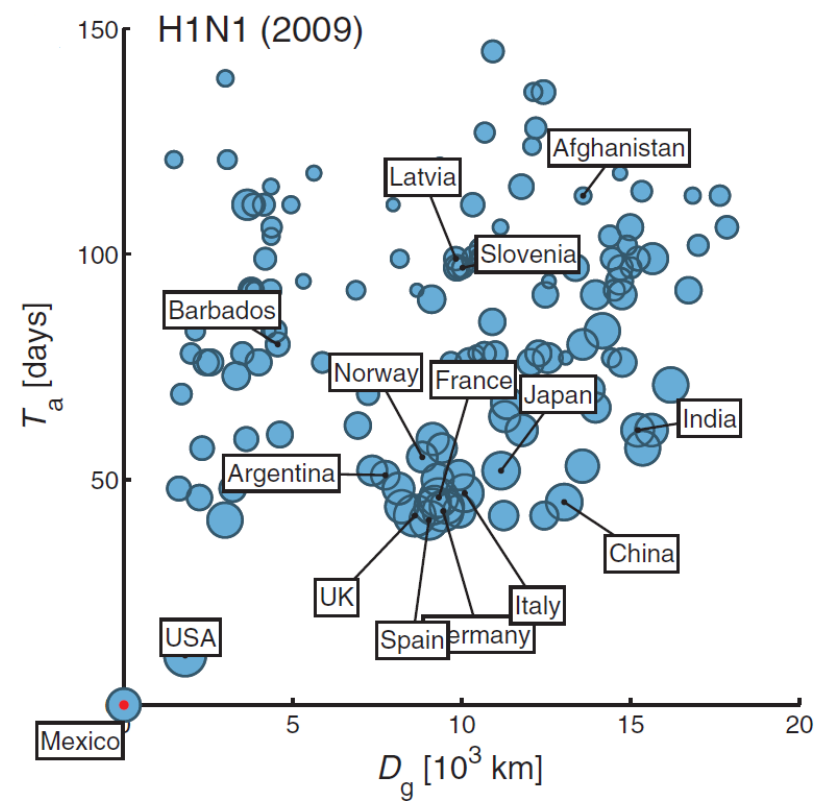

Figura 2.2: Propagação da doença $H 1 N 1$ em 2009 por países relacionando distância geográfica $D_{g}$ e tempo de chegada $T_{a}$ com respeito a seu país de origem, México. Imagem de (Brockmann e Helbing [2013]).

Portanto, existe um interesse em modelar como pode ser a dinâmica da propagação de uma doença, dada uma origem, ou que implica descobrir como foram os caminhos para chegar a uma certa 
população. Por isso, os autores propõem responder as seguentes questões:

- Onde surgiu o novo patógeno?

- Onde são esperados novos casos?

- Quando uma epidemia vai chegar em locais distantes?

- Quantos casos devem ser esperados?

\subsection{Derivação do modelo}

Consideramos uma população dividida em $M$ regiões, enumeradas por $n=1,2, \ldots, M$. Vamos supor que cada uma delas tem tamanho constante $N_{n}$ e a mobilidade está determinada por uma matriz $F=\left[F_{n m}\right]$ simétrica, ou seja, que é a mesma quantidade de indivíduos que viajam de $n$ a $m$ que de $m$ a $n$. Com isso a taxa de mobilidade é dada pela equação (1.4); e além disso a rede formada resulta ser conectada.

A ideia é descrever o sistema SIR em uma rede de uma maneira que possamos obter mais informação da propagação da doença. Para isso definimos os seguentes parâmetros:

\begin{tabular}{|ll|}
\hline Parâmetro & Significado \\
\hline$w_{n m}=\frac{F_{n m}}{N_{n}}$ & taxa de mobilidade da população $n$ para $m$. \\
$\Phi=\sum_{n, m} F_{n m}$ & quantidade total de indivíduos movendo-se por dia. \\
$\Omega=\sum_{n} N_{n}$ & tamanho total da população. \\
$c_{n}=\frac{N_{n}}{\Omega}$ & tamanho relativo da população $n$. \\
$f_{n m}=\frac{F_{n m}}{\Phi}$ & fração de fluxo da população que se move de $n$ para a $m$ por dia. \\
$\gamma=\frac{\Phi}{\Omega}$ & taxa de mobilidade global por dia. \\
$\omega_{n}=\sum_{m} w_{n m}$ & taxa de saída da população $n$ por dia. \\
$f_{n}=\sum_{m} f_{m n}$ & fracão de fluxo total da população $n$ por dia. \\
\hline
\end{tabular}

Claramente $f_{n m}=f_{m n}$, por que assumimos $F_{n m}=F_{m n}$. Vamos mostrar algumas relações que satisfazem estes parâmetros.

Lema 2.1 Para todo $n, m=1,2, \ldots, M$ temos que $\gamma=\frac{w_{n m} c_{n}}{f_{n m}}$.

Demostração: De fato, observe que

$$
\begin{aligned}
\gamma f_{n m} & =\frac{\Phi}{\Omega} \frac{F_{n m}}{\Phi} \\
& =\frac{F_{n m}}{\Omega} \\
& =\frac{w_{n m} N_{n}}{\Omega} \\
& =w_{n m} \frac{N_{n}}{\Omega} \\
& =w_{n m} c_{n} .
\end{aligned}
$$


Definindo o valor médio das taxas de saída como $\langle\omega\rangle=\sum_{m} \omega_{m} c_{m}$, temos o seguinte resultado.

Lema 2.2 O valor médio das taxas de saída de todas as populações é igual a taxa de mobilidade global para todo.

Demostração:

$$
\begin{aligned}
\langle\omega\rangle & =\sum_{m} \omega_{m} c_{m} \\
& =\sum_{m}\left(\left(\sum_{k} w_{m k}\right) c_{m}\right) \\
& =\sum_{k, m} w_{m k} c_{m} \\
& =\frac{1}{\Omega} \sum_{k, m} w_{m k} N_{m} \\
& =\frac{1}{\Omega} \sum_{k, m} F_{m k} \\
& =\frac{\phi}{\Omega} \\
& =\gamma
\end{aligned}
$$

Lema 2.3 Para todo $n=1,2, \ldots, M$ temos que $\frac{\Phi}{N_{n}}=\frac{\omega_{n}}{f_{n}}$.

Demostração: De fato,

$$
\begin{aligned}
\left(\frac{\Phi}{N_{n}}\right) f_{n} & =\left(\frac{\Phi}{N_{n}}\right)\left(\sum_{m} f_{m n}\right) \\
& =\left(\frac{\Phi}{N_{n}}\right)\left(\sum_{m} \frac{F_{m n}}{\Phi}\right) \\
& =\left(\frac{1}{N_{n}}\right)\left(\sum_{m} F_{m n}\right) \\
& =\sum_{m} \frac{F_{n m}}{N_{n}} \\
& =\sum_{m} \frac{w_{n m} N_{n}}{N_{n}} \\
& =\sum_{m} w_{n m} \\
& =\omega_{n}
\end{aligned}
$$

No sistema SIR em uma rede fazemos a substituição ou normalização, $j_{n}=\frac{I_{n}}{N_{n}}$ e $s_{n}=\frac{S_{n}}{N_{n}}$, como consideramos que a população é constante, então $r_{n}=1-s_{n}-j_{n}$. Para (1.6) temos que:

$$
\begin{aligned}
& \frac{d j_{n} N_{n}}{d t}=\frac{\alpha s_{n} N_{n} j_{n} N_{n}}{N_{n}}-\beta j_{n} N_{n}+\sum_{m \neq n} w_{m n} j_{m} N_{m}-w_{n m} j_{n} N_{n} \\
& N_{n} \frac{d j_{n}}{d t}=\alpha s_{n} j_{n} N_{n}-\beta j_{n} N_{n}+\sum_{m \neq n} w_{m n} j_{m} N_{m}-w_{n m} j_{n} N_{n},
\end{aligned}
$$


ou seja, que

$$
\begin{aligned}
\frac{d j_{n}}{d t} & =\alpha s_{n} j_{n}-\beta j_{n}+\frac{1}{N_{n}} \sum_{m \neq n} j_{m} w_{m n} N_{m}-j_{n} w_{n m} N_{n} \\
& =\alpha s_{n} j_{n}-\beta j_{n}+\frac{1}{N_{n}} \sum_{m \neq n} j_{m} F_{m n}-j_{n} F_{n m} \\
& =\alpha s_{n} j_{n}-\beta j_{n}+\frac{1}{N_{n}} \sum_{m \neq n} F_{m n}\left(j_{m}-j_{n}\right) \\
& =\alpha s_{n} j_{n}-\beta j_{n}+\frac{1}{N_{n}} \sum_{m \neq n}\left(\Phi f_{m n}\right)\left(j_{m}-j_{n}\right) \\
& =\alpha s_{n} j_{n}-\beta j_{n}+\frac{\Phi}{N_{n}} \sum_{m \neq n} f_{m n}\left(j_{m}-j_{n}\right) \\
& =\alpha s_{n} j_{n}-\beta j_{n}+\frac{\omega_{n}}{f_{n}} \sum_{m \neq n} f_{m n}\left(j_{m}-j_{n}\right) \quad(\text { pelo Lema 2.3) } \\
& =\alpha s_{n} j_{n}-\beta j_{n}+\omega_{n} \sum_{m \neq n} \frac{f_{m n}}{f_{n}}\left(j_{m}-j_{n}\right) \\
& =\alpha s_{n} j_{n}-\beta j_{n}+\omega_{n} \sum_{m \neq n} P_{m n}\left(j_{m}-j_{n}\right)
\end{aligned}
$$

onde $P_{m n}=\frac{f_{m n}}{f_{n}}$. Assim é possível construir uma matriz markoviana $P=\left[P_{n m}\right]$ onde $P_{m n}$ representa a probabilidade de um individuo sair da população $n$ e ir à população $m$. Resulta esta matriz não ser necessariamente simétrica e temos que:

$$
\sum_{m} P_{m n}=\sum_{m} \frac{f_{m n}}{f_{n}}=\frac{1}{f_{n}} \sum_{m} f_{m n}=\frac{f_{n}}{f_{n}}=1 .
$$

Se consideramos um caminho $\Gamma=\left\{n_{0}, n_{1}, \ldots, n_{L-1}, n_{L}\right\}$ de $L$ conexões em uma rede qualquer, temos que

$$
W(\Gamma)=P_{n_{L} n_{L-1}} \cdots P_{n_{1} n_{0}}=\prod_{i=0}^{L-1} P_{n_{i+1} n_{i}}
$$

é a probabilidade de um individuo tomar esse caminho, isto porque cada conexão é considerada independente das outras.

Lema 2.4 Dada uma rede conectada, para todo caminho $\Gamma=\left\{n_{0}, n_{1}, \ldots, n_{L-1}, n_{L}\right\}$ temos que $W(\Gamma) f_{n_{0}}=$ $W(-\Gamma) f_{n_{L}}$.

Demostração: De fato,

$$
\begin{aligned}
W(\Gamma) f_{n_{0}} & =\left(P_{n_{L} n_{L-1}} P_{n_{L-1} n_{L-2}} \cdots P_{n_{2} n_{1}} P_{n_{1} n_{0}}\right) f_{n_{0}} \\
& =\left(\frac{f_{n_{L} n_{L-1}}}{f_{n_{L-1}}} \frac{\left.f_{n_{L-1} n_{L-2}} \cdots \frac{f_{n_{2} n_{1}}}{f_{n_{L-2}}} \frac{f_{n_{1} n_{0}}}{f_{n_{0}}}\right) f_{n_{0}}}{}\right. \\
& =\frac{f_{n_{1} n_{0}} f_{n_{1} n_{2}} \cdots f_{n_{L-1} n_{L-2}} f_{n_{L} n_{L-1}}}{f_{n_{1}} f_{n_{2}} \cdots f_{n_{L-2}} f_{n_{L-1}}} \\
& =\frac{f_{n_{0} n_{1}}}{f_{n_{1}}} \frac{f_{n_{1} n_{2}}}{f_{n_{2}}} \cdots \frac{f_{n_{L-2} n_{L-1}}}{f_{n_{L-1}}} f_{n_{L-1} n_{L}}\left(\frac{f_{n_{L}}}{f_{n_{L}}}\right) \\
& =\left(\frac{f_{n_{0} n_{1}}}{f_{n_{1}}} \frac{f_{n_{1} n_{2}}}{f_{n_{2}}} \frac{f_{n_{L-2} n_{L-1}}}{f_{n_{L-1}}} \frac{f_{n_{L-1} n_{L}}}{f_{n_{L}}}\right) f_{n_{L}} \\
& =\left(P_{n_{0} n_{1}} P_{n_{1} n_{2}} \cdots P_{n_{L-2} n_{L-1}} P_{n_{L-1} n_{L}}\right) f_{n_{l}} \\
& =W(-\Gamma) f_{n_{L}} .
\end{aligned}
$$


Voltando para a normalização, similar ao feito na equação (1.5), e obtemos o novo sistema

$$
\begin{aligned}
& \frac{d s_{n}}{d t}=-\alpha s_{n} j_{n}+\omega_{n} \sum_{m \neq n} P_{m n}\left(s_{m}-s_{n}\right) \\
& \frac{d j_{n}}{d t}=\alpha s_{n} j_{n}-\beta j_{n}+\omega_{n} \sum_{m \neq n} P_{m n}\left(j_{m}-j_{n}\right)
\end{aligned}
$$

Além disso, pelo Lema 2.2 podemos estabelecer que a taxa de saída seja uniforme, ou seja, $\omega_{n}=\gamma$ para todo $n$, isto derivado da relação entre a capacidade de saída e a área de captação. Assim

$$
\begin{aligned}
& \frac{d s_{n}}{d t}=-\alpha s_{n} j_{n}+\gamma \sum_{m \neq n} P_{m n}\left(s_{m}-s_{n}\right) \\
& \frac{d j_{n}}{d t}=\alpha s_{n} j_{n}-\beta j_{n}+\gamma \sum_{m \neq n} P_{m n}\left(j_{m}-j_{n}\right)
\end{aligned}
$$

Cabe ressaltar que este sistema só depende dos dados de mobilidade e do tamanho total das populações.

Lema 2.5 Se $\omega_{n}=\gamma$ para todo $n=1,2, . ., M$ então $f_{n}=c_{n}$ para todo $n=1,2, \ldots, M$.

Demostração: Temos que

$$
\begin{aligned}
f_{n} & =\sum_{m} f_{m n} \\
& =\sum_{m} f_{n m} \\
& =\sum_{m} \frac{w_{n m} c_{n}}{\gamma} \quad \text { (pelo Lema 2.1) } \\
& =\frac{c_{n}}{\omega_{n}} \sum_{m} w_{n m} \\
& =\frac{c_{n} \omega_{n}}{\omega_{n}} \\
& =c_{n}
\end{aligned}
$$

Consequentemente, pelo Lema 2.4, temos que $W(\Gamma) c_{n_{0}}=W(-\Gamma) c_{n_{L}}$.

Agora a ideia é determinar o caminho mais provável que existe entre duas populações de uma rede conectada, sem se importar com conexão direta ou um caminho. Para isso, se uma população $n$ tem conexão com $m$ é estabelecida uma relação $l$ definida como

$$
l_{m n}=1-\ln \left(P_{m n}\right),
$$

o que significa que uma alta probabilidade é uma relação pequena de $n$ a $m$. Podemos ver que $l_{m n} \geq 1$ e dado que $P$ não é necessariamente uma matriz simétrica, então podemos ter $l_{n m} \neq l_{m n}$, mas é possível relacionar esses dois valores conforme o Lema abaixo:

Lema 2.6 Sejam $n$ e $m$ duas populações com conexão, então temos que $l_{n m}-\ln \left(f_{m}\right)=l_{m n}-\ln \left(f_{n}\right)$. 
Demostração: Temos que

$$
\begin{aligned}
l_{n m} & =1-\ln \left(\frac{f_{n m}}{f_{m}}\right) \\
& =1-\left(\ln \left(f_{n m}\right)-\ln \left(f_{m}\right)\right) \\
& =1-\ln \left(f_{n m} \frac{f_{n}}{f_{n}}\right)+\ln \left(f_{m}\right) \\
& =1-\left(\ln \left(\frac{f_{n m}}{f_{n}}\right)+\ln \left(f_{n}\right)\right)+\ln \left(f_{m}\right) \\
& =1-\ln \left(\frac{f_{m n}}{f_{n}}\right)-\ln \left(f_{n}\right)+\ln \left(f_{m}\right) \\
& =l_{m n}-\ln \left(f_{n}\right)+\ln \left(f_{m}\right)
\end{aligned}
$$

Ou equivalentemente, pelo Lema $2.4, l_{n m}-\ln \left(c_{m}\right)=l_{m n}-\ln \left(c_{n}\right)$; ou seja, se $c_{n}>c_{m}$, então $l_{m n}>l_{n m}$. Isto capta a noção intuitiva de que um indivíduo escolhido aleatoriamente em uma grande população é menos propenso a se mudar para uma pequena população conectada do que um indivíduo da pequena população se deslocalizando para a grande população (apesar de existir um equilíbrio de fluxo entre ambas as populações).

Para cada caminho $\Gamma=\left\{n, n_{1}, \ldots, n_{L-1}, m\right\}$ da população $n$ para $m$ de $L$ conexões definimos a relação $\lambda$ como

$$
\lambda(\Gamma)=L-\ln (W(\Gamma))
$$

ou seja, que é a soma da relação $l$ de conexões. Podemos afirmar que dois caminhos diferentes entre a mesmo origem e destino podem ter diferentes valores de $\lambda$ e além disso $\lambda(\Gamma) \geq L$ e ainda satisfazem o seguinte lema

Lema 2.7 Dadas duas populações $n$ e $m$ qualquer em uma rede conectada e $\Gamma=\left\{n, n_{1}, \ldots, n_{L-1}, m\right\}$ um caminho de L conexões, então $\lambda(\Gamma)-\ln \left(f_{n_{0}}\right)=\lambda(-\Gamma)-\ln \left(f_{n_{L}}\right)$

Demostração:

$$
\begin{aligned}
\lambda(\Gamma)-\ln \left(f_{n_{0}}\right) & =L-\ln (W(\Gamma))-\ln \left(f_{n_{0}}\right) \\
& =L-\ln \left(W(\Gamma) f_{n_{0}}\right) \\
& =L-\ln \left(W(-\Gamma) f_{n_{L}}\right) \quad(\text { pelo Lema 2.4) } \\
& =L-\ln (W(-\Gamma))-\ln \left(f_{n_{L}}\right) \\
& =\lambda(-\Gamma)-\ln \left(f_{n_{L}}\right),
\end{aligned}
$$

ou equivalentemente, $\lambda(\Gamma)-\ln \left(c_{n_{0}}\right)=\lambda(-\Gamma)-\ln \left(c_{n_{L}}\right)$, e tem o mesmo significado de que um indivíduo escolhido aleatoriamente em uma grande população é menos propenso a se mudar para uma pequena população do que um indivíduo da pequena população se deslocalizando para a grande população.

Finalmente, a distância efetiva, denotada por $d(m, n)$, entre a população $n$ e $m$ está definida como

$$
d(m, n)=\min _{\Gamma} \lambda(\Gamma)
$$

entre todos os caminhos possíveis da população $n$ até $m$. O caminho $\Gamma$ que dá o mínimo, é denominado o caminho mais provável. A denominação de distância, refere-se a que muda a distância geográfica, não a distância no sentido matemático já que não satisfaz a simetria. 
Assim, para cada nó $n$ obtemos todos os caminhos mais prováveis dirigidos para as outras populações, a maneira de representar isto é um novo grafo, onde o nó $n$ é colocado como centro, os outros nós são colocados conforme a distância efetiva (mantém a escala) e as arestas são de acordo à rota dos caminhos.

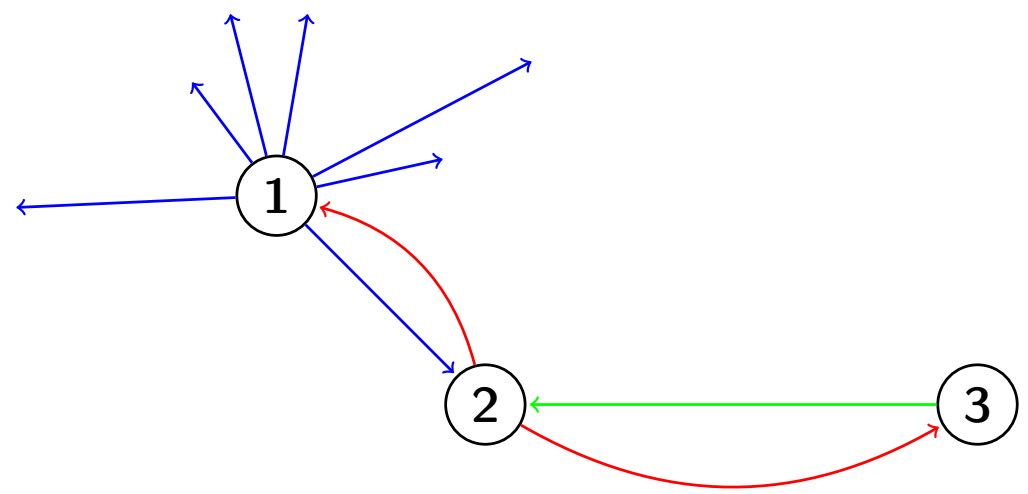

Figura 2.3: Exemplo da mobilidade de uma rede de $M \geq 9$ nós

Os autores propõem um exemplo simples para explicar, consideramos uma rede com $M \geq 9$ nós, onde uma parte dela está descrita pela Figura 2.3. Por simplicidade, assumimos que a quantidade de tráfego é igual ao longo das conexões da figura. Vemos que a população 3 só tem conexão com 2, logo a probabilidade $P_{23}=1$; para sair da população 2 tem duas opções, pode chegar a 1 ou 3 , e como estamos supondo que tem a mesma quantidade de tráfego, então $P_{12}=P_{32}=\frac{1}{2}$. Porém, a população 1 tem conexão com outras 7 populações de igual tráfego, logo $P_{21}=\frac{1}{7}$, em particular todas as conexões azuis tem essa mesma probabilidade.

Com isso, as distâncias efetivas são conforme a:

$$
\begin{aligned}
& d(1,2)=1-\ln \left(\frac{1}{2}\right)=1.69314 \\
& d(3,2)=1-\ln \left(\frac{1}{2}\right)=1.69314 \\
& d(2,3)=1-\ln (1)=1 \\
& d(2,1)=1-\ln \left(\frac{1}{7}\right)=2.94591 \\
& d(3,1)=2-\ln \left(\left(\frac{1}{7}\right)\left(\frac{1}{2}\right)\right)=1-\ln \left(\frac{1}{7}\right)+1-\ln \left(\frac{1}{2}\right)=4.63805
\end{aligned}
$$

e

$$
d(1,3)=2-\ln \left((1)\left(\frac{1}{2}\right)\right)=2-\ln \left(\frac{1}{2}\right)=2.69314 .
$$

Os grafos possíveis para a propagação de uma doença dependendo a população inicial estão representados na Figura 2.4. Podemos afirmar que se a doença iniciar na população 1, ela vai demorar muito mais tempo em expandir-se que se iniciar em 2 e em 3. Porem se iniciar em 2 vai demorar menos que se começara em 1.

Além disso, a distância efetiva e os caminhos mais prováveis permitem estimar a origem de uma epidemia quando se tem os dados das populações onde chegou a doença em um tempo $t>0$. A ideia é que em cada grafo resultante, marcar as populações onde chegou a doença, então a origem é aquele grafo onde essa marcação é a mais concêntrica ou radial, ou seja, a mais circular. 


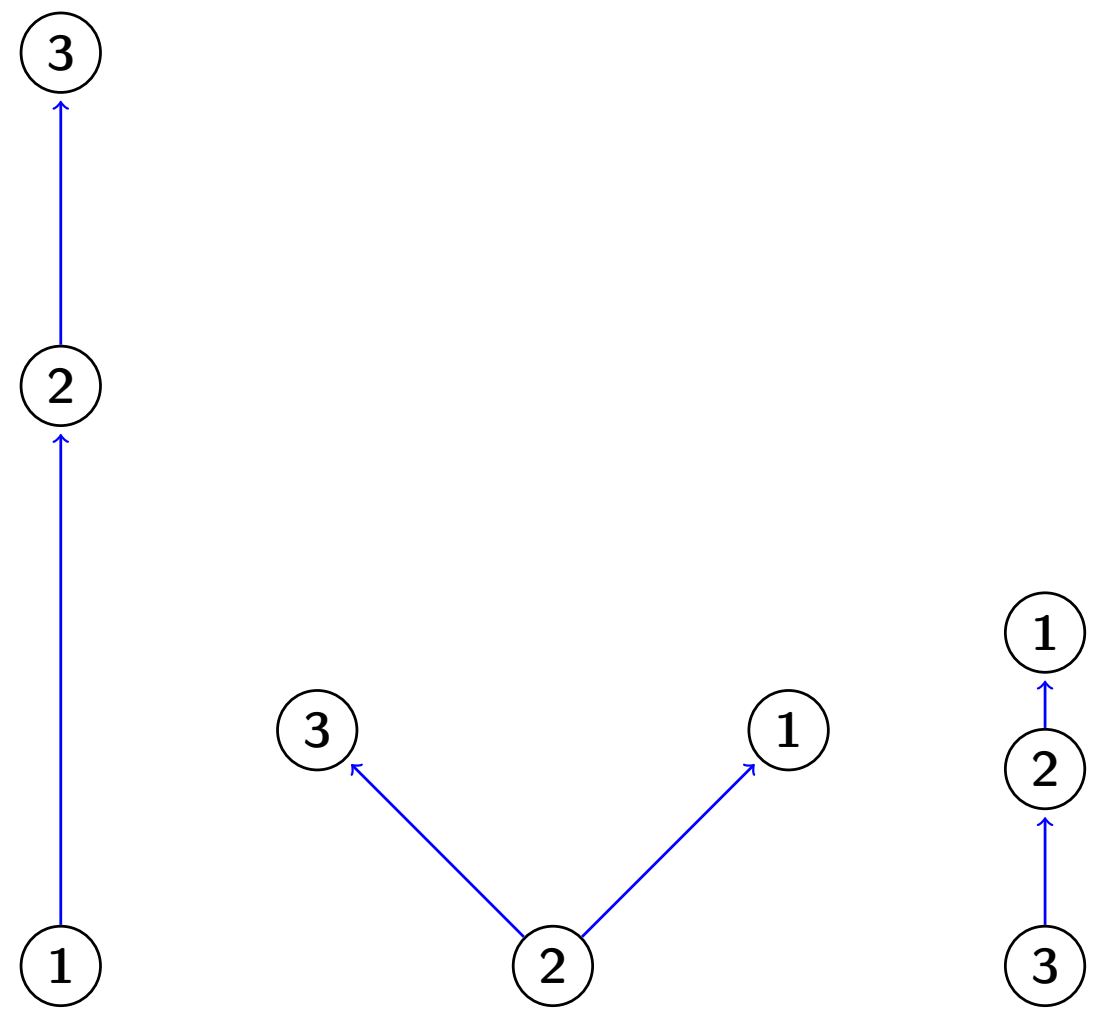

Figura 2.4: Representação dos possíveis caminhos mais prováveis da figura 2.3.

Dado um nó de origem $k$, a distância efetiva permite relacionar uma velocidade efetiva, como $v(m, n)=\frac{d(m, n)}{T_{a}(m, n)}$, onde $T_{a}(m, n)$ corresponde ao tempo desde que a doença começou em $n$ até chegar a $m$. Cabe aclarar que os nós $n$ e $m$ devem pertencer a um mesmo caminho mais provável que tenha a origem com qualquer outra população. Consequentemente, esta velocidade resulta constante, ou seja que a relação de tempo de chegada $T_{a}$ e a distância efetiva $d$ é linear. Logo

$$
\frac{T_{a}\left(n, k^{\prime}\right)}{T_{a}\left(m, k^{\prime}\right)}=\frac{d\left(n, k^{\prime}\right)}{d\left(m, k^{\prime}\right)}
$$

para qualquer $n, k^{\prime}, m=1,2, \ldots M$ populações que pertençam ao mesmo caminho mais provável da origem $k$ com qualquer outra população.

\subsection{Resultados}

Para testar o novo modelo os autores utilizaram a rede global de mobilidade (GMN) que é construída a partir de dados fornecidos pelo Official Airline Guide (Brockmann e Helbing [2013]), o conjunto de dados inclui um total de 4.069 aeroportos e o número de assentos em vôos comerciais programados entre pares de aeroportos ao longo de um período de três anos, que resultam proporcional ao número de passageiros que viajam e com média igual a 175.

Os dados estão representados pelo grafo da Figura 2.5, os nós representam os aeroportos e as arestas não direcionados representam o tráfego entre eles (as cores dividem o mundo por partes), ou seja, é suposto que viajam a mesma quantidade de pessoas entre dois aeroportos. Logo a rede resultante consiste em 4069 nós e 25453 voos e a quantidade total de passageiros por dia é $\phi=\sum_{i, j} F_{i j}=8.91 \times 10^{6}$. 


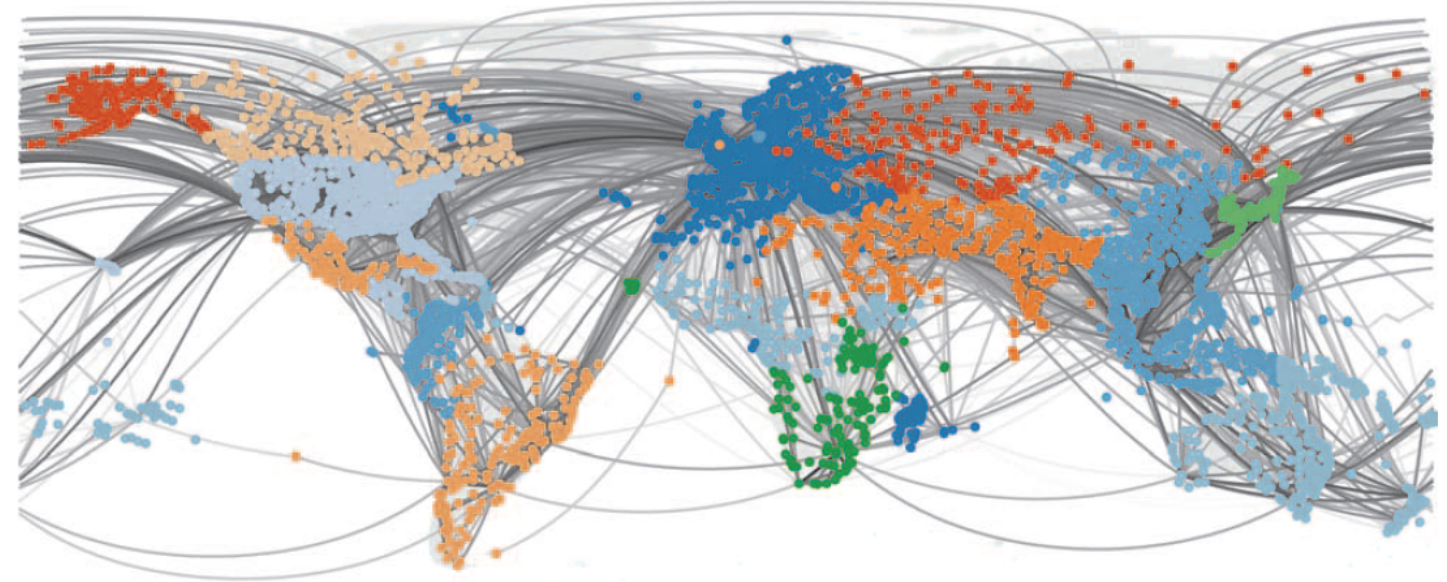

Figura 2.5: Rede global de viagens aéreas com 4069 nós e 25453 conexões não direcionados. Imagem tomada de (Brockmann e Helbing [2013]).

Na aplicação à disseminação da pandemia H1N1 de 2009, mencionada na secção 2.1, foi usada uma rede projetada GMNc em que os nós representam países inteiros e voos que os conectam representam o tráfego agregado entre os países. Esta rede possui $N=189$ nós e $L=5004$ conexões. A figura 2.6 descreve a relação entre a distância efetiva e os tempos de chegada da doença, tendo em conta que a origem foi México.

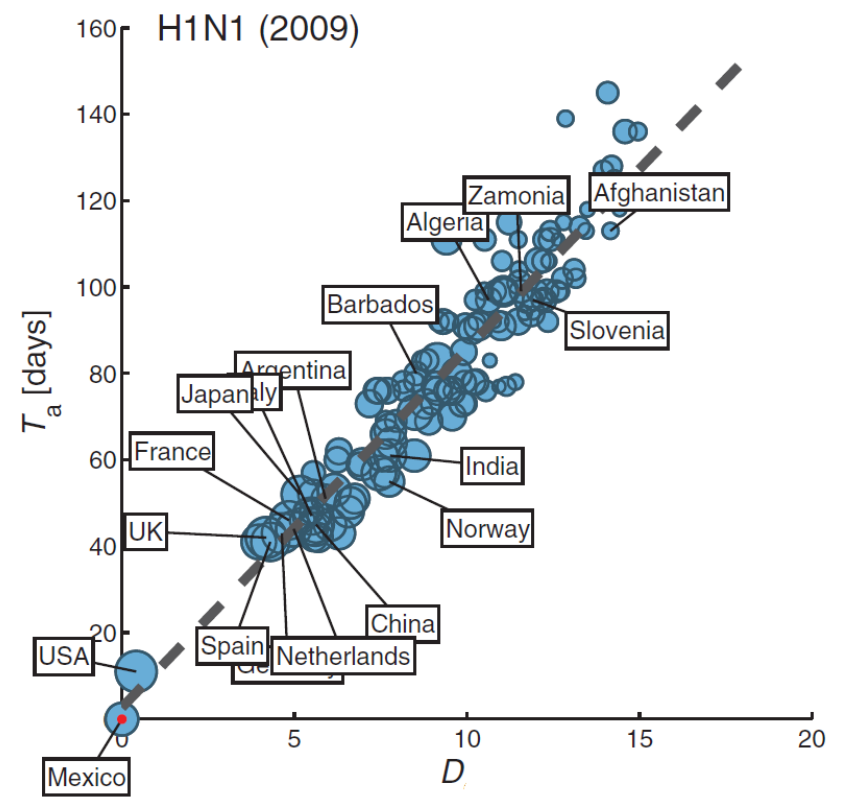

Figura 2.6: Propagação da doença H1N1 de 2009 por países relacionando distância efetiva $D$ e tempo de chegada $T_{a}$ com respeito a seu país de origem México. Imagem de (Brockmann e Helbing [2013]).

Similarmente, para a doença $S A R S$ de 2003 foram tomados 29 países, a Figura 2.7 descreve a relação entre a distância efetiva e os tempos de chegada da doença, tendo em conta que a origem foi China. 


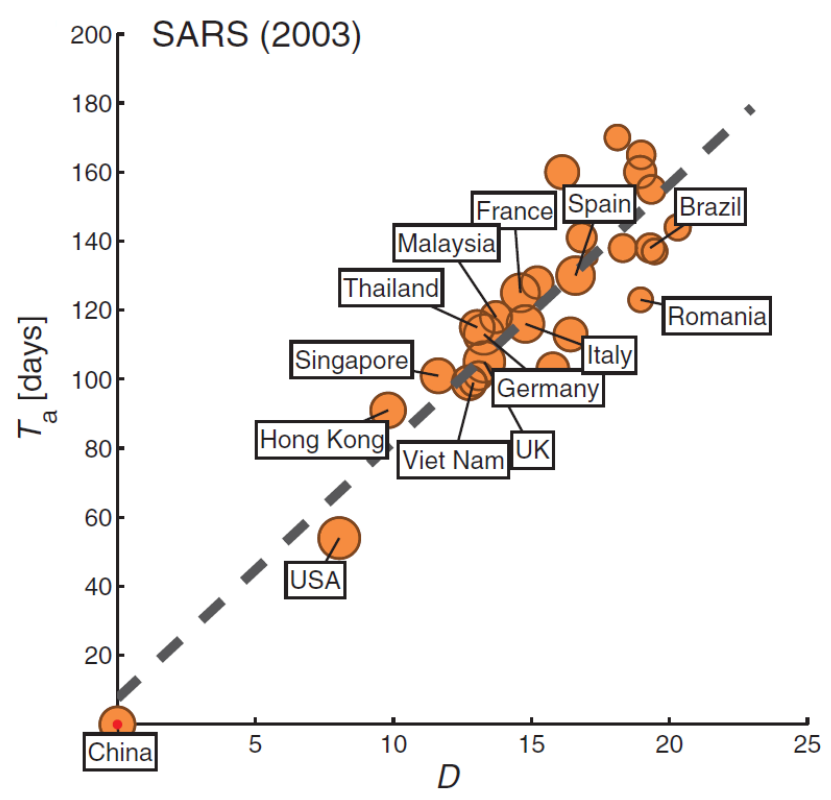

Figura 2.7: Propagação da doença $S A R S$ de 2003 por países relacionando distância efetiva $D$ e tempo de chegada $T_{a}$ com respeito a seu pais de origem China. Imagem de (Brockmann e Helbing [2013]).

Além disso, os autores propuseram um exemplo usando todos os nós da rede e as conexões mencionadas, supondo $R_{0}=1.5, \beta=0.285, \gamma=2.8 * 10^{-3}$ (todos parâmetros em dias), e cuja origem é o aeroporto de Hong Kong. A Figura 2.8 mostra a relação de distancia geográfica e tempos de chegada com essas hipóteses, as cores mantê-se como na Figura 2.5.

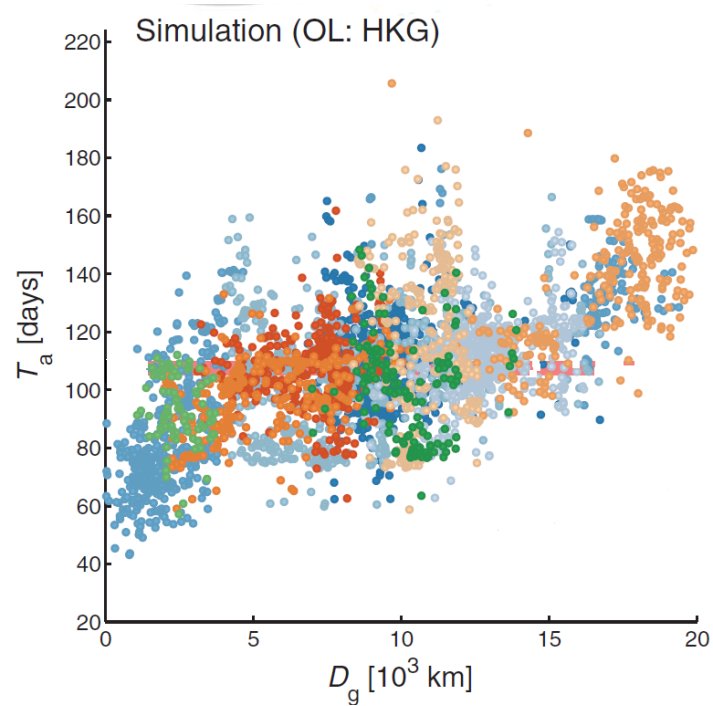

Figura 2.8: Propagação de uma doença simulada pela rede global relacionando distância geográfica e tempo de chegada com respeito a seu aeroporto de origem Hong Kong. Imagem de (Brockmann e Helbing [2013]).

As Figuras 2.9 e 2.10 correspondem aos resultados do modelo, a relação de distância efetiva e tempo de chegada, e o grafo dos caminhos mais prováveis sendo a origem o aeroporto de Hong Kong. As cores são um indicativo de como é a dinâmica, realmente não tem um padrão, seguem a distância geográfica. 


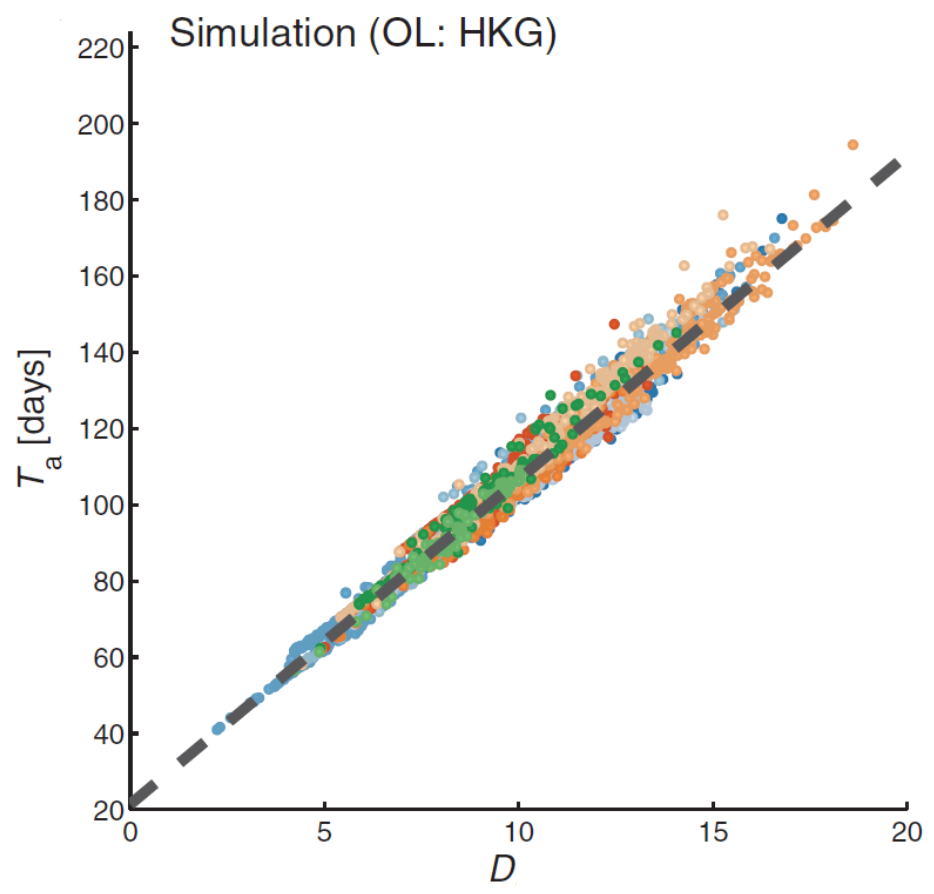

Figura 2.9: Propagação de uma doença simulada pela rede relacionando distância efetiva e tempo de chegada com respeito a seu aeroporto de origem Hong Kong. Imagem de (Brockmann e Helbing [2013]).

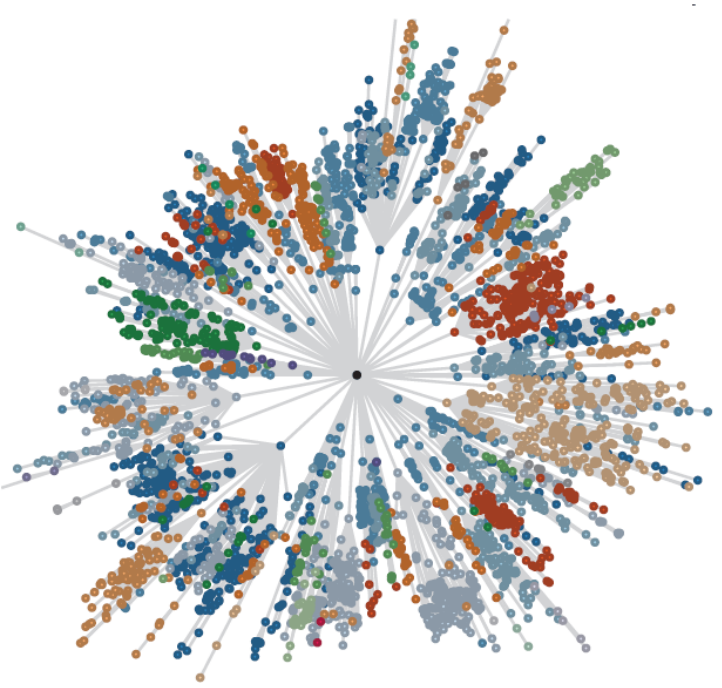

Figura 2.10: Grafo de caminhos mais prováveis de uma propagação de uma doença simulada pela rede onde a origem é o aeroporto de origem Hong Kong. Imagem de (Brockmann e Helbing [2013]). 
A Figura 2.11 corresponde a "snapshots" por dias da propagação na rede e no grafo de caminhos mais prováveis.

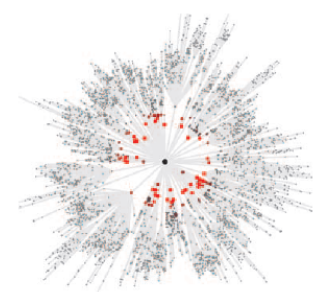

$\mathrm{T}=41 \mathrm{~d}$.

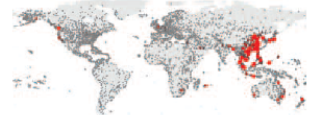

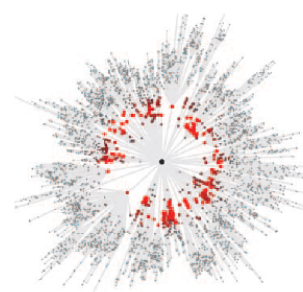

$\mathrm{T}=51 \mathrm{~d}$.

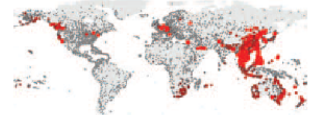

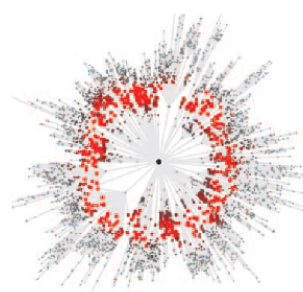

$\mathrm{T}=62 \mathrm{~d}$.

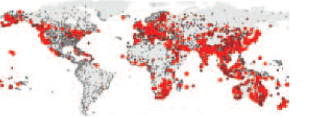

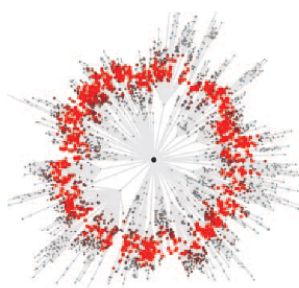

$\mathrm{T}=72 \mathrm{~d}$.

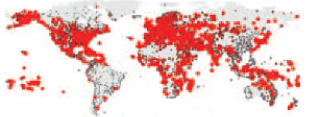

Figura 2.11: Snapshots por dias da propagação de uma rede com origem em Hong Kong da rede e do grafo dos caminhos mais prováveis onde. Imagem de (Brockmann e Helbing [2013]).

\subsection{Simulação numérica}

O artigo de Brockmann e Helbing [2013] apresenta bons resultados da relação linear entre a distância efetiva e os tempos de chegada das doenças de SARS em 2003 e da H1N1 em 2009. Além disso mostra para um exemplo hipotético o novo grafo e sua propagação. Nesta parte expomos com exemplos e confirmamos suas conclusões.

Vamos supor uma rede descrita pela Figura 2.12. A população está divida em 10 regiões e cujo tamanho de cada nó esta descrito na seguente maneira

\begin{tabular}{|c|c|}
\hline Nó & Tamanho \\
\hline 1 & 5000 \\
2 & 5000 \\
3 & 6250 \\
4 & 12500 \\
5 & 20000 \\
6 & 6250 \\
7 & 3750 \\
8 & 5000 \\
9 & 8750 \\
10 & 17500 \\
\hline
\end{tabular}

A mobilidade por dia está representada pela seguente matriz $F_{10 x 10}$ :

$$
F=\left[\begin{array}{cccccccccc}
0 & 50 & 50 & 100 & 0 & 0 & 0 & 0 & 0 & 0 \\
50 & 0 & 0 & 0 & 0 & 0 & 0 & 150 & 0 & 0 \\
50 & 0 & 0 & 0 & 200 & 0 & 0 & 0 & 0 & 0 \\
100 & 0 & 0 & 0 & 200 & 100 & 0 & 0 & 0 & 0 \\
0 & 0 & 200 & 200 & 0 & 0 & 0 & 0 & 0 & 400 \\
0 & 0 & 0 & 100 & 0 & 0 & 100 & 50 & 0 & 0 \\
0 & 0 & 0 & 0 & 0 & 100 & 0 & 0 & 50 & 0 \\
0 & 150 & 0 & 0 & 0 & 50 & 0 & 0 & 0 & 0 \\
0 & 0 & 0 & 0 & 0 & 0 & 50 & 0 & 0 & 300 \\
0 & 0 & 0 & 0 & 400 & 0 & 0 & 0 & 300 & 0
\end{array}\right]
$$




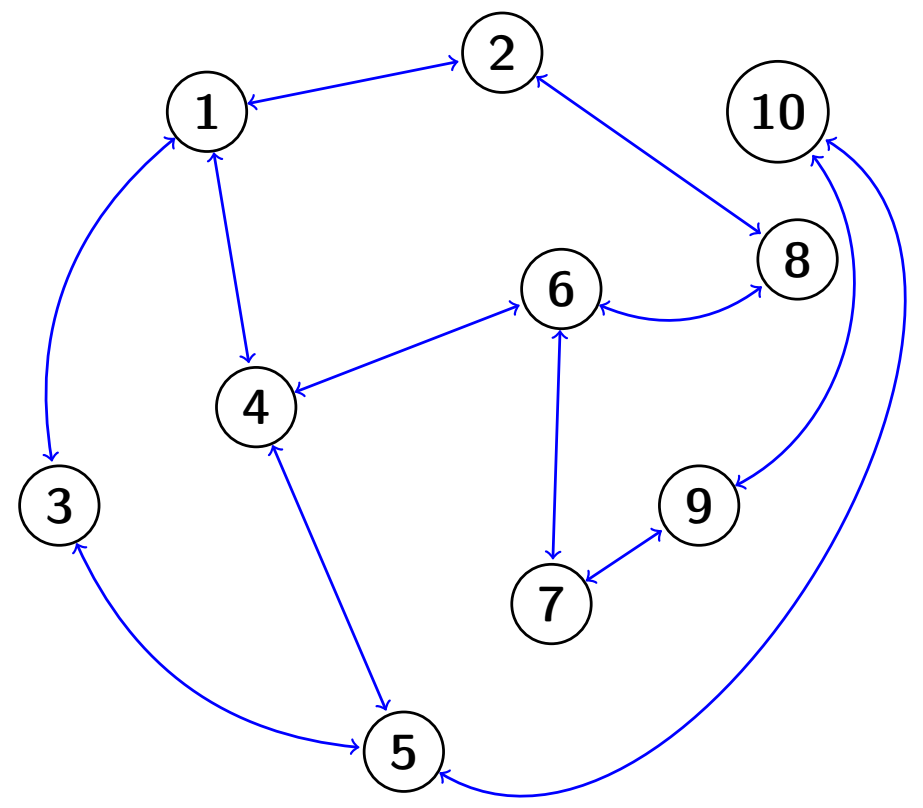

Figura 2.12: Rede de simulação

Além disso, $\gamma=\frac{\sum_{n m} F_{n m}}{\sum_{n} N_{n}}=\frac{3600}{90000}=0.04$, podemos afirmar que $\gamma=\omega_{n}$ para todo $n=1,2, \ldots, 10$, satisfazendo as hipóteses do modelo das equações (2.2) e (2.3). Posteriormente determinamos a matriz $P_{10 x 10}$ da seguinte maneira

$$
P=\left[\begin{array}{cccccccccc}
0 & 0.25 & 0.2 & 0.25 & 0 & 0 & 0 & 0 & 0 & 0 \\
0.25 & 0 & 0 & 0 & 0 & 0 & 0 & 0 . \overline{6} & 0 & 0 \\
0.25 & 0 & 0 & 0 & 0.25 & 0 & 0 & 0 & 0 & 0 \\
0.5 & 0 & 0 & 0 & 0.25 & 0.4 & 0 & 0 & 0 & 0 \\
0 & 0 & 0.8 & 0.5 & 0 & 0 & 0 & 0 & 0 & 0.57 \\
0 & 0 & 0 & 0.25 & 0 & 0 & 0 . \overline{6} & 0 . \overline{3} & 0 & 0 \\
0 & 0 & 0 & 0 & 0 & 0.4 & 0 & 0 & 0.14 & 0 \\
0 & 0.75 & 0 & 0 & 0 & 0.2 & 0 & 0 & 0 & 0 \\
0 & 0 & 0 & 0 & 0 & 0 & 0 . \overline{3} & 0 & 0 & 0.42 \\
0 & 0 & 0 & 0 & 0.5 & 0 & 0 & 0 & 0.85 & 0
\end{array}\right]
$$

\section{Exemplo 1}

Vamos supor que $\alpha=1, \beta=0.6$ e a origem é o nó 5 , com uma pessoa infectada, e que as outras regiões têm toda sua população suscetível, portanto o grafo dos caminhos mais prováveis vem dado como na Figura 2.13, onde a origem vem de cor verde e as linhas rosas ajudam a uma melhor visão radial da origem. 


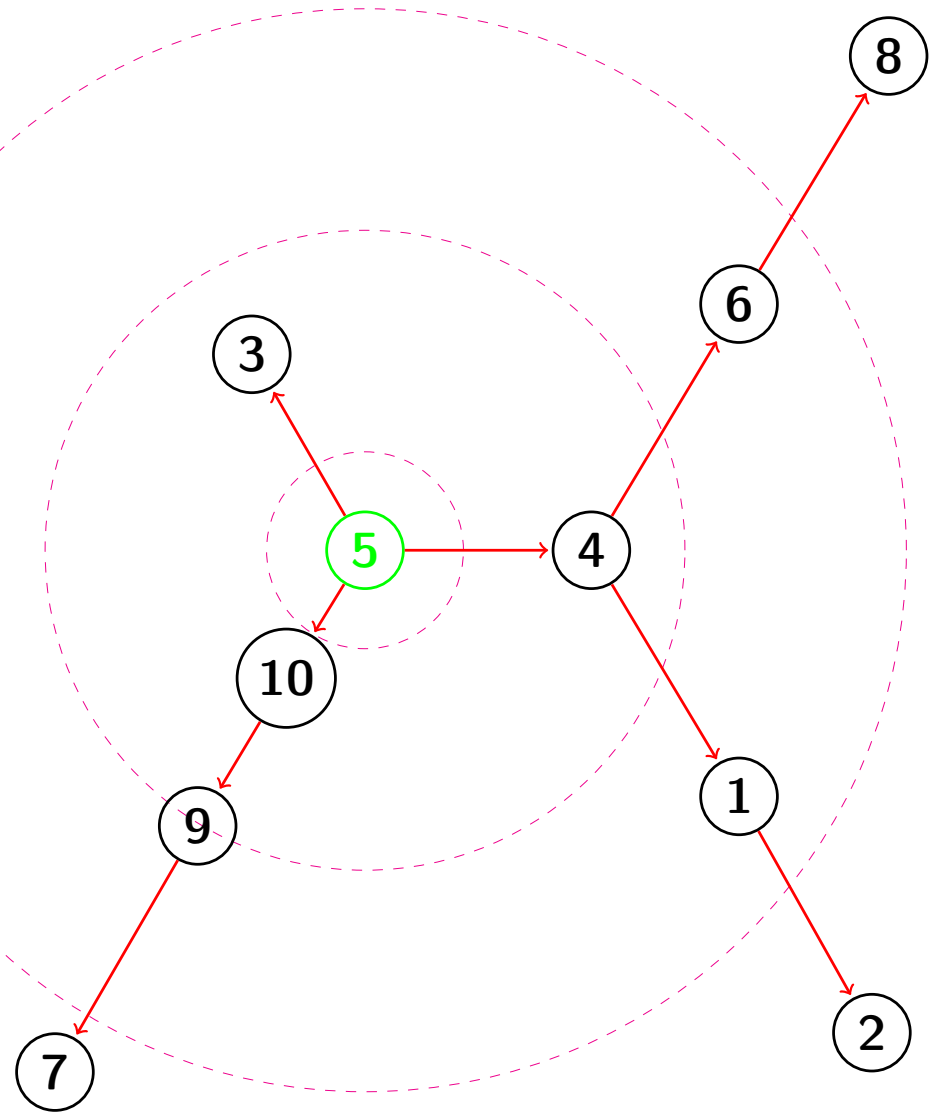

Figura 2.13: Grafo de caminhos mais prováveis da simulação 3.

Por meio do programa $R$ podemos obter as soluções de um sistema de equações diferencias ordinárias com condições iniciais num intervalo finito de tempo usando o método de Runge Kutta de ordem 4. Além disso programamos para poder obter as distâncias efetivas e os caminhos mais prováveis em Fortran.

Os resultados obtidos do tempo de chegada, distância efetiva e velocidade efetiva são mostrados conforme abaixo

\begin{tabular}{|l|cccccccccc|}
\hline Nó & 1 & 2 & 3 & 4 & 5 & 6 & 7 & 8 & 9 & 10 \\
\hline Distância efetiva & 4.6 & 7.0 & 2.3 & 2.3 & 0 & 4.6 & 6.3 & 7.2 & 3.4 & 1.6 \\
\hline Tempo de chegada & 12 & 16 & 7 & 7 & 1 & 12 & 15 & 17 & 11 & 6 \\
\hline Velocidade efetiva & 0.38 & 0.43 & 0.32 & 0.32 & 0 & 0.38 & 0.42 & 0.42 & 0.3 & 0.26 \\
\hline
\end{tabular}

Em média a velocidade efetiva é de 0.38 , a Figura 2.14 mostra a relação de distância efetiva e o tempo de chegada da doença, consideramos que o tempo de chegada é, quando existir, uma pessoa infectada no nó. Posteriormente, na Figura 2.15 mostramos a dinâmica da fracão de infectados em cada população.

Na Figura 2.16 mostramos o processo por dias de chegada da doença do grafo da rede e o grafo de caminhos mais prováveis, a origem está de cor verde e em cada passo observamos a propagação da doença em uma nova população conforme os resultados, as populações onde já chegou a doença ficam de cor vermelha, as flechas azuis mostram a direção da propagação e os círculos de rosa mostram a propagação radial no grafo de caminhos mais prováveis . 


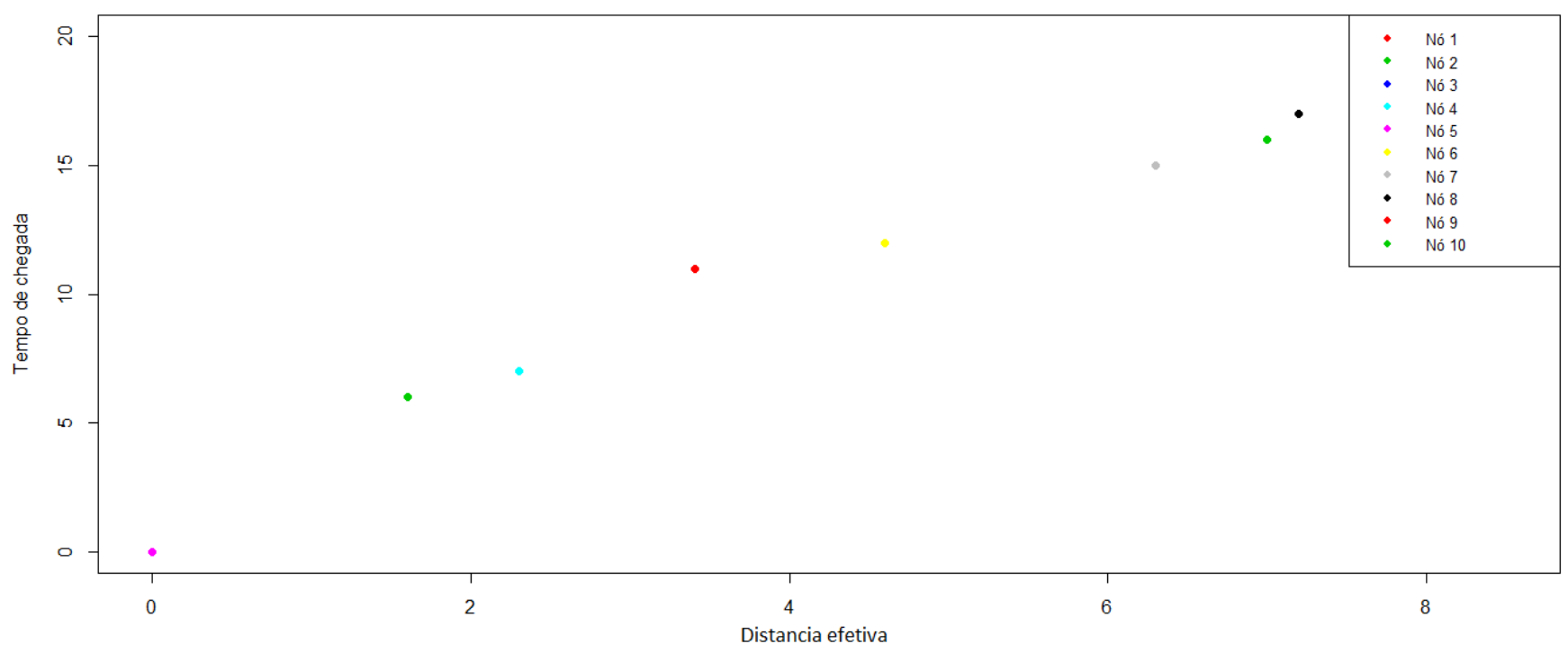

Figura 2.14: Relação de distância efetiva e o tempo de chegada da doença do exemplo 1.

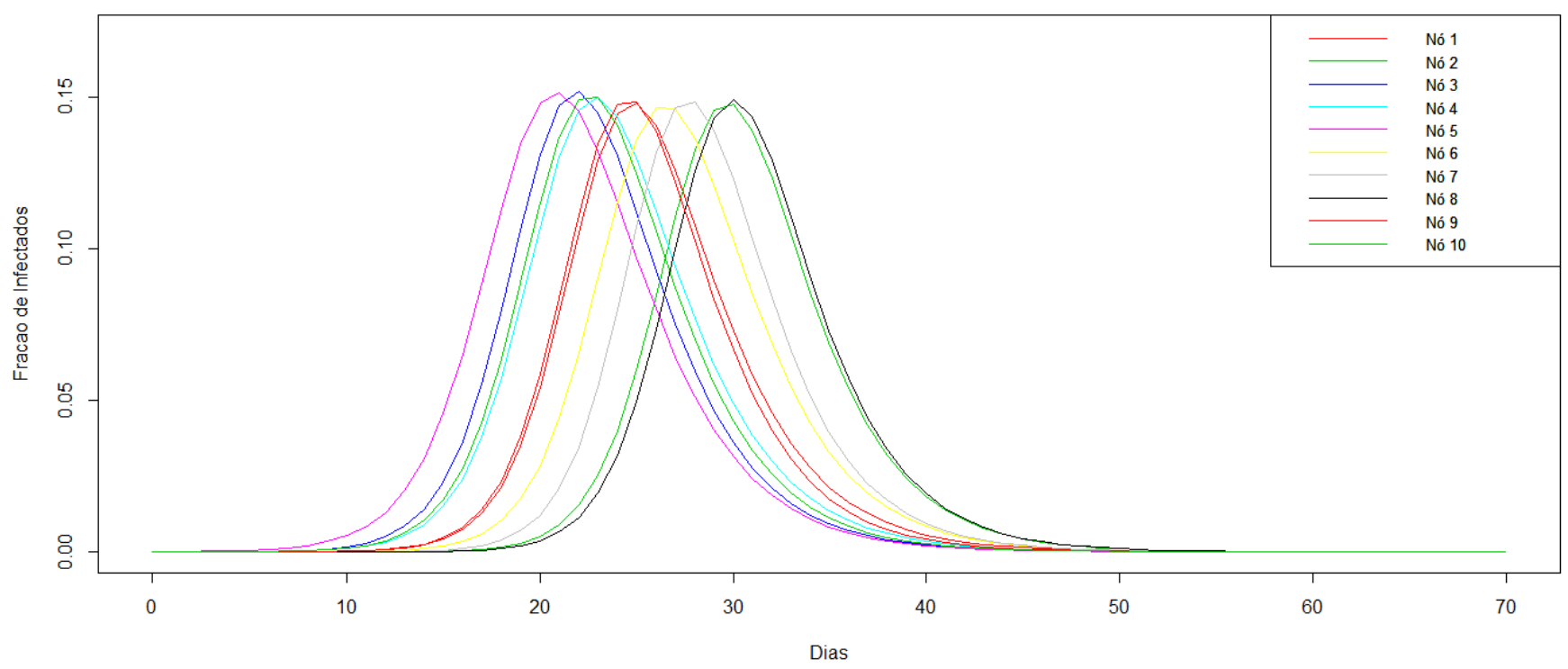

Figura 2.15: Dinâmica da fracão de infectados de cada nó do exemplo 1. 


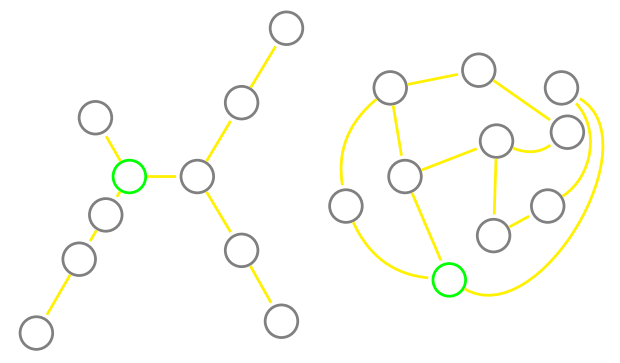

Dia 1

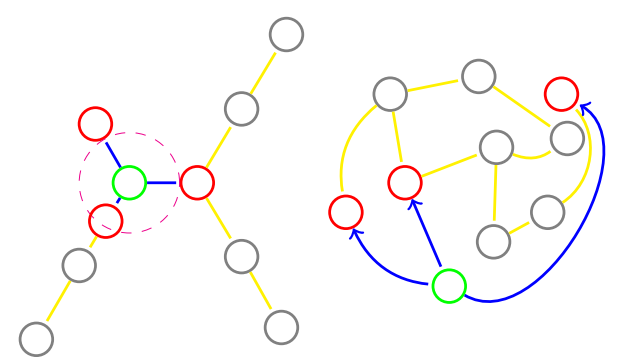

Dia 7

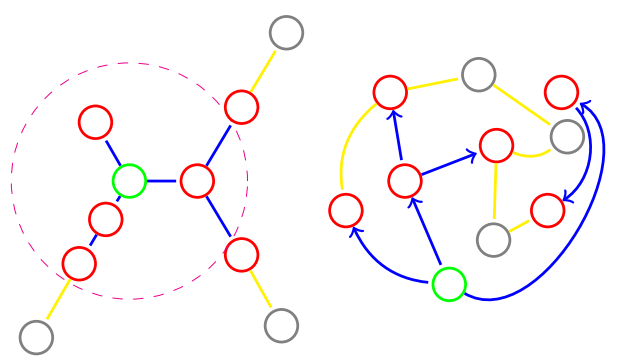

Dia 12
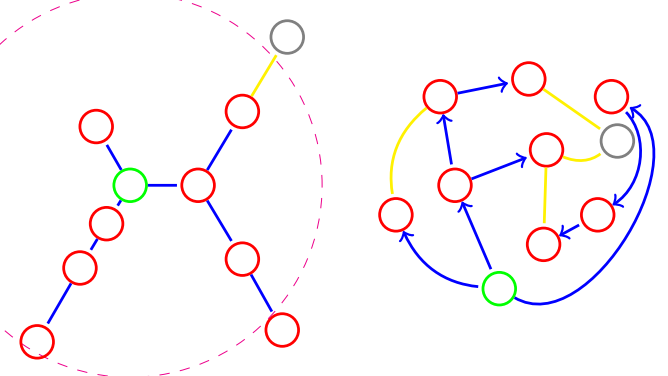

Dia 16

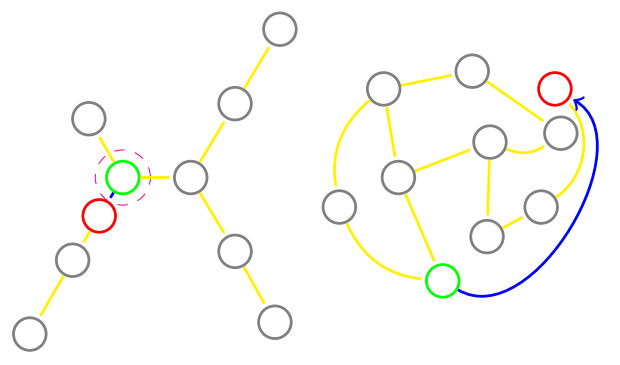

Dia 6

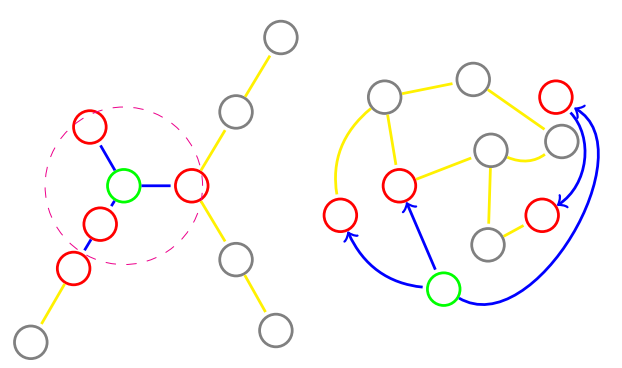

Dia 11

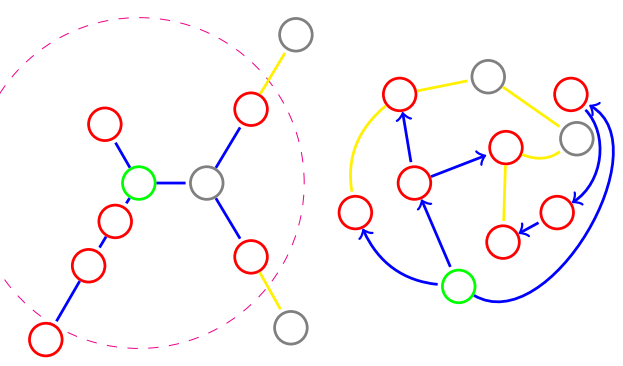

Dia 15

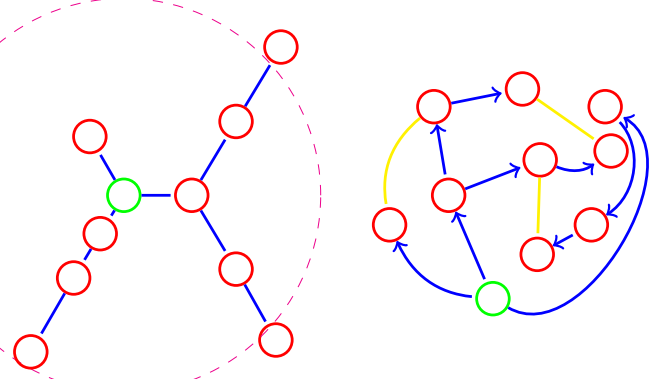

Dia 17

Figura 2.16: Dinâmica da propagação do exemplo 1. 


\section{Exemplo 2}

Continuando com a mesma rede, mas supondo $\alpha=1, \beta=0.6$ e que a origem é o nó 6 com uma pessoa infectada e as outras tem toda sua população suscetível, mostramos o grafo dos caminhos mais prováveis na Figura 2.17, onde a origem vem de cor verde e as linhas rosas ajudam a uma melhor visão radial da origem. Os resultados obtidos do tempo de chegada, distância efetiva e

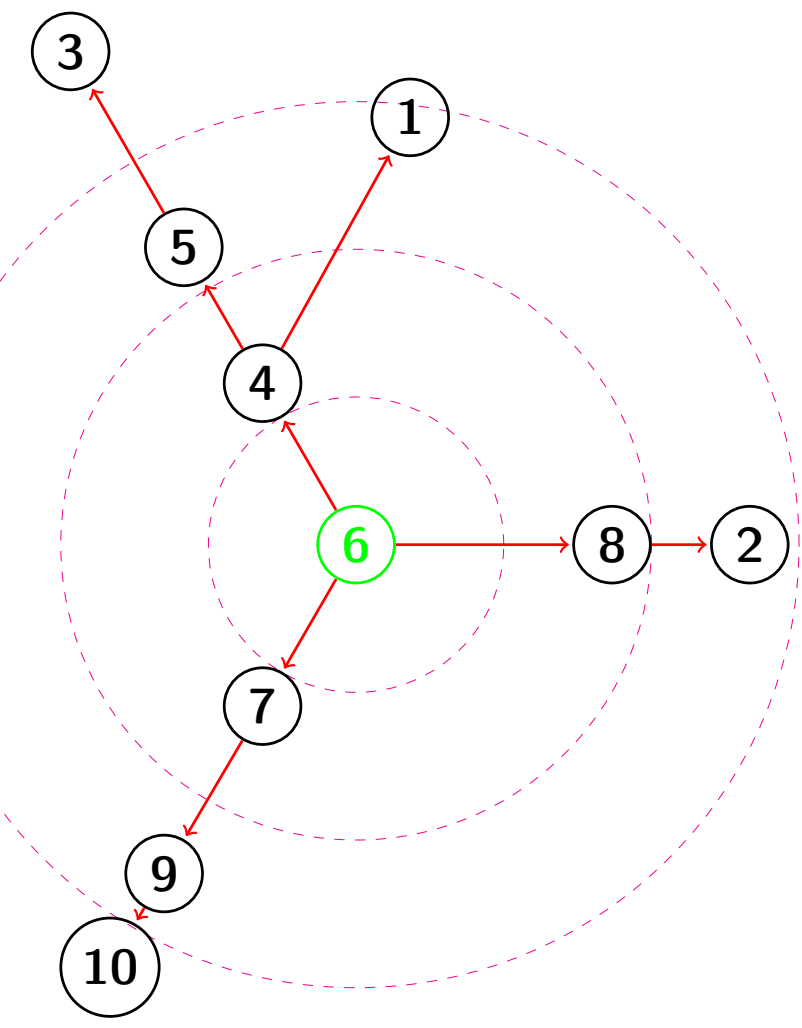

Figura 2.17: Grafo de caminhos mais prováveis da simulação 1.

velocidade efetiva são mostrados conforme abaixo:

\begin{tabular}{|l|cccccccccc|}
\hline Nó & 1 & 2 & 3 & 4 & 5 & 6 & 7 & 8 & 9 & 10 \\
\hline Distância efetiva & 4.3 & 4.0 & 5.9 & 1.9 & 3.6 & 0 & 1.9 & 2.6 & 4.0 & 5.1 \\
\hline Tempo de chegada & 14 & 12 & 18 & 7 & 12 & 1 & 7 & 9 & 13 & 16 \\
\hline Velocidade efetiva & 0.30 & 0.28 & 0.32 & 0.27 & 0.30 & 0 & 0.27 & 0.28 & 0.3 & 0.31 \\
\hline
\end{tabular}

Em média a velocidade efetiva é de 0.291 , a Figura 2.18 mostra a relação de distância efetiva e o tempo de chegada da doença. Posteriormente na Figura 2.19 mostramos a dinâmica da fracão de infectados em cada população. 


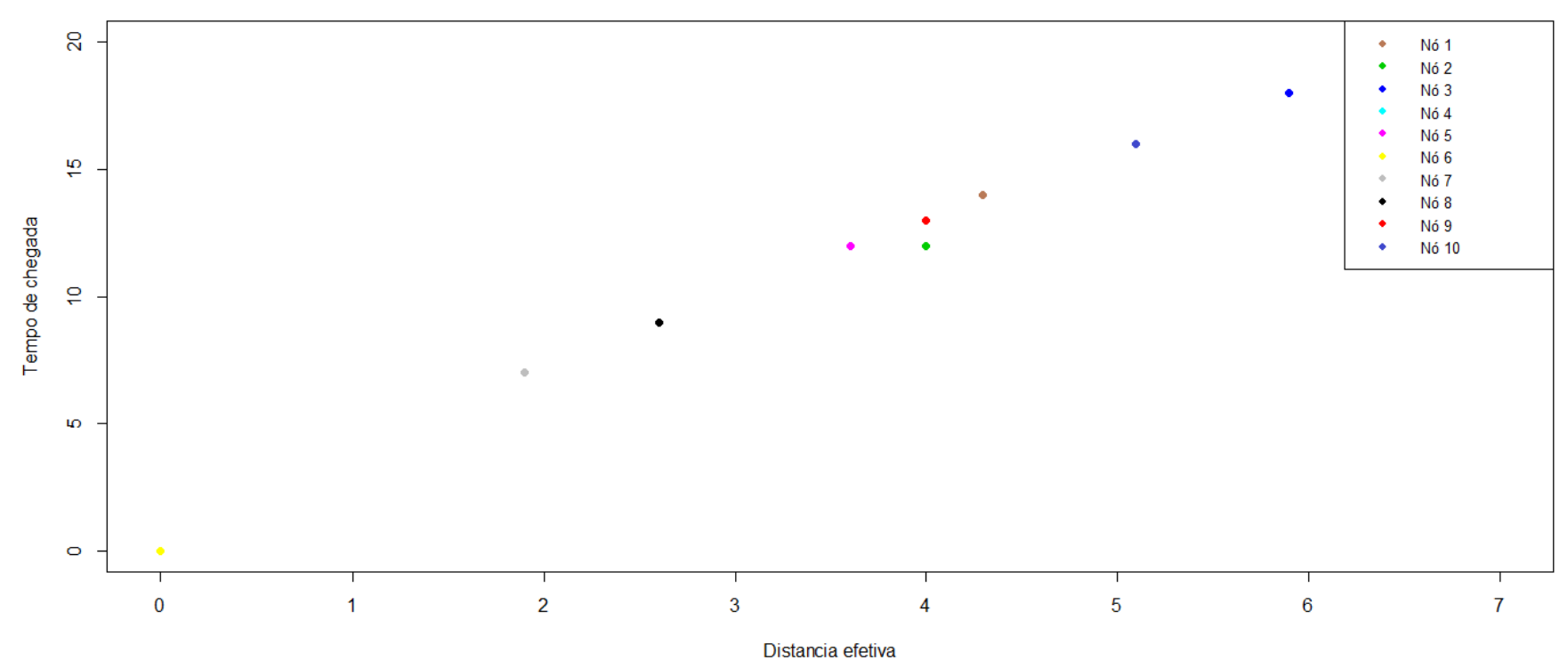

Figura 2.18: Relação de distancia efetiva e tempo de chegada em dias do exemplo 2.

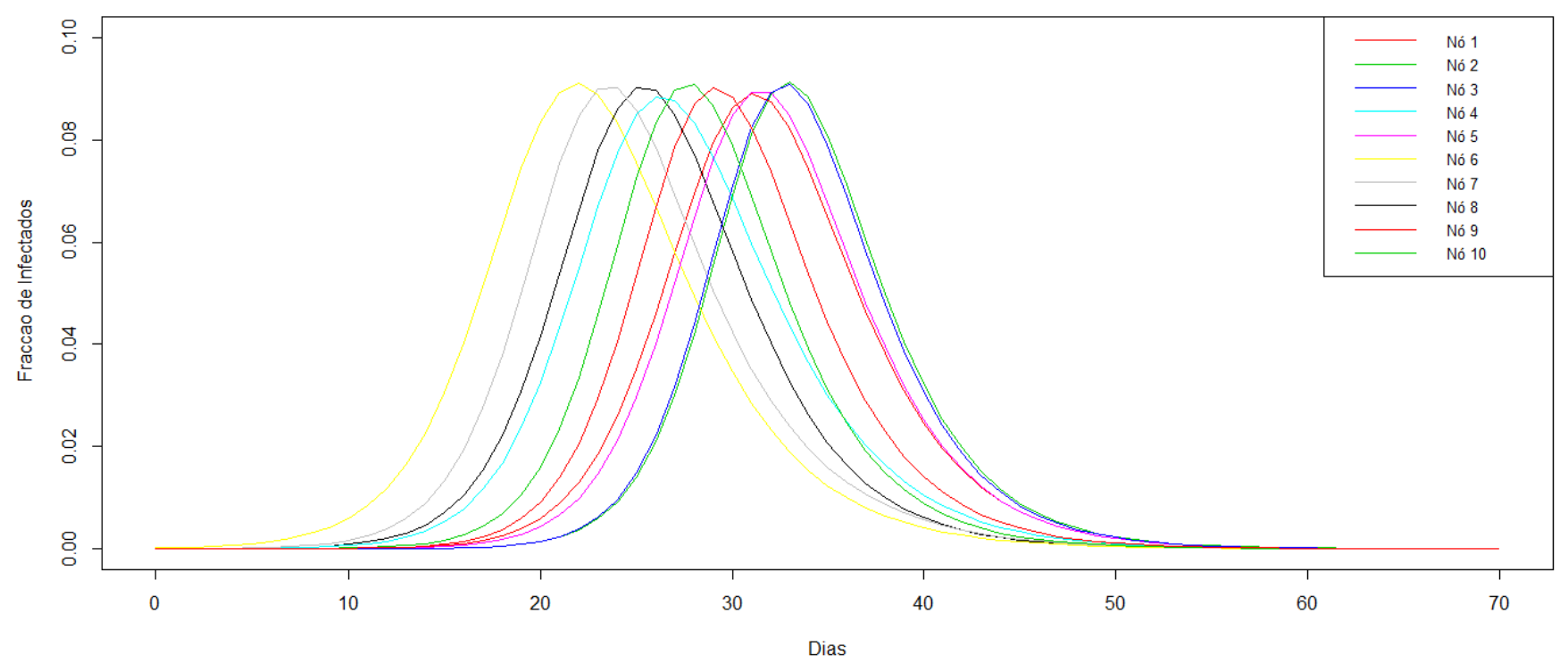

Figura 2.19: Dinâmica da fracão de infectados de cada nó do exemplo 2. 


\section{Exemplo 3}

Similarmente à dinâmica da simulação 2 , mas mudando para $\alpha=1.2, \beta=1$, e igualmente a origem é o nó 6 com uma pessoa infectada e as outras regiões tem toda sua população suscetível, obtemos que o grafo dos caminhos mais prováveis é a mesma Figura 2.17. Os resultados obtidos do tempo de chegada, distância efetiva e velocidade efetiva são mostrados conforme abaixo

\begin{tabular}{|l|cccccccccc|}
\hline Nó & 1 & 2 & 3 & 4 & 5 & 6 & 7 & 8 & 9 & 10 \\
\hline Distância efetiva & 4.3 & 4.0 & 5.9 & 1.9 & 3.6 & 0 & 1.9 & 2.6 & 4.0 & 5.1 \\
\hline Tempo de chegada & 22 & 20 & 35 & 11 & 20 & 1 & 12 & 14 & 21 & 24 \\
\hline Velocidade efetiva & 0.19 & 0.2 & 0.16 & 0.17 & 0.18 & 0 & 0.15 & 0.18 & 0.19 & 0.21 \\
\hline
\end{tabular}

Em media a velocidade efetiva é de 0.18. A Figura 2.20 mostra a relação de distância efetiva e o tempo de chegada da doença. Da mesma forma na Figura 2.21 mostramos a dinâmica da fracão de infectados em cada população.

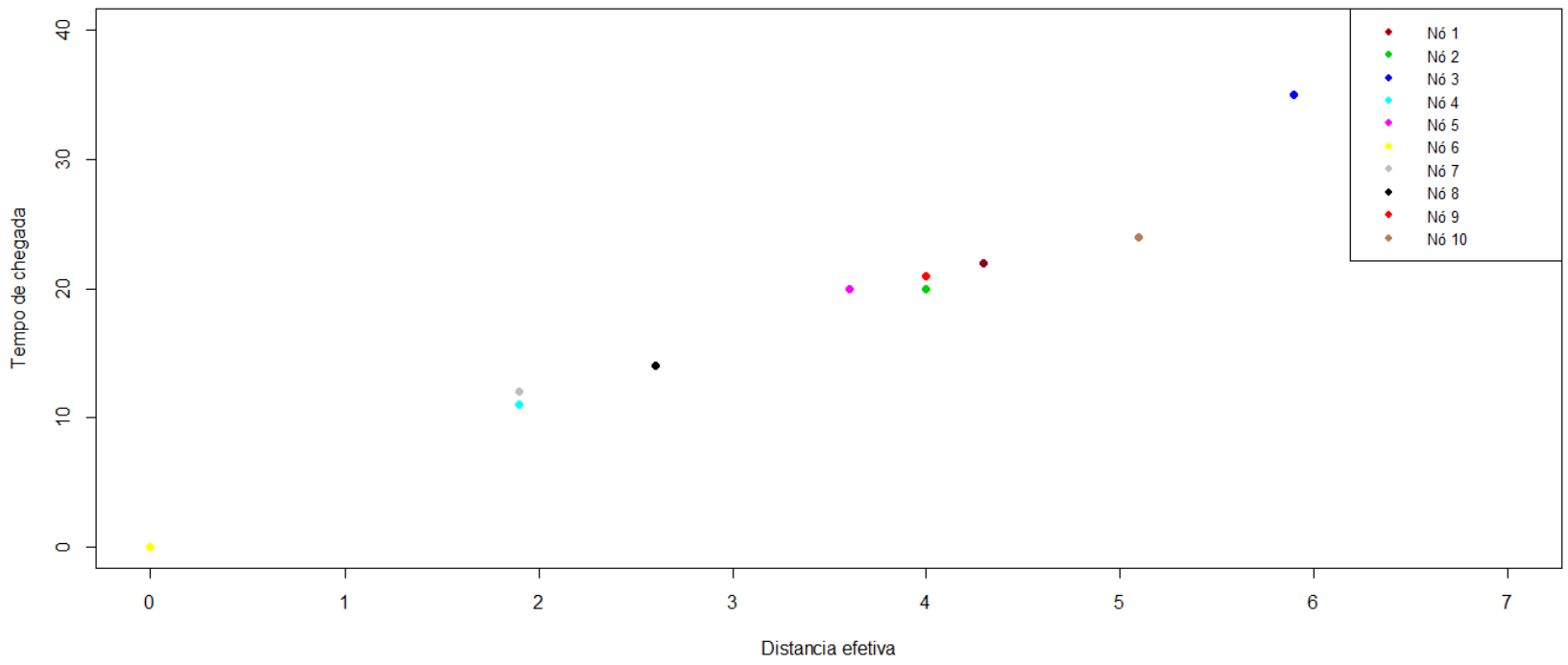

Figura 2.20: Relação de distancia efetiva e tempo de chegada em dias do exemplo 3 .

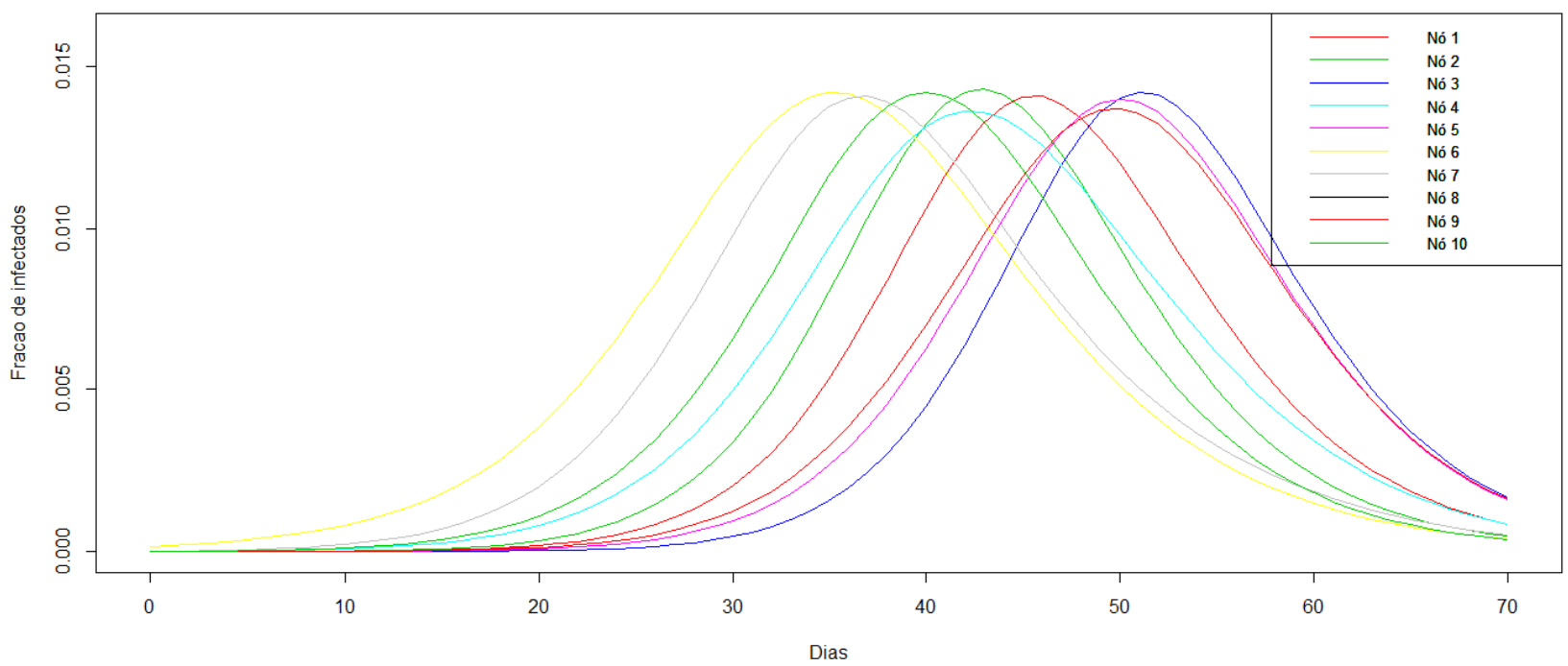

Figura 2.21: Dinâmica da fracão de infectados de cada nó do exemplo 3. 


\section{Comentários}

As Figuras 2.18, 2.20 e 2.14 mostram que a relação entre a distância efetiva e os tempos de chegadas é quase linear. Em consequência a propagação no grafo de caminhos mais prováveis é radial, o processo feito na Figura 2.16 mostra exatamente isto.

Obtemos em média a velocidade constante de $0.38,0.291$ e 0.18 nos exemplos 1,2 e 3 , respetivamente, o que mostra que de fato a velocidade vem dependendo dos parâmetros $\alpha, \beta$ e da origem. Nos exemplos 2 e 3 tinham diferentes $\alpha$ e $\beta$ mas a mesma origem e nos exemplos 1 e 2 tinham os mesmos $\alpha$ e $\beta$ é diferente origem, não encontramos relação das velocidades efetivas.

Com relação à dinâmica dos infectados de cada população podemos afirmar que entre elas são similares com respeito à fracão de infectados e com isso a quantidade de infectados depende do tamanho de cada população; o que muda é o tempo da dinâmica que depende do tempo de chegada, as Figuras 2.14, 2.19 e 2.21 mostram isto. 


\section{Capítulo 3}

\section{Aplicação}

A dengue é um problema de saúde de rápido crescimento com cerca de 2,5 bilhões de pessoas em risco principalmente nos países do sul e sudeste da Ásia, na América Central e do Sul e na África (Guzman et al. [2010]). Estima-se que haja entre 50 e 100 milhões de casos de dengue a cada ano, dos quais 500.000 são graves infecções que colocam em risco a vida (Bhatt et al. [2013], Gubler [2002]).

Neste capitulo expomos sobre a doença, damos um balanço geral da doença no Brasil, expomos um problema sobre a mobilidade do estado de Rio de Janeiro no ano 2012 e apresentamos uma proposta para resolve-lo.

\section{$3.1 \quad$ Dengue}

A dengue é uma doença infecciosa onde os seres humanos são o principal hospedeiro do vírus, transmitida principalmente pela picada da fêmea do mosquito particularmente de Aedes aegipty ou em menores casos do Aedes albopictus, Aedes polynesiensis e o Aedes scutellaris, ou ainda através de sangue e de derivados infectados através da doação de órgãos. (Halstead [2007], Organization et al. [2009])

São conhecidos quatro sorotipos de dengue: DEN1, DEN2, DEN3 e DEN4, uma vez contaminada por um destes sorotipos, o paciente adquire imunidade permanente ao sorotipo já contraído e imunidade temporária para os demais sorotipos, assim, é possível contrair até quatro vezes dengue. (Halstead [2007])

São comuns duas formas de manifestação da doença: clássica e hemorrágica. A dengue clássica é a forma mais leve da doença, o indivíduo apresenta sintomas semelhantes aos da gripe como febre, dores de cabeça, fraqueza muscular, náuseas e perda de apetite. A dengue hemorrágico é mais grave, podendo ser letal, além dos sintomas presentes na forma clássica, são observado no paciente sangramento pelo nariz, boca e gengiva, vômito com ou sem sangue, pele pálida, fria e úmida e dificuldade respiratória. (Rigau-Pérez et al. [1998])

Uma fêmea do mosquito que se alimenta da sangue de uma pessoa infectada com dengue, infecta-se com o vírus nas células que revestem seu intestino. Depois de cerca de 8 a 10 dias, o vírus propagase para outros tecidos do inseto, como a glândula salivar do mosquito e assim é subsequentemente liberado em sua saliva. O mosquito se mantém infectado até a sua morte, podendo transmitir o vírus durante todo esse período. O Aedes aegypti encontra-se, principalmente, no meio urbano devido a problemas como: armazenamento de água em recipientes inadequados, falta de fiscalização apropriada em estabelecimentos e residências que armazenam pneus, vasos de plantas, assim como nos depósitos de lixos. (Gibbons e Vaughn [2002]) 


\subsection{Balanço da dengue no Brasil}

O Brasil é considerado um país tropical na sua totalidade por causa do clima quente e úmido que proporciona um ambiente receptivo e altamente favorável para a proliferação do vetor da dengue. As diferentes zonas climáticas têm diferenças na dinâmica da chuva nas áreas da faixa costeira, variação da altitude e assim por diante. A atividade da dengue ocorre ao longo do ano, mas a maioria dos surtos e os maiores níveis de infestação vetorial mostram um padrão sazonal marcado, ocorrido durante a estação chuvosa brasileira, de dezembro a maio, que também são os meses mais quentes do ano (Siqueira Jr et al. [2005]).

O país reporta casos de dengue desde 1980, sendo responsável por cerca de 60 por cento das notificações de América-latina desde 1995 até 2005, se reportam já os quatro sorotipos e determina-se a doença em 27 estados do país, o sorotipo predominante é o DEN1. Na Tabela 3.1 temos um resumo histórico da dengue no Brasil e na Figura 3.1 mostramos os casos de dengue confirmados por laboratório desde 1994 até 2014 junto com as mortes, esta informação baseada no artigo Fares et al. [2015].

\begin{tabular}{|c|c|c|c|}
\hline Ano & Atividade reportada & Sorotipo & Localização \\
\hline 1845 & $1^{\mathrm{a}}$ epidemia de dengue reportada & Indefinido & Rio de Janeiro \\
\hline \multirow[t]{2}{*}{1981} & \multirow{2}{*}{$\begin{array}{l}1^{\mathrm{a}} \text { epidemia de dengue no Brasil após } \\
\text { a reinfestação de Aedes aegypti }\end{array}$} & DEN1 & \multirow[t]{2}{*}{ Roraima } \\
\hline & & DEN4 & \\
\hline 1986-1987 & Epidemia & DEN1 & Rio de Janeiro \\
\hline 1990 & $1^{\mathrm{a}}$ identificação de DEN2 & DEN2 & Rio de Janeiro \\
\hline \multirow[t]{2}{*}{$1990-2000$} & \multirow{2}{*}{$\begin{array}{l}\text { DENV espalhou-se intensificado } \\
\text { contribuindo para vários surtos }\end{array}$} & DEN1 & \multirow[t]{2}{*}{ Sudeste e Nordeste } \\
\hline & & DEN2 & \\
\hline 2000 & $1^{\mathrm{a}}$ identificação de DEN3 & DEN3 & Rio de Janeiro \\
\hline 2002 & $\begin{array}{l}\text { Um dos maiores surtos de dengue } \\
\text { desde o surgimento do vírus }\end{array}$ & DEN3 & Rio de Janeiro \\
\hline \multirow[t]{3}{*}{$2000-2007$} & \multirow{3}{*}{$\begin{array}{l}\text { Brasil reporta mais do } 60 \% \text { de casos } \\
\text { no mundo }\end{array}$} & DEN1 & \multirow[t]{3}{*}{ Todos os estados } \\
\hline & & DEN2 & \\
\hline & & DEN3 & \\
\hline $2007-2008$ & $\begin{array}{l}\text { Surto intenso, com elevado } \\
\text { número de casos graves e mortes }\end{array}$ & DEN2 & Rio de Janeiro \\
\hline 2009 & Surto grande & DEN2 & Espirito Santo \\
\hline \multirow[t]{3}{*}{2010} & \multirow[t]{3}{*}{ Vários surtos } & DEN1 & \multirow[t]{3}{*}{21 estados do Brasil } \\
\hline & & DEN2 & \\
\hline & & DEN3 & \\
\hline 2012 & Ressurgimento do DEN4 & DEN4 & $\begin{array}{l}\text { Roraima, Amazonas, } \\
\text { Amapá, Pará, São Paulo } \\
\text { Rio de Janeiro }\end{array}$ \\
\hline
\end{tabular}

Tabela 3.1: Atividade do Dengue no Brasil entre 1845 até 2014

No Brasil, Aedes Aegypti é responsável pela transmissão da dengue desde o início dos anos 80, Aedes Albopictus foi introduzido no Brasil em 1986 e está presente em todos os estados brasileiros, não é considerado um vetor de DEN no país e não foi associado a epidemias de dengue. No entanto, a ocorrência de transmissão vertical de DEN2 e DEN3 em Aedes Aegypti e Aedes Albopictus já foi observado em Fortaleza e levanta questões sobre o potencial de transmissão de DEN pela Aedes Albopictus no Brasil. Na verdade, estudos no estado do Rio de Janeiro mostraram que Aedes Albopictus era a espécie dominante em pneus descartados usados como armadilhas. (Fares et al. [2015])

Muitos fatores sustentam a proliferação de Aedes Aegypti e consequentemente a transmissão sus- 


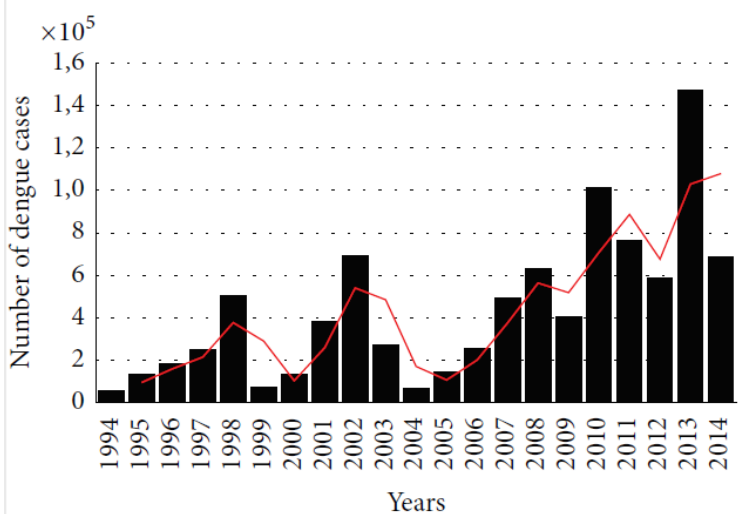

(a)

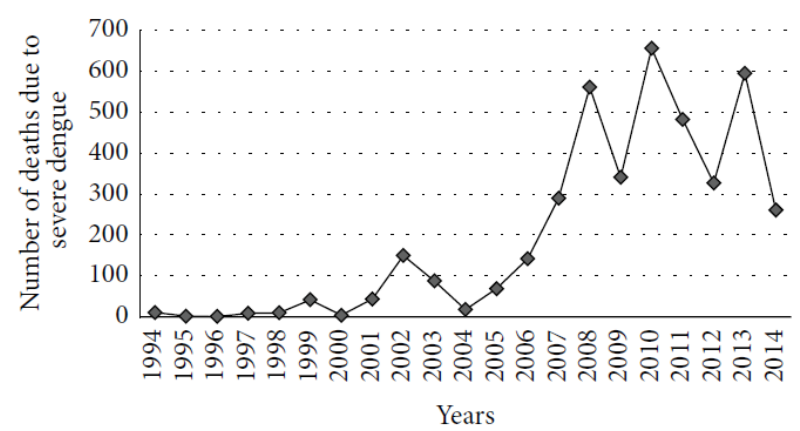

(b)

Figura 3.1: (a) Número de casos confirmados por laboratório de dengue no Brasil de 1994 a 2014. (b) Mortes por causa da dengue no Brasil de 1994 a 2014. Imagem de (Fares et al. [2015]).

tentada de doenças transmitidas por mosquitos no Brasil, incluindo o clima, alta densidade populacional humana em grandes cidades, status socioeconômico precário e falta de infraestrutura, particularmente saneamento adequado. As condições meteorológicas e as variações sazonais podem afetar a distribuição e a abundância do vetor.

Atualmente, não existe uma vacina segura e eficaz para a dengue, mas tem vários institutos adiando a pesquisa de implementação. Porém, o controle das infecções por DEN depende exclusivamente do controle vetorial. Neste contexto, algumas medidas de prevenção foram adotadas no Brasil, como desenvolvimento e implementação de campanhas de conscientização pública para educar a população com o objetivo de reduzir a reprodução do Aedes Aegypti.

\subsection{Um problema}

Do ano 2012 temos os dados de infectados de dengue por cidade em semanas do sudeste do Brasil. Nós estabelecemos o estudo no estado do Rio de Janeiro. Estas notificações são normalizadas pela população urbana e logo filtradas para retirar todas as cidades em que não houve um surto (definido como uma quantidade de notificações acima de 300 a cada 100.000 habitantes).

Após esse filtro, foi procurado o foco da doença, isto é, as primeiras cidades em que os surtos foram encontradas e após encontrar o primeiro surto, todas as cidades em que o surto foi encontrado na mesma semana ou na semana seguinte entravam para o foco. Com o foco, foi feita a correlação entre as cidades do foco e as outras cidades em que ocorreram surtos, com o delay de uma semana, o limiar para que esta correlação criasse uma aresta na árvore foi de 0.85 .

Considerando que o foco é o nível 1, e as cidades que tinham uma correlação o nível 2, procurávamos os próximos níveis fazendo a correlação entre as cidades restantes e as cidades dos níveis anteriores com os respectivos delays. O grafo terminava de crescer quando encontrasse um nível em que não houvesse nenhuma cidade. As cidades restantes não entravam no grafo.

Obtivemos em total 13 cidades após o filtro do surto, enumeramos elas como segue, 


\begin{tabular}{|ll|}
\hline Nó & Cidade \\
\hline 1 & Rio de Janeiro \\
2 & Itaboraí \\
3 & Nilópolis \\
4 & Niterói \\
5 & São Gonçalo \\
6 & Valência \\
7 & Angra dos Reis \\
8 & Mesquita \\
9 & Cabo Frio \\
10 & Volta Redonda \\
11 & Duque das Caixas \\
12 & Maricá \\
13 & Itaperuna \\
\hline
\end{tabular}

Na Tabela 3.2 apresentamos o resultado da correlação, onde significa que o nó 1 propagou a doença em uma semana para os nós $2,3, \ldots, 6$ e em duas semanas para o nó 7 ; enquanto que os nós $8, . ., 13$ não propagaram a doença nem chegou de outro nó.

\begin{tabular}{|c|c|c|c|c|c|c|}
\hline & 2 & 3 & 4 & 5 & 6 & 7 \\
\hline 1 & 1 semana & 1 semana & 1 semana & 1 semana & 1 semana & 2 semanas \\
\hline 8 & & & & & & \\
\hline 9 & & & & & & \\
\hline 10 & & & & & & \\
\hline 11 & & & & & & \\
\hline 12 & & & & & & \\
\hline 13 & & & & & & \\
\hline
\end{tabular}

Tabela 3.2: Correlação do ano 2012 do estado de Rio de Janeiro

Uma melhor representação disto é o grafo da Figura 3.2, que é equivalente ao grafo de caminhos prováveis do Capitulo 2. A cor verde corresponde ao nó que é origem da doença, as conexões azuis indicam que a doença chegou em uma semana e a conexão vermelha corresponde que a doença chegou em duas semanas a outras populações.

Portanto, temos o grafo resultante da distancia efetiva do capitulo 2 e os dados de incidência de infectados. A pergunta adequada é: Como foi a mobilidade entre estas cidades para obter estes resultados?

\subsection{Proposta de solução ao problema}

A ideia para resolver este problema, como na modelagem matemática, é fixar algumas hipóteses e estimar alguns parâmetros. Para isso estabelecemos que o comportamento da dinâmica das cidades dos nós $n=1,2, \ldots, 7$ está determinada pelas equações 2.2 e 2.3, que chamaremos de Sistema do estado de Rio de Janeiro de 2012, logo devemos determinar ou supor os parâmetros $\alpha, \beta$, $\gamma$, a matriz $P$ e as condições iniciais do sistema.

Nós vamos supor que os parâmetros $\alpha$ e $\beta$ são determinados pela cidade de origem, isto se justifica porque a origem expande a doença e portanto os parâmetros dependem dela, então estabelecemos a cidade do Rio de Janeiro como um sistema SIR local normalizado. 


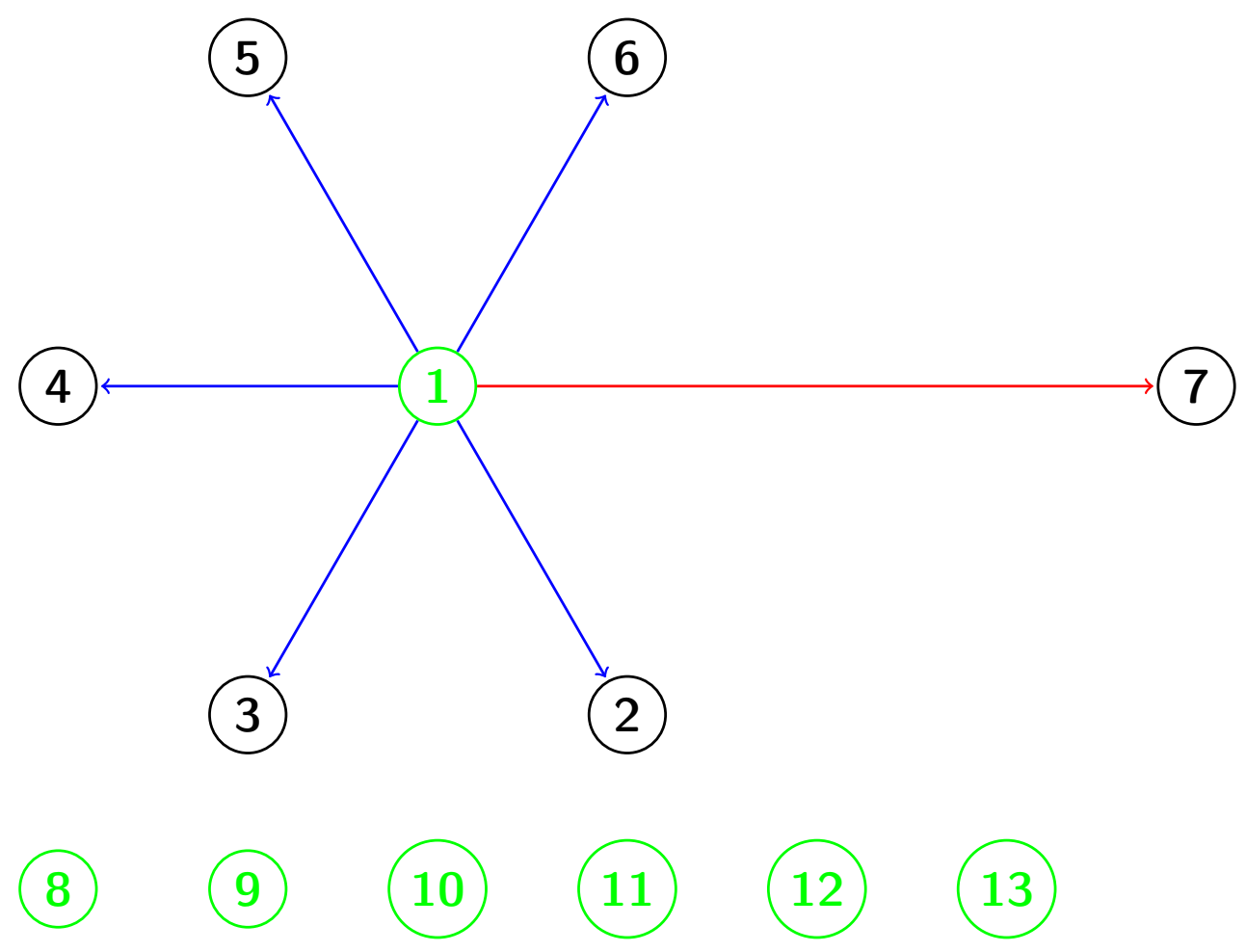

Figura 3.2: Grafo do dengue do ano 2012

Logo com o método de Monte Carlo estimamos os parâmetros $\alpha, \beta$ e as condições iniciais comparando a solução do sistema $j(t)$, com $t \in[0,365]$, com os dados reais por meio do erro definido como

$$
E=0.002449194 \sqrt{\frac{\sum_{k=1}^{17}|j(7 k)-\bar{j}|^{2}}{17}},
$$

onde $j(7 k)$ é o valor estimado da solução do sistema e $\overline{j^{k}}$ é o dado real da semana $k$. Estamos comparando só até a semana 17 porque foi a semana onde teve o surto a cidade do Rio de Janeiro que foi igual a 0,002449194 . A ideia é obter um erro global porque estamos trabalhando com valores no intervalo $[0,1]$ e isto já faz que o erro seja pequeno.

Daí, obtemos que $\alpha=0.6543532, \beta=0.591573, I(0)=6.59094 E-05$ e $S(0)=0.966527$, mostramos na Figura 3.3 a comparação da solução estimada e os dados reais.

Não podemos supor $j_{n}(0)=0$ nem $s_{n}(0)=N_{n}$ nas cidades $n=2,3, \ldots, 7$, porque na realidade temos dados do ano anterior de infectados, e consequentemente de recuperados sem importar o sorotipo. Logo com os valores obtidos $\alpha$ e $\beta$ realizamos um processo similar, mas só estimamos as condições inicias para cada nó $n=2,3, \ldots, 7$ supondo um sistema SIR local normalizado e o erro equivalente a

$$
E=\max _{k=1, \ldots, 17} \overline{j^{k}} \sqrt{\frac{\sum_{k=1}^{17}\left|j(7 k)-\overline{j^{k}}\right|^{2}}{17} .}
$$

Cabe ressaltar que mantemos a semana do surto da origem, mas está mudando o valor máximo que vai depender dos dados que cada cidade. Logo, obtemos os resultados descritos na Tabela 3.3.

As estimativas até agora levam em conta somente a dinâmica local, agora devemos implementar a 


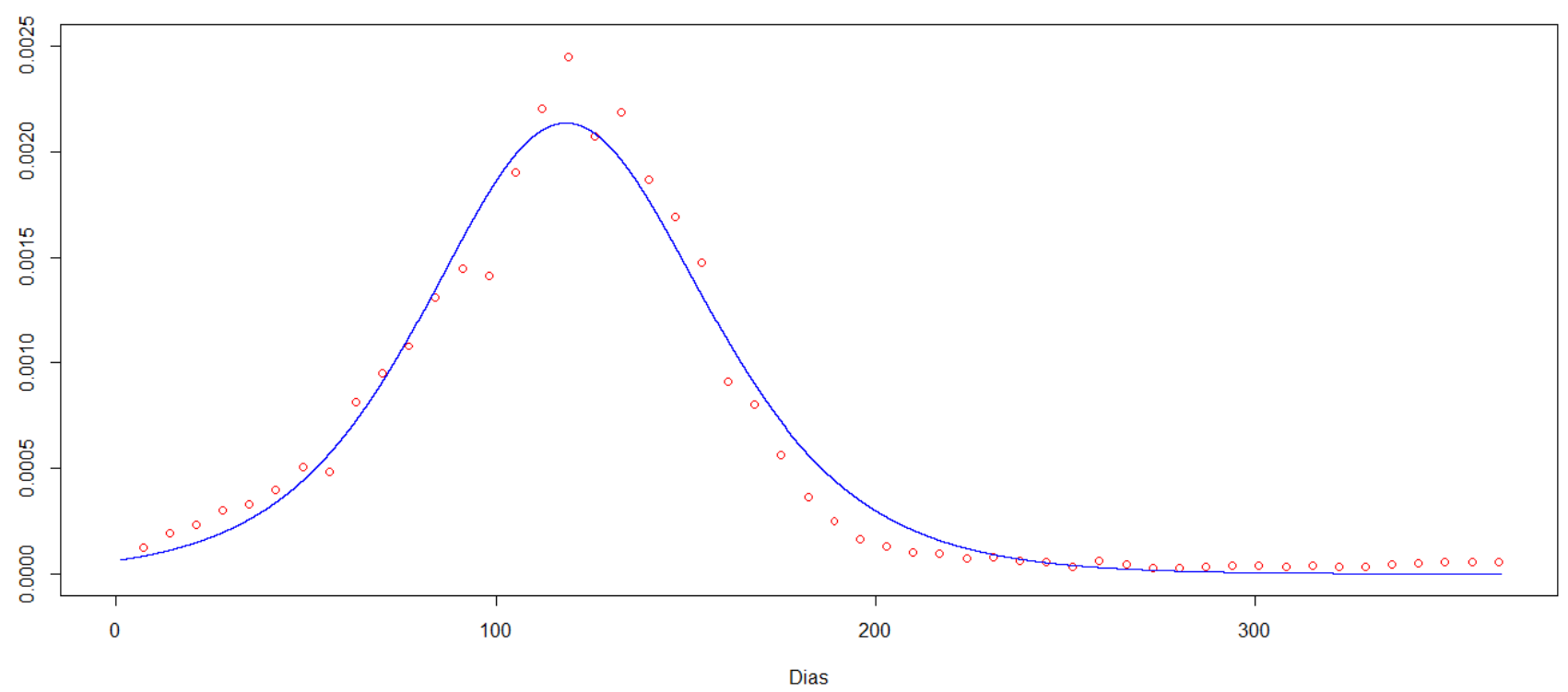

Figura 3.3: Solução $j(t)$ de um sistema SIR local normalizado com $N=6320446, \alpha=0.6543532$, $\beta=0.591573, S(0)=0.966527, I(0)=6.590943 e-05$ e $t \in[0,365]$ de cor azul, correspondente a cidade de Rio de Janeiro. Junto com os dados reais normalizados de infectados do ano 2012 da mesma cidade de cor vermelha.

\begin{tabular}{|l|l|l|}
\hline $\mathrm{n}$ & $j_{n}(0)$ & $s_{n}(0)$ \\
\hline 2 & 0.0002162 & 0.9379024 \\
\hline 3 & $9.842 \mathrm{E}-06$ & 0.96555 \\
\hline 4 & $2.923 \mathrm{E}-05$ & 0.9603 \\
\hline 5 & $6.5303 \mathrm{E}-05$ & 0.9380 \\
\hline 6 & $4.1759 \mathrm{E}-05$ & 0.971186 \\
\hline 7 & $5.8857 \mathrm{E}-05$ & 0.9331122 \\
\hline
\end{tabular}

Tabela 3.3: Estimativa das condições inicias do sistema de Rio de Janeiro de 2012.

rede da Figura (3.2). Pela equação (2.5), temos que $P_{n 1}=P_{m 1}$ para $n, m=2,3, \ldots, 6$ e pela equação (2.1), $5 P_{n 1}+P_{71}=1$ para qualquer $n=2,3, \ldots, 6$, em particular, $P_{71}=1-5 P_{21}$. De novo pela equação (2.5), temos que

$$
\begin{aligned}
d(7,1) & =2 d(2,1) \\
1-\ln \left(P_{71}\right) & =2\left(1-\ln \left(P_{21}\right)\right) \\
2 \ln \left(P_{21}\right)-\ln \left(1-5 P_{21}\right) & =1 \\
\ln \left(\frac{\left(P_{21}\right)^{2}}{1-5 P_{21}}\right) & =1 \\
\left(P_{21}\right)^{2}+5 \exp (1) P_{21}-\exp (1) & =0,
\end{aligned}
$$

sendo um polinômio quadrado, cuja solução positiva e real é $P_{21} \approx 0.19714$. Portanto, $P_{7,1} \approx 0.0143$ e $P_{n 1} \approx 0.19714$ para todo $n=2,3, \ldots, 6$.

Além disso, vamos supor que a mobilidade de qualquer cidade $n=2,3, \ldots, 7$ é dominada pelas viagens para a cidade de Rio de Janeiro, isto é justificado já que a cidade é a capital do estado e portanto domina o setor industrial e turístico. Porém, realisticamente, mesmo que pequeno, deve 
haver alguma mobilidade entre outras cidades, adicionamos isso a partir de um parâmetro $\epsilon$. Com isso, a matriz de mobilidade é dada por

$$
P=\left[\begin{array}{ccccccc}
0 & 1-5 \epsilon & 1-5 \epsilon & 1-5 \epsilon & 1-5 \epsilon & 1-5 \epsilon & 1-5 \epsilon \\
0.19714 & 0 & \epsilon & \epsilon & \epsilon & \epsilon & \epsilon \\
0.19714 & \epsilon & 0 & \epsilon & \epsilon & \epsilon & \epsilon \\
0.19714 & \epsilon & \epsilon & 0 & \epsilon & \epsilon & \epsilon \\
0.19714 & \epsilon & \epsilon & \epsilon & 0 & \epsilon & \epsilon \\
0.19714 & \epsilon & \epsilon & \epsilon & \epsilon & 0 & \epsilon \\
0.01430 & \epsilon & \epsilon & \epsilon & \epsilon & \epsilon & 0
\end{array}\right]
$$

$\operatorname{com} \epsilon=0.0001$.

Assim, nosso sistema do estado do Rio de Janeiro está descrito por

$$
\begin{aligned}
& \frac{d s_{n}}{d t}=-0.968982 s_{n} j_{n}+\gamma \sum_{m \neq n} P_{m n}\left(s_{m}-s_{n}\right) \\
& \frac{d j_{n}}{d t}=0.968982 s_{n} j_{n}-0.8482008 j_{n}+\gamma \sum_{m \neq n} P_{m n}\left(j_{m}-j_{n}\right)
\end{aligned}
$$

Daqui, similarmente, realizamos a estimativa do parâmetro $\gamma$ e usando o erro da equação (3.1), temos que $\gamma=0.0001104747$, os erros de cada nó estão apresentados na Tabela 3.4 e mostramos desde a Figura 3.4 até a Figura 3.10 os resultados gráficos das soluções $j_{n}(t)$ do sistema juntos com os dados reais de cada nó $n=1,2, \ldots, 7$.

\begin{tabular}{|l|l|}
\hline $\mathrm{n}$ & Erro \\
\hline 1 & $3.469006 \mathrm{E}-06$ \\
\hline 2 & $1.225707 \mathrm{E}-07$ \\
\hline 3 & $1.089510 \mathrm{E}-07$ \\
\hline 4 & $2.166766 \mathrm{E}-07$ \\
\hline 5 & $4.448860 \mathrm{E}-08$ \\
\hline 6 & $9.696459 \mathrm{E}-07$ \\
\hline 7 & $2.873922 \mathrm{E}-08$ \\
\hline
\end{tabular}

Tabela 3.4: Erro de cada nó no sistema de Rio de Janeiro de 2012

Se fosse considerado cada nó $n=2,3, . ., 7$, por um sistema SIR local normalizado, as estimativas dos parâmetros $\alpha, \beta$ e condições inicias determinadas pelo erro da equação (3.1) estão descritas na Tabela 3.5.

\begin{tabular}{|r|r|r|r|r|r|}
\hline nó & $i_{n}(0)$ & $s_{n}(0)$ & $\alpha$ & $\beta$ & Erro \\
\hline 2 & 0.000124 & 0.9569 & 0.7827 & 0.7248 & $6.1390620 \mathrm{E}-08$ \\
\hline 3 & $4.5666 \mathrm{E}-06$ & 0.9433 & 0.5910 & 0.5080 & $1.5948470 \mathrm{E}-07$ \\
\hline 4 & $2.949 \mathrm{E}-06$ & 0.9938724 & 0.5057 & 0.4655 & $2.5690395 \mathrm{E}-07$ \\
\hline 5 & 0.0001294 & 0.9781 & 0.5530 & 0.5251 & $5.5694664 \mathrm{E}-08$ \\
\hline 6 & $5.0292 \mathrm{E}-06$ & 0.9977882 & 1.225028 & 1.1446 & $8.1716520 \mathrm{E}-07$ \\
\hline 7 & $5.66 \mathrm{E}-05$ & 0.9544 & 1.2109 & 1.128 & $5.3838439 \mathrm{E}-08$ \\
\hline
\end{tabular}

Tabela 3.5: Estimativa dos parâmetros $\alpha, \beta$ e condições iniciais se cada nó fosse uma dinâmica de um sistema SIR local normalizado, além do erro obtido para $n=2,3, \ldots, 7$. 


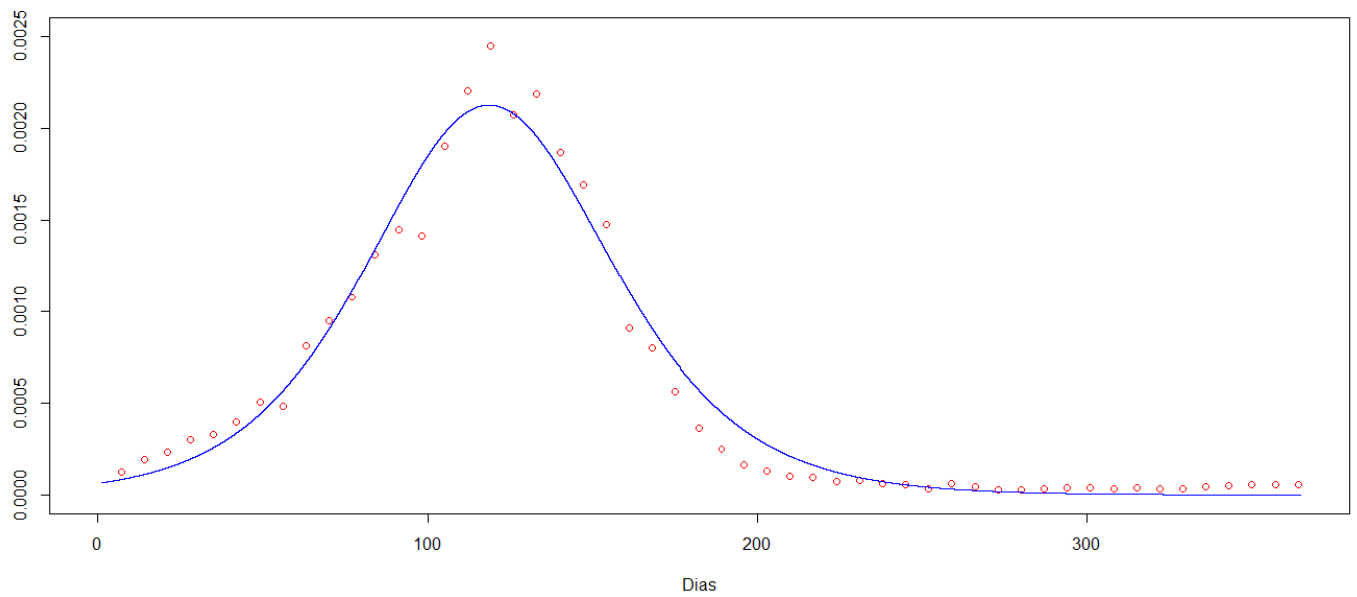

Figura 3.4: Solução $j_{1}(t)$ do sistema do estado Rio de Janeiro de 2012 com $t \in[0,365]$ de cor azul, correspondente a cidade de Rio de Janeiro, junto com os dados reais normalizados dos infectados.

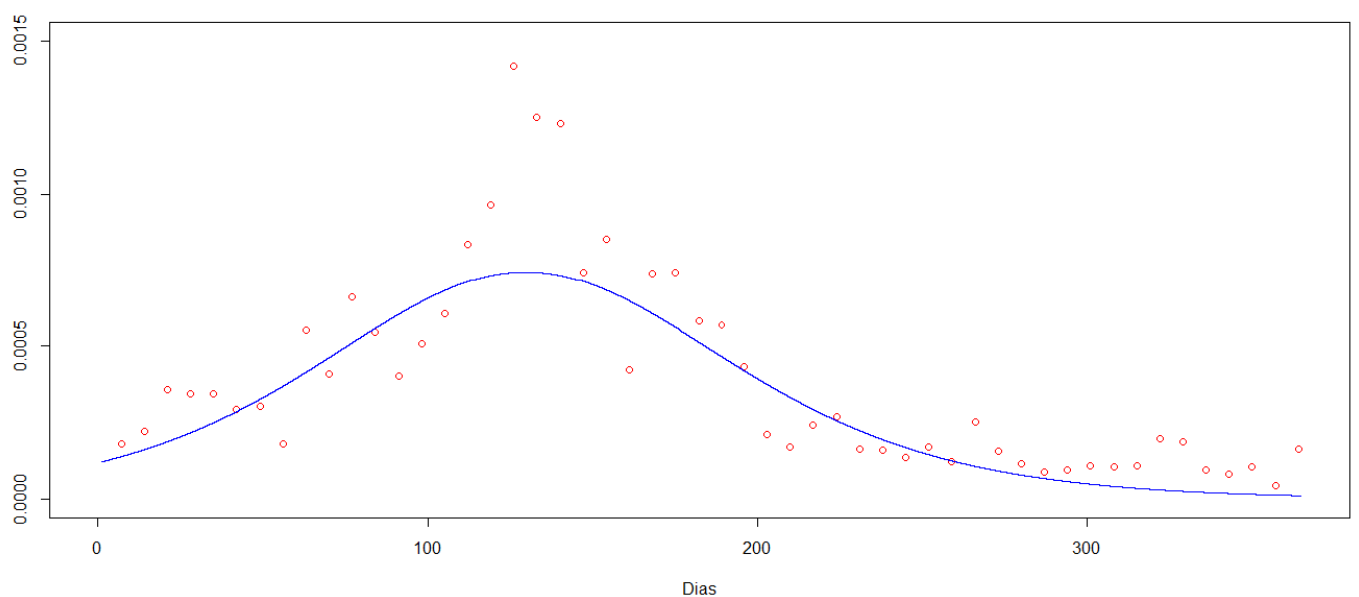

Figura 3.5: Solução $j_{2}(t)$ do sistema do estado Rio de Janeiro de 2012 com $t \in[0,365]$ de cor azul, correspondente a cidade de Itaboraí, junto com os dados reais normalizados dos infectados.

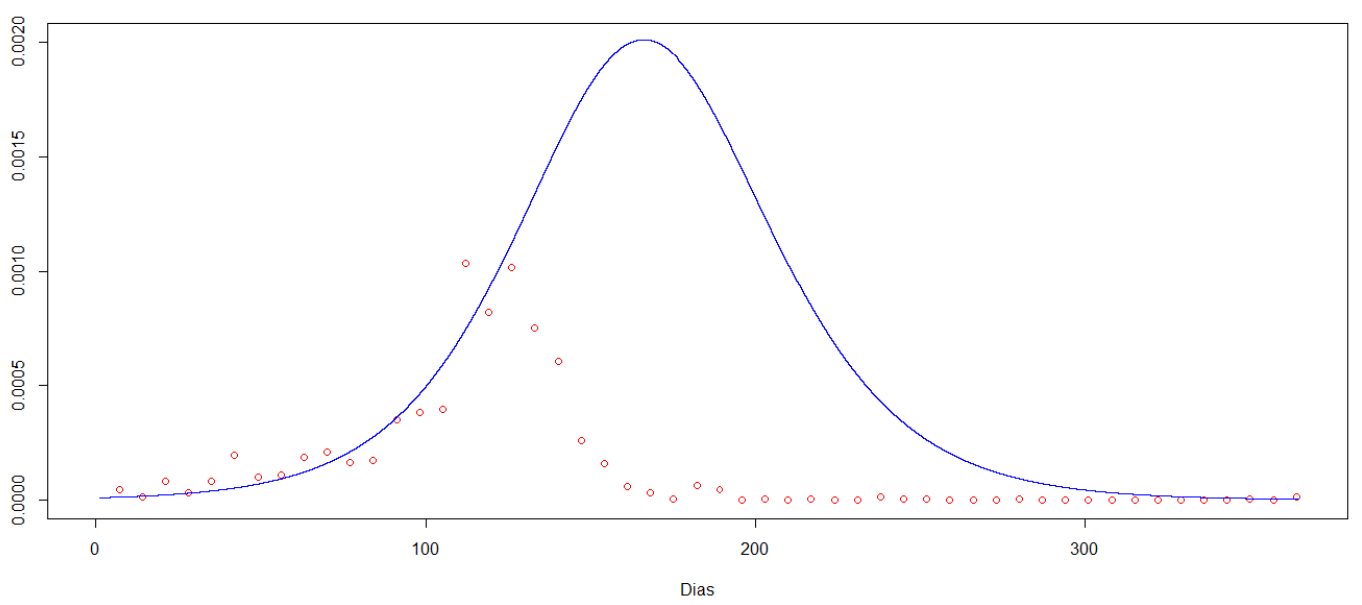

Figura 3.6: Solução $j_{3}(t)$ do sistema do estado Rio de Janeiro de 2012 com $t \in[0,365]$ de cor azul, correspondente a cidade de Nilópolis, junto com os dados reais normalizados de infectados. 


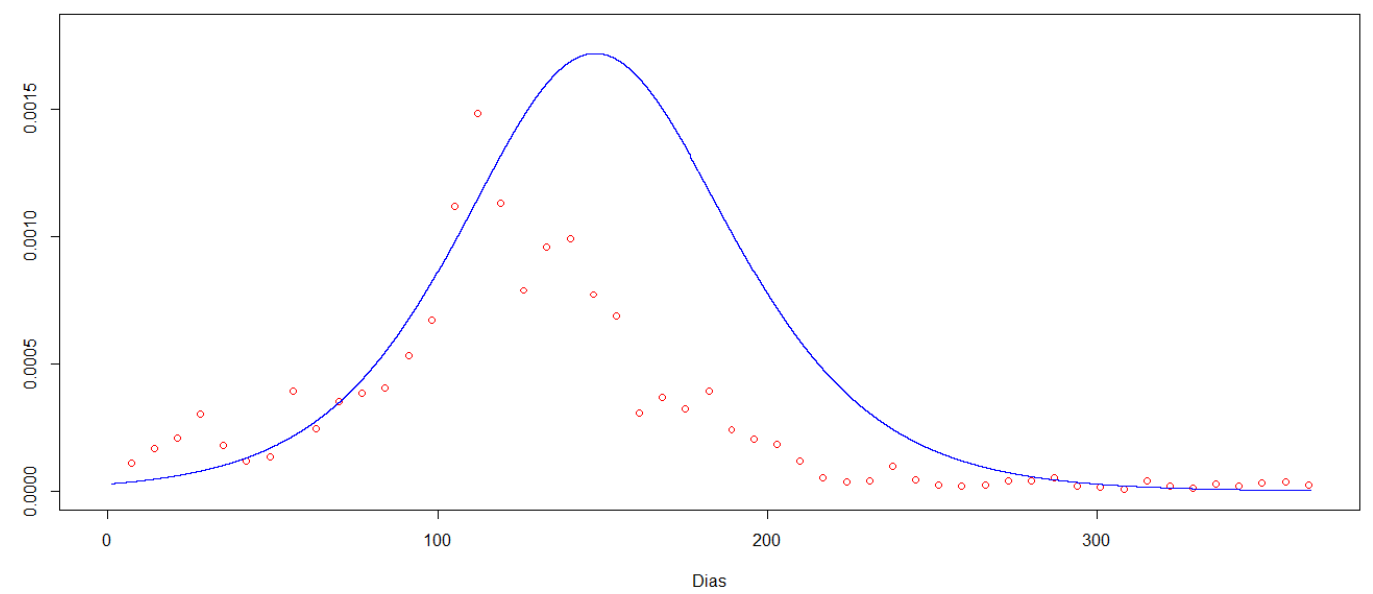

Figura 3.7: Solução $j_{4}(t)$ do sistema do estado Rio de Janeiro de 2012 com $t \in[0,365]$ de cor azul, correspondente a cidade de Niterói, junto com os dados reais normalizados de infectados.

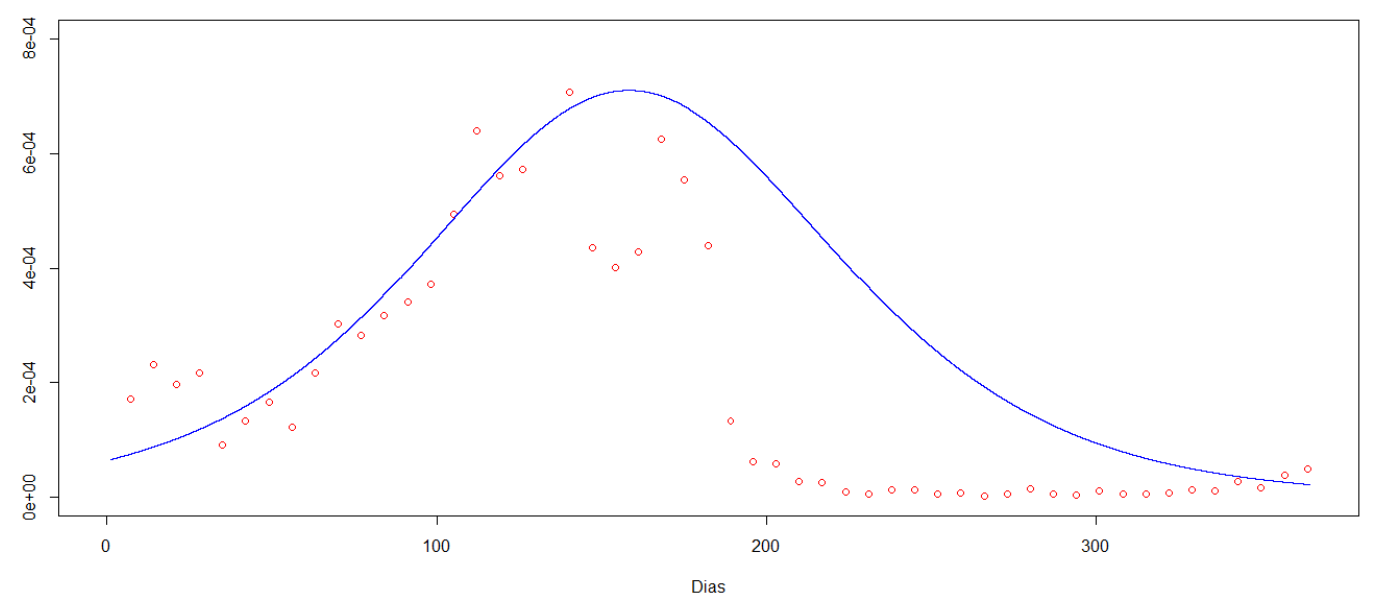

Figura 3.8: Solução $j_{5}(t)$ do sistema do estado Rio de Janeiro de 2012 com $t \in[0,365]$ de cor azul, correspondente a cidade de São Gonçalo, junto com os dados reais normalizados dos infectados.

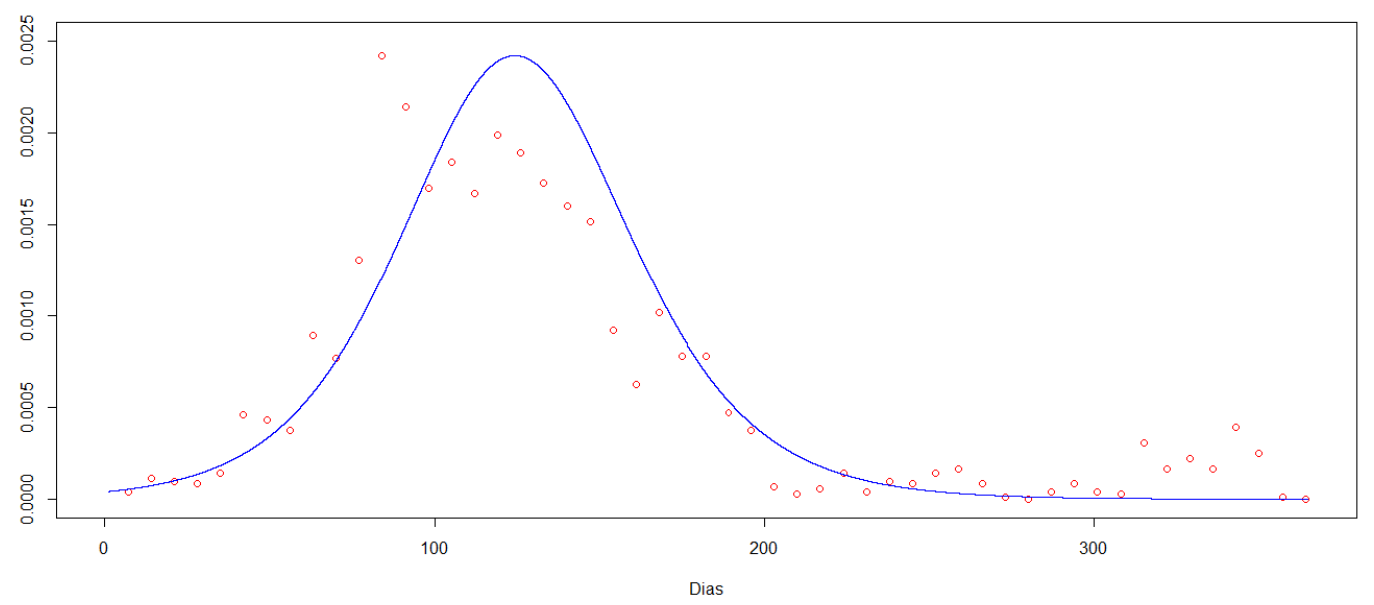

Figura 3.9: Solução $j_{6}(t)$ do sistema do estado Rio de Janeiro de 2012 com $t \in[0,365]$ de cor azul, correspondente a cidade de Valência, junto com os dados reais normalizados de infectados.

\subsection{Análises da proposta}

O objetivo do modelo é obter informação da mobilidade das pessoas entre as 7 cidades, cuja movimentação permite a transmissão da doença. O que nós fizemos foi obter as probabilidades de 


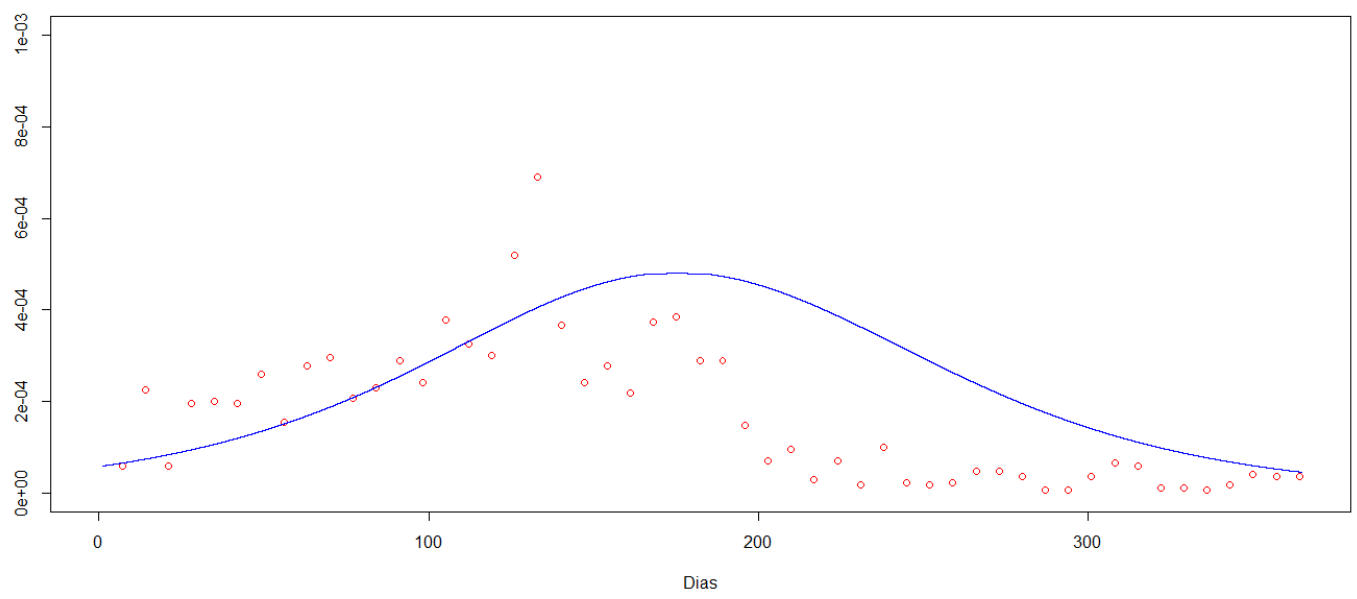

Figura 3.10: Solução $j_{3}(t)$ do sistema do estado Rio de Janeiro de 2012 com $t \in[0,365]$ de cor azul, correspondente a cidade de Angra dos Reis, junto com os dados reais normalizados de infectados.

saída de cada uma das cidades para as outras. Por meio da equação 2.5 determinamos as probabilidades de sair da origem e ir para outro nó, o resto de probabilidades foram supostas e para a verificação da eleição analisaremos com mais detalhe.

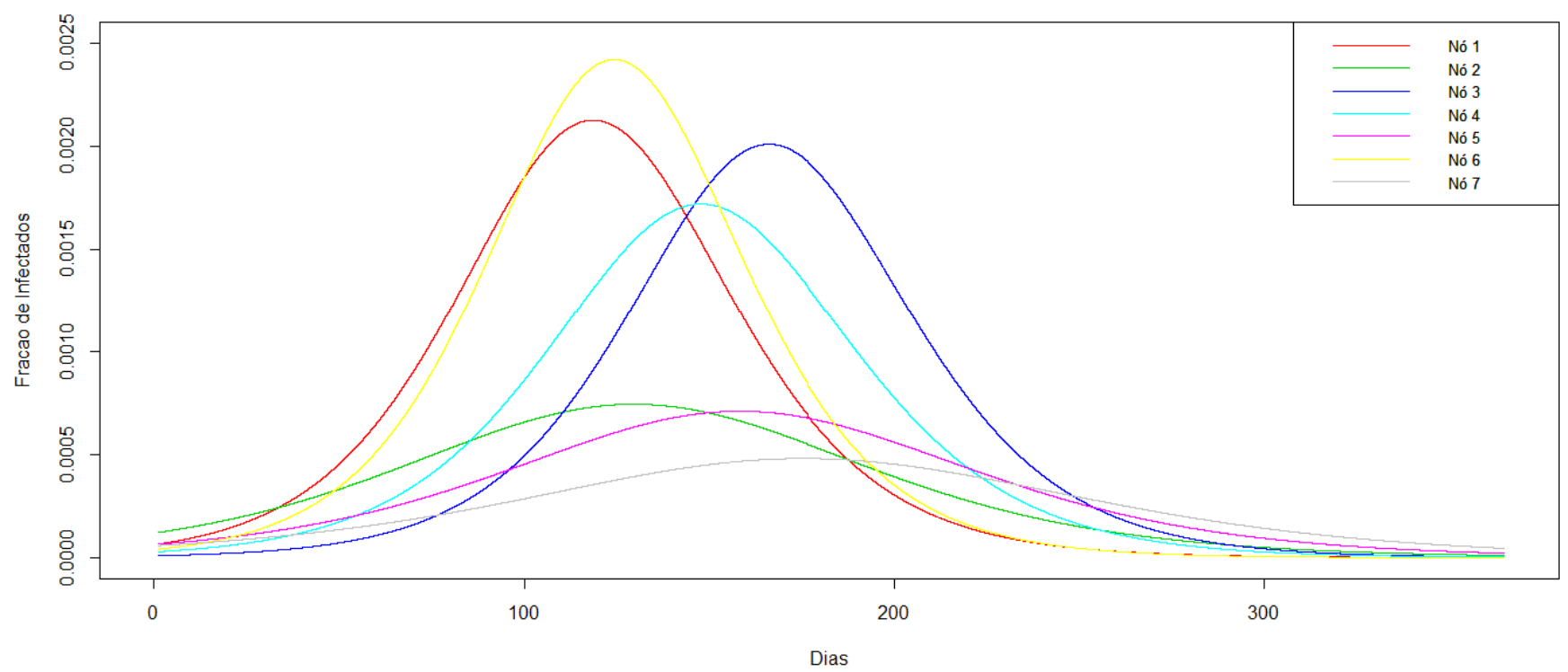

Figura 3.11: Dinâmica dos infectados de todos os nós do sistema do estado Rio de Janeiro de 2012 com $t \in[0,365]$.

Para os nós diferentes da origem as condições iniciais dos infectados foram diferentes de zero e não toda a população é suscetível então o modelo permitiu a mudança das soluções e não ficam exatamente iguais, dando mais sentido à realidade.

\section{Parâmetros $\alpha$ e $\beta$}

O modelo têm as 7 cidades com os mesmos parâmetros $\alpha=0.6543$ e $\beta=0.5915$, dado que o estado é pequeno poderíamos afirmar que o contato e a taxa de recuperação pode ser similar.

Se fosse considerada a dinâmica local em cada nó, temos que Valença tem os dois parâmetros grandes, enquanto que Nilópolis, Niterói e São Gonçalo apresentam similaridades entre eles e com os parâmetros do modelo os quais são as cidades mais próximas a Rio de Janeiro; porém Angra do 
Reis considera muito pequenos estes valores.

\section{Parâmetro $\gamma$}

Determinamos que $\gamma=0.0001104747$, como foi mencionado no Capitulo 1, este tipo de modelo vem derivado do suposto que as viagens são de longa duração, ou seja, a pessoa fica no lugar de destino um tempo, portanto tem sentido que este valor seja pequeno.

Além disso, podemos afirmar que cada das cidades do modelo têm aproximadamente essa taxa de saída por dia, para a origem resultam aproximadamente 700 saindo de Rio de Janeiro para os outros nós tendo em conta que tem 6320446 habitantes aproximadamente.

\section{Condições iniciais}

Vamos mostrar as estimativas dos infectados, suscetíveis de cada nó do modelo de sistema do estado de Rio de Janeiro do 2012 e da dinâmica local comparando com o tamanho da população

\begin{tabular}{|c|c|c|c|c|c|}
\hline Nó & Tamanho & $I_{n}$ do modelo & $S_{n}$ do modelo & $I_{n}$ local & $S_{n}$ local \\
\hline 2 & 218008 & 47 & 204446 & 28 & 208612 \\
3 & 157425 & 2 & 152002 & 1 & 148500 \\
4 & 487562 & 2 & 468206 & 2 & 484540 \\
5 & 999728 & 65 & 937745 & 130 & 977834 \\
6 & 71843 & 3 & 69765 & 1 & 71685 \\
7 & 169511 & 10 & 158173 & 10 & 161782 \\
\hline
\end{tabular}

Enquanto aos infectados temos similitudes em Nilópolis, Niterói, Valença e Angra dos Reis, enquanto em Itaboraí e em São Gonçalo juntas estimativas são diferentes dos outros. Porém a diferença dos suscetíveis é percebida melhor pela quantidade, este tipo de dados não tem registro, como foi mencionado no ano 2012 foi o ressurgimento do DEN4 então a maior parte da população ficaria suscetível.

\section{Erro}

A melhor maneira de avaliar é por meio do erro, como temos os dados normalizados o erro dos mínimos quadrados é pequeno daí a eleição de obter a média e logo multiplicar pelo máximo.

No modelo os nós 3, 4,5 e 7 mostram um erro menor que no caso se fosse a dinâmica local normalizada, ou seja que ajusta ainda melhor, no caso Nilópolis, Niterói e São Gonçalo são as cidades mais próximas Rio de Janeiro, o que diz que ajusta muito bem o modelo. Os nós 1,2 e 6 tem um erro maior que se fosse a dinâmica local normalizada, mas o erro não tem muita diferença. A origem propaga os infectados, ou seja que diminui a traves do tempo, então era de esperar que o erro fosse menor. Enquanto aos nós 2 e 6, o erro tem diferença de $1.2257 E-07$ a $6.13906 E-08$ e $9.69645 E-07$ a $8.17165 E-07$. 


\section{Conclusões}

O trabalho de Dirk Brockmann e Dirk Helbing sob hipóteses fortes de uniformidade e equilíbrio, consegue descrever o avanço de uma doença epidêmica em nível global. Nossa contribuição neste trabalho foi o de fazer uma releitura da definição de distância efetiva para uma rede, que no caso original foi aplicada a uma escala especial global.

Essa releitura foi aplicada a uma rede de escalar especial bem menor. Conseguimos assim, a partir de dados indiretos de uma doença descrever a rede de mobilidade, ou seja, a probabilidade de um individuo se deslocar entre duas regiões.

Aplicamos essa teoria à dengue, uma doença endêmica no Brasil, que a cada ano registra inúmeros casos novos. Entender os fatores que resultam fundamentais a transmissão da doença é fundamental para um controle eficaz da mesma. Nosso trabalho mostrou como a ideia original de (Brockmann e Helbing [2013]) pode ser utilizada para encontrar afirmações sobre a mobilidade entre algumas idades do estado do Rio de Janeiro, mobilidade essa que se ajusta aos casos registrados de dengue no estado em 2012.

O desafia seguinte é como utilizar tal informação para um controle efetivo da doença. Cabe ressaltar que, com outro modelos, temos alguns resultados de mobilidade, com outro ponto de vista, por exemplo ( Amaku et al. [2016]). Os próximos passos seriam, então, comparar tais abordagens e verificar como melhor abordar o problema e controlar efetivamente a epidemia. 


\section{Referências Bibliográficas}

Alvim et al.(2013) Moacyr Alvim, Abderrahman Iggidr, Jair Koiller, Maria Lucia Penna, Gauthier Sallet e Max Souza. Onset of a vector borne disease due to human circulation-uniform, local and network reproduction ratios. Tese de Doutorado, INRIA. Citado na pág. 11

Amaku et al.(2016) Marcos Amaku, Franciane Azevedo, Marcelo Nascimento Burattini, Giovanini Evelim Coelho, Francisco Antonio Bezerra Coutinho, D Greenhalgh, LF Lopez, RS Motitsuki, Annelies Wilder-Smith e E Massad. Magnitude and frequency variations of vector-borne infection outbreaks using the ross-macdonald model: explaining and predicting outbreaks of dengue fever. Epidemiology E3 Infection, 144(16):3435-3450. Citado na pág. 49

Anderson et al.(1992) Roy M Anderson, Robert M May e B Anderson. Infectious diseases of humans: dynamics and control, volume 28. Wiley Online Library. Citado na pág. 1, 8

Bailey et al.(1975) Norman TJ Bailey et al. The mathematical theory of infectious diseases and its applications. Charles Griffin \& Company Ltd, 5a Crendon Street, High Wycombe, Bucks HP13 6LE. Citado na pág. 1

Bennett et al.(2014) John E Bennett, Raphael Dolin e Martin J Blaser. Principles and practice of infectious diseases. Elsevier Health Sciences. Citado na pág. 3

Bhatt et al.(2013) Samir Bhatt, Peter W Gething, Oliver J Brady, Jane P Messina, Andrew W Farlow, Catherine L Moyes, John M Drake, John S Brownstein, Anne G Hoen, Osman Sankoh et al. The global distribution and burden of dengue. Nature, 496(7446):504-507. Citado na pág. 37

Brockmann e Helbing(2013) Dirk Brockmann e Dirk Helbing. The hidden geometry of complex, network-driven contagion phenomena. Science, 342(6164):1337-1342. Citado na pág. iii, v, xi, 1, 2, $15,16,23,24,25,26,27,49$

Brockmann et al.(2006) Dirk Brockmann, Lars Hufnagel e Theo Geisel. The scaling laws of human travel. Nature, 439(7075):462-465. Citado na pág. 8

Brockmann et al.(2009) Dirk Brockmann, Vincent David e Alejandro Morales Gallardo. Human mobility and spatial disease dynamics. Reviews of nonlinear dynamics and complexity, 2:1-24. Citado na pág. 8

Burden e Faires(1989) Richard L Burden e J Douglas Faires. Numerical analysis pws. Kent Publishing Co. Boston. Citado na pág. 12

Cameron et al.(2008) Mark J Cameron, Jesus F Bermejo-Martin, Ali Danesh, Matthew P Muller e David J Kelvin. Human immunopathogenesis of severe acute respiratory syndrome (sars). Virus research, 133(1):13-19. Citado na pág. 16

Colwell et al.(1996) Rita R Colwell et al. Global climate and infectious disease: the cholera paradigm*. Science, 274(5295):2025-2031. Citado na pág. 15

Fares et al.(2015) Rafaelle CG Fares, Katia PR Souza, Germán Añez e Maria Rios. Epidemiological scenario of dengue in brazil. BioMed research international, 2015. Citado na pág. xii, 38, 39 
Fineberg(2014) Harvey V Fineberg. Pandemic preparedness and response - lessons from the h1n1 influenza of 2009. New England Journal of Medicine, 370(14):1335-1342. Citado na pág. 16

Gibbons e Vaughn(2002) Robert V Gibbons e David W Vaughn. Dengue: an escalating problem. BMJ: British Medical Journal, 324(7353):1563. Citado na pág. 37

Gubler(2002) Duane J Gubler. Epidemic dengue/dengue hemorrhagic fever as a public health, social and economic problem in the 21st century. Trends in microbiology, 10(2):100-103. Citado na pág. 37

Guzman et al.(2010) Maria G Guzman, Scott B Halstead, Harvey Artsob, Philippe Buchy, Jeremy Farrar, Duane J Gubler, Elizabeth Hunsperger, Axel Kroeger, Harold S Margolis, Eric Martínez et al. Dengue: a continuing global threat. Nature Reviews Microbiology, 8:S7-S16. Citado na pág. 37

Halstead(2007) Scott B Halstead. Dengue. The Lancet, 370(9599):1644-1652. Citado na pág. 37

Hofbauer et al.(1988) Josef Hofbauer, Karl Sigmund et al. The theory of evolution and dynamical systems: mathematical aspects of selection. Number Sirsi) i9780521358385. Citado na pág. 1

Keeling e Rohani(2008) Matt J Keeling e Pejman Rohani. Modeling infectious diseases in humans and animals. Princeton University Press. Citado na pág. 1, 3, 4, 5, 6, 8

Kermack e McKendrick(1927) William O Kermack e Anderson G McKendrick. A contribution to the mathematical theory of epidemics. Em Proceedings of the Royal Society of London A: mathematical, physical and engineering sciences, volume 115, páginas 700-721. The Royal Society. Citado na pág. 1

Metropolis e Ulam(1949) Nicholas Metropolis e Stanislaw Ulam. The monte carlo method. Journal of the American statistical association, 44(247):335-341. Citado na pág. 13

Montagnier(2002) Luc Montagnier. A history of hiv discovery. Science, 298(5599):1727-1728. Citado na pág. 15

Organization et al.(2009) World Health Organization et al. Dengue guidelines for diagnosis, treatment, prevention and control: new edition. Citado na pág. 37

Rigau-Pérez et al.(1998) José G Rigau-Pérez, Gary G Clark, Duane J Gubler, Paul Reiter, Eduard J Sanders e A Vance Vorndam. Dengue and dengue haemorrhagic fever. The Lancet, 352 (9132):971-977. Citado na pág. 37

Rosengard et al.(2002) Ariella M Rosengard, Yu Liu, Zhiping Nie e Robert Jimenez. Variola virus immune evasion design: expression of a highly efficient inhibitor of human complement. Proceedings of the National Academy of Sciences, 99(13):8808-8813. Citado na pág. 15

Siqueira Jr et al.(2005) João Bosco Siqueira Jr, Celina Maria Turchi Martelli, Giovanini Evelim Coelho, Ana Cristina da Rocha Simplício e Douglas L Hatch. Dengue and dengue hemorrhagic fever, brazil, 1981-2002. Emerging infectious diseases, 11(1):48. Citado na pág. 38

Takeuchi(1996) Yasuhiro Takeuchi. Global dynamical properties of Lotka-Volterra systems. World Scientific. Citado na pág. 1

Ziegler(2013) Philip Ziegler. The black death. Faber \& Faber. Citado na pág. 15 